\title{
EL AYMARA DE CHILE (FONOLOGÍA, TEXTOS, LÉXICO)
}

\author{
María Teresa Poblete M. \\ Adalberto Salas
}

\begin{abstract}
RESUMEN
El presente artículo ofrece un análisis completo de la fonología de la lengua aymara de Chile. El estudio incluye una descripción detallada de los fonemas segmentales. Además, discute los rasgos suprasegmentales y la composición de la estructura silábica de esta lengua. Finalmente, tres textos ilustran el análisis fonológico previo.
\end{abstract}

\begin{abstract}
This article presents a complete phonological analysis of the Aymara language of Chile. It includes a detailed description of the segmental phonemes as well as a discussion of the suprasegmental features and the syllabic structure of the language. Besides, the phonological analysis is illustrated with three different texts.
\end{abstract}

\section{Introducción}

En Chile la lengua aymara es hablada por una población que ha sido estimada en un rango que va entre las 9.000 personas (Dannemann y Valencia 1989: 11) y las 14.000 personas (Gundemann 1994:135), tradicionalmente residentes en la precordillera y franja altiplánica de las Regiones I y II, desde el límite norte del país hasta la cuenca del río Salado, en la Provinica de El Loa (poblados de Ayquina y Toconce). Según Dannemann y Valencia (1989:11) el límite sur del territorio aymara de la II Región pasa por el poblado de Talabre, en la orilla oriental del Gran Salar de Atacama. Dentro de este territorio el mayor número de hablantes de aymara se encuentra en la I Región, en el área altiplánica de la Provincia de Parinacota, y en la precordillera y el altiplano de la Provincia de Iquique. Por otra parte, la población aymara radicada en la precordillera de las Provincias de Arica y Parinacota, de la I Región, y en la Provinicia del Loa, de la II Región, y todo el segmento que ha optado por la emigración a las ciudades (principalmente Arica e Iquique), utiliza el castellano como lengua de la vida cotidiana. Según Gundermann (1994:139, cuadro 3) de una población aymara chilena total de unas 33.000 personas, sólo unas 14.000 retienen en algún grado relevante el uso del vernáculo.

El aymara hablado en suelo chileno ha sido poco estudiado. Hay solamente dos breves descripciones de la fonología en el altiplano iquiqueño: Clair-Vasiliadis (1976) y Salas Valencia 
(1988). Harmelink (1985) dedica un capítulo (pp.10-17) a la discusión de la variación fonológica y léxica en el aymara altiplánico de Parinacota e Iquique, complementada con listas léxicas comparativas de Bolivia y Chile (Apéndices 4 y 7 ).

En las páginas que siguen presentamos una nueva versión, sustancialmente ampliada, de la descripción bosquejada en Salas y Valencia (1988), a la que hemos añadido tres textos traducidos y anotados y un léxico aymara-castellano y castellano-aymara. A diferencia de la versión de 1988, restringida al altiplano de la Provincia de Iquique (poblados de Enquelga, Colchane, Mauque, Cariquima y Villablanca), ahora incluimos los siguientes poblados del altiplano parinacoteño, representados por uno, dos o tres informes cada uno: Visviri, General Lagos, Guacollo, Coronel Alcérreca, Parinacota, Chujlluta, Ancolacane, Colpitas, Caquena, Putre y Guallatire, a los que se añadió Belén, un poblado precordillerano. Este conjunto de localidades abarca la mayor parte del área altiplánica de la I Región, desde Visviri por el norte hasta Villablanca por el sur. También hemos tenido oportunidad de estudiar material peruano (Puno) y boliviano (La Paz), lo que nos ha permitido intentar un esbozo comparativo que muestra, en líneas generales, semejanzas y diferencias entre el aymara de Chile y el aymara central. Para efectos de la comparación hemos recurrido además a fuentes bibliográficas de información fonológica, gramatical y léxica: Ross (1963), Cotari et al. (1978), Herrero et al. (1978) y Hardman et al. (1988).

\section{Fonología}

\subsection{Sistema fonológico}

\subsubsection{Fonemas segmentales}

Los fonemas segmentales son 29 , de los cuales tres son vocales: $/ \mathrm{i}, \mathrm{a}, \mathrm{u}, / ;$ dos son semiconsonantes: /j, w/, y 24 son consonantes: / p, p", p', t, t", t', k, k", k', q, q", q', c, c", c', s, $\chi, x$, $\mathrm{m}, \mathrm{n}, \tilde{\mathrm{n}}, 1, \lambda, \mathrm{r} /$.

\subsubsection{Realización fonética}

La realización fonética típica de los fonemas es la siguiente:

Vocales: anterior $/ \mathrm{i} /$, central $/ \mathrm{a} / \mathrm{y}$ posterior $/ \mathrm{u} /$; las vocales anterior $/ \mathrm{i} / \mathrm{y}$ posterior $/ \mathrm{u} / \mathrm{son}$ altas; la vocal central /a/ es baja; la vocal posterior / $\mathrm{d} /$ es redondeada; las vocales central $/ \mathrm{a} / \mathrm{y}$ anterior /i/ son no redondeadas. Todas las vocales son orales.

Semiconsonantes: anterior $/ \mathrm{j} / \mathrm{y}$ posterior $/ \mathrm{w} /$. Posterior es redondeada, anterior es no redondeada.

Consonantes: hay 18 obstruyentes: /p, p", p', t, t", t', k, k", k', q, q", q', c, c", c', s, x, $\chi / y$ seis resonantes: /m, n, n, l, $\lambda, r$. Entre las obstruyentes hay 12 oclusivas: /p, p", p', t, t", t', k, k", $\mathrm{k}^{\prime}, \mathrm{q}, \mathrm{q}$ ", q'/; tres africadas: /c, c", $\mathrm{c}^{\prime} / \mathrm{y}$ tres fricativas: /s, $\mathrm{x}, \chi /$. Entre las resonantes hay tres nasales: $/ \mathrm{m}, \mathrm{n}, \tilde{\mathrm{n}} /$, dos laterales $/ \mathrm{l}, \lambda /$ y una vibrante multiple $/ \mathrm{r} /$. Todas las obstruyentes son sordas, todas las resonantes son sonoras. Las oclusivas y las africadas son puras: /p, t, k, q, c/; aspiradas: /p", t', k", q", c"/ o glotalizadas: /p', t', k', q', c'/. La aspiración y la glotalización oscilan en- 
tre mínimas y moderadas. Tres oclusivas ocurren en el punto bilabial: /p, p", p'/; tres en el punto alveolar: /t, t", t'/, tres en el punto palatal: / k, k", k'/ y tres en el punto uvular: /q, q", q'/. Las tres africadas, /c, c", c'/, ocurren en el punto alveopalatal. Las fricativas ocurren en el punto alveolar $/ \mathrm{s} /$, palatal $/ \mathrm{x} / \mathrm{y}$ uvularar $/ \chi /$. Las nasales ocurren en el punto bilabial $/ \mathrm{m} /$, alveolar $/ \mathrm{n} / \mathrm{y}$ alveopalatal / $\tilde{n} /$. Las laterales son alveolar $/ / /$ y alveopalatal $/ \lambda /$. La vibrante $/ \mathrm{r} /$ ocurre en el punto alveolar. La fricativa alveolar /s/ es apical; la fricativa palatal / $\mathrm{x} /$ es dorsal; la fricativa uvular $/ \chi /$ es postdorsal.

\subsubsection{Rasgos articulatorios mínimos}

En términos de los rasgos articulatorios mínimos de su realización fonética de norma, los fonemas pueden ser descritos así:

Vocales:

/i/ anterior

/a/ central

$/ \mathrm{u} /$ posterior

Semiconsonantes:

/j/ anterior

/w/ posterior

En las consonantes hay que considerar que no hay oclusivas alveopalatales y que no hay más africadas que las alveopalatales, lo que sugiere la existencia de una hiperclase "intemupta" que contiene oclusivas y africadas y que se oponen a las "continuas" (fricativas). La articulación africada queda asociada a las interruptas alveopalatales y la articulación oclusiva queda asociada a las demás interruptas (bilabiales, alveolares, palatales y uvulares). Sin embargo, conviene mantener la sub-clase "africadas" separada de las oclusivas debido a diferencias en el comportamiento tras consonante nasal: en algunas áreas chilenas las oclusivas puras se sonorizan tras consonante nasal, lo que no ocurre con la africada pura. En consecuencia, las consonantes pueden ser descritas así:

$/ \mathrm{p} /$ interrupta, pura, bilabial

$/ \mathrm{p} " /$ interrupta, aspirada, bilabial

$/ \mathrm{p}^{\prime} /$ interrupta, glotalizada, bilabial

$/ \mathrm{t} /$ interrupta, pura, alveolar

$/ \mathrm{t} " /$ interrupta, aspirada, alveolar

/t'/ interrupta, glotalizada, alveolar

$/ \mathrm{k} /$ interrupta, pura, palatal

$/ \mathrm{k} " /$ interrupta, aspirada, palatal

$/ \mathrm{k}^{\prime} /$ interrupta, glotalizada, palatal

/q/ interrupta, pura, uvular

/q"/ interrupta, aspirada, uvular

/q'/ interrupta, glotalizada, uvular 
/c/ interrupta, pura, alveopalatal

$/ \mathrm{c} /$ interrupta, aspirada, alveopalatal

$/ c^{\prime} /$ interrupta, glotalizada, alveopalatal

/s/ continua, alveolar

/x/ continua, palatal

$|\chi|$ continua, uvular

$/ \mathrm{m} /$ nasal, bilabial

$/ \mathrm{n} /$ nasal, alveolar

/ñ $/$ nasal, alveopalatal

/1/ lateral, alveolar

$I \lambda /$ lateral, alveopalatal

$/ \mathrm{r} /$ vibrante

\subsubsection{La sílaba}

La estructura típica de la sílaba incluye un foco obligatorio, un frontis opcional y una coda opcional. Los fonemas se distribuyen en las posiciones frontal, focal y codal agrupados en dos clases: vocales (V) y consonantes (C), entre las que se encuentran las consonantes propiamente tales (o sea, tanto en términos articulatorios como distribucionales) y las semiconsonantes (o sea, vocales articulatorias altas distribuidas como consonantes). En el foco silábico aparece una vocal $(\mathrm{V})$, en el frontis aparece una consonante $(\mathrm{C})$, en la coda aparece una consonante $(\mathrm{C})$ :

+ Frontis

$\mathrm{C}$
+ Foco

$\mathrm{V}$
+ Coda

$\mathrm{C}$

En consecuencia, las configuraciones silábicas de norma son:

\begin{tabular}{|c|c|c|}
\hline V & /u.ta/ & casa \\
\hline VC & /ur.pu/ & neblina \\
\hline CV & /c'u.qi/ & papa \\
\hline $\mathrm{CVC}$ & $/ c^{\prime} u \chi . \tilde{n} a /$ & verde \\
\hline
\end{tabular}

en los ejemplos siguientes $\mathrm{C}$ es una semiconsonante:

$\begin{array}{lll}\mathrm{VC} & \text { /aw.ti/ } & \text { estación seca } \\ \mathrm{CV} & \text { /wa.ri/ } & \text { vicuña } \\ \mathrm{CVC} & \text { /way.k'a/ } & \text { ají }\end{array}$

Se han encontrado sílabas de configuración atípica en algunas palabras como:

$\begin{array}{ll}\text { /c"a. } \chi w a / & \text { chancado, triturado de piedra } \\ \text { /lu.rya/ } & \text { papelillo } \\ \text { /q"i.ñwa/ } & \text { queñua, un arbusto altiplánico }\end{array}$


en las que es anómalo el grupo consonántico frontal (CCV) de la segunda sílaba, o como:

$\begin{array}{ll}\text { /ams.ta/ } & \text { cuesta } \\ \text { /awk.ci/ } & \text { suegro } \\ \text { /cilq.ta/ } & \text { paso, zancada, tranco } \\ \text { /tayk.ci/ /tayx.ci/ } & \text { suegra }\end{array}$

en las que es anómalo el grupo consonántico codal (VCC) de la primera sílaba. Debe notarse que /q"i.ñwa/ presenta una variante con la configuración normal /q"iñ.wa/, o sea, con las dos consonantes contiguas /...ñw.../ distribuidas en sílabas separadas.

\subsubsection{La configuración silábica de las palabras}

Las palabras de diccionario (raíces no verbales solas, raíces verbales con el solo sufijo -ña de infinitivo) pueden estar formadas por dos, tres y cuatro sílabas. Los bisílabos constituyen la mayoría del corpus estudiado: $\pm 75 \%$. Siguen los trisílabos, con un $\pm 22 \%$. Son marginales los tetrasílabos $( \pm 3 \%)$.

Los tipos silábicos se distribuyen así en la configuración de la palabra:

$\begin{array}{ll}\text { V } & \text { Solo en la sílaba inicial } \\ \text { VC } & \text { Solo en la sílaba inicial } \\ \text { CVC } & \text { Solo en sílaba no inicial } \\ \text { CV } & \text { En cualquier sílaba }\end{array}$

Las excepciones a esta pauta de distribución son cuatro ( $\pm 0.7 \%)$, en todas ellas aparece una sílaba medial formada o iniciada por V:

$\begin{array}{ll}\text { /ta.ik.ci/ } & \text { suegra } \\ \text { /c'i.a.ra/ } & \text { negro } \\ \text { /ki.u.la/ } & \text { perdiz pequeña, codorniz } \\ \text { /c'i.a.ra.na/ } & \text { mojado }\end{array}$

En la primera sílaba de los bisílabos se dan todas las configuracines silábicas de norma y la segunda sílaba solo puede ser del tipo CV:
$1^{\text {a }}$ Sílaba
$2^{\mathrm{a}}$ Sílaba
$\mathrm{V}$
$\mathrm{VC}$
CV
CVC
CV

como en:

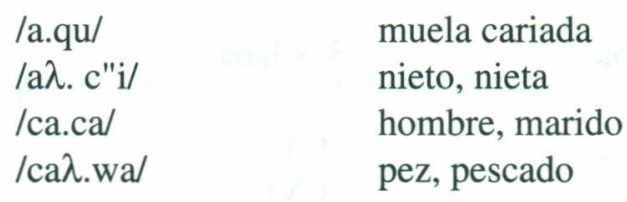


Palabras de estructura atípica, como:

$\begin{array}{ll}\text { /c"a. } \chi w a / & \text { chancado, triturado de piedra } \\ \text { /qi.ñwa/ } & \text { queñua, un arbusto altiplánico } \\ \text { /ams.ta/ } & \text { cuesta } \\ \text { /awk.ci/ } & \text { suegro } \\ \text { /cilq.ta/ } & \text { paso, tranco, zancada }\end{array}$

son excepcionales $( \pm 1.2 \%)$. La mayor parte de los bisílabos tiene la configuración CV.CV $( \pm 65 \%)$. Siguen las configuraciones CVC.CV $( \pm 29 \%)$, V.CV $( \pm 3 \%)$ y VC.CV $( \pm 3 \%)$. En los trisílabos la primera sílaba puede presentar todas las combinaciones posibles $(\mathrm{V}, \mathrm{VC}, \mathrm{CV}$, $\mathrm{CVC}$ ); la segunda sílaba solo puede ser CV o CVC; y la última, solo CV:

$\begin{array}{lcc}1^{\text {a Sílaba }} & 2^{\text {a Sílaba }} & 3^{\text {a }} \text { Sílaba } \\ \text { VC } & \mathrm{CV} & \\ \mathrm{CV} & \mathrm{CVC} & \mathrm{CV} \\ \mathrm{CVC} & & \end{array}$

Las configuraciones registradas son:

\begin{tabular}{|c|c|c|}
\hline V.CV.CV & /a.cu.ku/ & ratón \\
\hline V.CVC.CV & /a.kan.xi/ & aquí \\
\hline VC.CV.CV & /a $\lambda . p a . c u /$ & alpaca \\
\hline CV.CV.CV. & 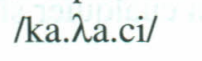 & hombro \\
\hline CV.CVC.CV & /q'a.sar. $\chi a /$ & sarna \\
\hline CVC.CV.CV & /xam.p'a.tu/ & sapo \\
\hline CVC.CVC.CV & /pir.pin.tu/ & mariposa \\
\hline
\end{tabular}

La mayor parte de los trisílabos sigue el patrón CV.CV.CV $( \pm 63 \%)$. Siguen V.CV.CV $( \pm 14 \%)$, CVC.CV.CV $( \pm 11 \%)$, CV.CVC.CV $( \pm 9 \%)$, CV.CV.CV $( \pm 5 \%)$ y V.CVC.CV $( \pm 2 \%)$. Son típicas palabras como:

$\begin{array}{ll}\text { /ta.ik.ci/ } & \text { suegra } \\ \text { /c'i.a.ra/ } & \text { negro } \\ \text { /ki.u.la/ } & \text { perdiz pequeña, codorniz }\end{array}$

que constituyen $\pm 2 \%$ del total de trisílabos. Hay que tener presente que /c'i.a.ra/ y /ki.u.la/ son variantes ocasionales de las formas normales /c'a.ra/ y /ki.ewu.la/ o /kiw.la/. Esto deja como realmente excepcional solo a /ta.ik.ci/.

La primera sílaba de los tetrasílabos simples es $\mathrm{V}$, VC o CV; la segunda puede ser $\mathrm{CV} 0$ $\mathrm{CVC}$, la tercera puede ser CV o CVC, y la última solo CV:

$\begin{array}{llll}1^{\mathrm{a}} \text { sílaba } & 2^{\mathrm{a}} \text { sílaba } & 3^{\mathrm{a}} \text { sílaba } & 4^{\mathrm{a}} \text { sílaba } \\ \mathrm{V} & \mathrm{CV} & \mathrm{CV} & \\ \mathrm{VC} & \mathrm{CVC} & \mathrm{CVC} & \mathrm{CV} \\ \mathrm{CV} & \mathrm{CV} & \end{array}$


No se han encontrado palabras en que aparezcan contiguas dos sílabas del tipo CVC. Las configuraciones documentadas son:

\begin{tabular}{|c|c|c|}
\hline V.CV.CV.CV & /a.nu.qa.ra/ & perro \\
\hline & /a.ña.t"u.ya/ & zorrino \\
\hline VC.CV.CV.CV & /al.qa.ma.ri/ & jote \\
\hline CV.CV.CVC.CV & /c"i.c"i.lin.k"a/ & mosca \\
\hline & 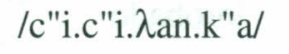 & mosca \\
\hline & /xa.ra.ran.k"u/ & lagartija \\
\hline & /xa.ri.rin.k"u/ & lagartija \\
\hline CV.CVC.CV.CV & 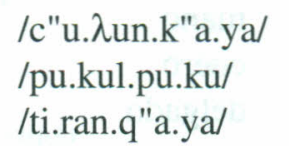 & $\begin{array}{l}\text { hielo } \\
\text { ave silvestre altiplánica } \\
\text { quijada }\end{array}$ \\
\hline
\end{tabular}

La única excepción documentada es /c'i.a.ra.na/ 'mojado' que presenta una sílaba interna del tipo V, que de norma aparece solo en sílaba inicial. Hay que tener presente que /c' i.a.ra.na/ es una variante ocasional de la forma regular/c'a.ra.na/.

La mayor parte de los pocos tetrasílabos que aparecen corresponden a compuestos, como:

$$
\begin{array}{ll}
\text { /ni.na.c"a.q"a/ } & \text { fogón } \\
\text { /c'ix.ta.mu.qu/ } & \text { tobillo }
\end{array}
$$

o flexiones, como:
/p'u.su.ta.ta/
hinchado
/ñu.sam.ta.ta/
podrido

El único pentasílabo que apareció en la muestra fue /t"a.ya.xa.ma.c'i/ "un ave altiplánica', claramente un compuesto de /t"aya/ 'viento' y /xamac'i/ 'pájaro'.

\subsubsection{Reduplicación}

Está registrado un pequeño número $( \pm 1 \%)$ de palabras formadas por reduplicación,

\begin{tabular}{|c|c|}
\hline \multicolumn{2}{|r|}{ cierta ave silvestre altiplánica } \\
\hline / $\lambda$ aka $\lambda$ aka/ & cierta ave silvestre altiplánica \\
\hline /qalaqala/ & pedregal \\
\hline 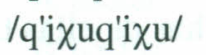 & rayo \\
\hline /t"ayat"aya/ & escalofríos \\
\hline /warawara/ & estrella \\
\hline
\end{tabular}
como:

puede apreciarse que en todos los casos documentados recurren sílabas del tipo CV. 


\subsubsection{Isovocalismo}

Son muy frecuentes ( $\pm 45 \%$ ) las palabras que presentan la misma vocal en todas sus sílabas. La mayor parte $( \pm 88 \%)$ son bisílabos, como:

$\begin{array}{ll}\text { /ca.ra/ } & \text { pierna, muslo } \\ \text { /cin.qi/ } & \text { vulva } \\ \text { /cu.tu/ } & \text { jorobado }\end{array}$

Los trisílabos como:

$\begin{array}{ll}\text { /am.pa.ra/ } & \text { mano } \\ \text { /li.pi.c'i/ } & \text { cuero } \\ \text { /xu.c'u.su/ } & \text { delgado }\end{array}$

alcanzan un $\pm 11 \%$ del total de palabras isovocálicas. Descontadas las palabras reduplicadas, hay dos tetrasílabos isovocálicos:
/k'i.si.mi.ri./
hormiga
/pu.kul.pu.ku/
cierta ave silvestre altiplánica

\subsubsection{Isoconsonantismo central}

En la muestra aparece un cierto número de palabras $( \pm 2 \%)$ que presentan la misma consonante en todas sus sílabas. Todas ellas son bisilábicas, como:

$\begin{array}{ll}\text { /ca.ca/ } & \text { hombre, esposo } \\ \text { /ku.ka/ } & \text { coca } \\ \text { /k"a.k"a/ } & \text { tartamudo } \\ \text { /ma.ma/ } & \text { madre } \\ \text { /ni.na/ } & \text { fuego } \\ \text { /ñu.ñu/ } & \text { senos, ubres } \\ \text { /qa.qa/ } & \text { cueva } \\ \text { /qu.qa/ } & \text { árbol añoso y grande } \\ \text { /wa.wa/ } & \text { bebé } \\ \text { /ta.ta/ } & \text { padre }\end{array}$

Nótese que algunos de ellos, son, además, isovocálicos. Hardman et al. (1988: 43) registran "una subclase de raíces nominales de la forma CVCCVque tiene la forma $\mathrm{C}_{1} \mathrm{~V}_{1} \mathrm{C}_{2} \mathrm{C}_{1} \mathrm{~V}_{1}$ y que se distinguen por el hecho de que muchas de ellas tienen significados descriptivos especiales". En la nota 8 (Harman et al. 1988: 64) viene una lista parcial de estas raíces. En la muestra apareció un pequeño número de ítemes que presentan esta estructura, pero su significado no presenta nada especial:

$\begin{array}{ll}\text { /par.pa/ } & \text { médula, tuétano } \\ \text { /kan.ka/ } & \text { asado, carne asada } \\ \text { /kur.ku/ } & \text { jorobado, giboso }\end{array}$




$\begin{array}{ll}\text { /t"an.t"a/ } & \text { viejo, inservible (de las cosas) } \\ \text { /cix.c"i/ } & \text { granizo } \\ \text { /t'an.t'a/ } & \text { pan }\end{array}$

$\mathrm{A}$ los que se pueden añadir otros que tiene la forma $\mathrm{C}_{1} \mathrm{~V}_{1} \mathrm{C}_{2} \mathrm{C}_{1} \mathrm{~V}_{2}$, como:

$\begin{array}{ll}\text { /kun.ka/ } & \text { cuello, cogote } \\ \text { /kaג.ku/ } & \text { amargo } \\ \text { /kaw.ki/ } & \text { ¿dónde? } \\ \text { /tun.ti/ } & \text { color indefinido o desteñido }\end{array}$

\subsubsection{Frecuencia de los fonemas}

Las vocales representan $\pm 47 \%$ del material fónico de la lengua. La más frecuente es /a/ con $\pm 50 \%$ del universo vocálico, seguida por $/ \mathrm{i} / \pm 25 \%$ y $/ \mathrm{u} / \pm 25 \%$. Entre las consonantes las más frecuentes son /c', k, k', $\lambda, \mathrm{q}, \mathrm{r}, \mathrm{s}, \mathrm{w}, \mathrm{x} / \mathrm{con} \pm 3 \%$ cada una; seguidas por /c, k", l, p, t, $\chi, \mathrm{m} /$ con $\pm 2 \%$ cada una; $y / c^{\prime \prime}, n, \tilde{n}, p^{\prime \prime}, p^{\prime}, q^{\prime \prime}, q^{\prime}, t^{\prime \prime}, t^{\prime}, y / c o n \pm 1 \%$ cada una.

\subsubsection{Distribución de los fonemas en la sílaba y la palabra}

Las tres vocales pueden aparecer en el foco silábico, solas como en:

$\begin{array}{ll}\text { /i.si/ } & \text { ropa } \\ \text { /a.ru/ } & \text { voz } \\ \text { /u.ma/ } & \text { agua }\end{array}$

o precedidas de frontis, como en:

$\begin{array}{ll}\text { /c'a.p"i/ } & \text { espina } \\ \text { /c'i.si/ } & \text { tiempo frío } \\ \text { /c'u.ñu/ } & \text { chuño }\end{array}$

o seguidas de coda, como en :

$\begin{array}{ll}\text { /in.ti/ } & \text { sol } \\ \text { /a } \lambda . c^{\prime \prime} \text { / } & \text { nieto, nieta } \\ \text { /ur.qu/ } & \text { macho }\end{array}$

o precedidas de frontis y seguidas de coda, como en:
/c'is. $\lambda \mathrm{i} /$
sucio, manchado
/c'as.ka/
cabellera desgreñada y sucia
/c'ux.ña/
verde

Todas las consonantes pueden aparecer en el frontis, como en:

$\begin{array}{ll}\text { /pa.ka/ } & \text { águila } \\ \text { /ta.pa/ } & \text { nido } \\ \text { /ca.ra/ } & \text { pierna, muslo } \\ \text { /ka.yu/ } & \text { pie, pierna } \\ \text { /qa.cu/ } & \text { hembra }\end{array}$




$\begin{array}{ll}\text { /p"a.sa/ } & \text { barro comestible } \\ \text { /t"a.k"i/ } & \text { camino } \\ \text { /c"a.ma/ } & \text { grano grueso, a medio moler } \\ \text { /k"a.ra/ } & \text { salado } \\ \text { /q"a.na/ } & \text { luz, claridad } \\ \text { /p'i.qi/ } & \text { cabeza } \\ \text { /t'a.p"a/ } & \text { desabrido, sin sal } \\ \text { /c'a.ra/ } & \text { negro } \\ \text { /k'a.na/ } & \text { trenza } \\ \text { /q"a.sa/ } & \text { estanque de regadío } \\ \text { /sa.wu/ } & \text { telar } \\ \text { /xa.c'a/ } & \text { lágrima } \\ \text { /ma.q'a/ } & \text { comida } \\ \text { /na.ya/ } & \text { yo } \\ \text { /ña.sa/ } & \text { nariz } \\ \text { /la.p'a/ } & \text { piojo } \\ \text { / } \text { /a.xa/ } & \text { herida } \\ \text { /wa.k'a/ } & \text { faja } \\ \text { /ya.q'a/ } & \text { orina }\end{array}$

pero $/ \chi, \mathrm{r} / \mathrm{se}$ dan en posición frontal solamente en sílaba no inicial, como en:

$\begin{array}{ll}\text { /su. } \chi \mathrm{u} / & \text { ronco, afónico } \\ \text { /su.ri/ } & \text { avestruz }\end{array}$

Entre las consonantes codales las más frecuentes son $/ \mathrm{n} / \mathrm{con} \pm 28 \%$ de las ocurrencias de coda, $/ \mathrm{r} / \operatorname{con} \pm 12 \%, / \chi / \operatorname{con} \pm 9 \%, \mathrm{y} / \mathrm{y} / \operatorname{con} \pm 95, / \mathrm{s} / \operatorname{con} \pm 8 \%, / \mathrm{x} / \operatorname{con} \pm 7 \%, / \lambda / \operatorname{con} \pm 5 \%$, $/ \mathrm{m} / \operatorname{con} \pm 5 \%, / 1 / \mathrm{con} \pm 4 \%$.

Las interruptas son infrecuentes en posición codal: /q/ con menos del $2 \%$ y /c, k, t/ con menos del $1 \%$ cada una. No están documentadas en esta posición /p, p", p', t", t', c", c', k", k', q", q'/. Ejemplos:

\begin{tabular}{|c|c|}
\hline /lan.k"u/ & grueso \\
\hline /c'ar.k"i/ & charqui \\
\hline /sax.ra/ & demonio, diablo \\
\hline /k'ay.ra/ & rana, sapito de lluvia \\
\hline /c'as.ka/ & cabellera desgreñada y sucia \\
\hline /k'aw.na/ & huevo \\
\hline /nax.ra/ & pezuña \\
\hline /waג.pa/ & gallina \\
\hline /xam.p'i/ & tostado de cereales, de habas o de quinua \\
\hline /mal.q'a/ & garganta \\
\hline /p"aq.si/ & luna, mes \\
\hline /xac.ta.ña/ & estornudo \\
\hline /入uk.t'a/ & lejía en moldecitos para acompañar la coca \\
\hline /pat. $\chi \mathrm{a} /$ & altiplano \\
\hline
\end{tabular}


La vocal /i/ puede ocurrir precedida en la misma sílaba por cualquier consonante de la lengua como en:

\begin{tabular}{|c|c|}
\hline /pi.tu/ & $\begin{array}{l}\text { bebida preparada con harina tostada de algún } \\
\text { cereal desleída en agua }\end{array}$ \\
\hline /ti.ti/ & gato montés \\
\hline /ci.ñi/ & diente de leche \\
\hline /ki.wu/ & colmillo \\
\hline /qi.na/ & quena, un tipo de flauta andina \\
\hline /p"i.si/ & gato \\
\hline /c"i.ya/ & cuarta, medida de longitud \\
\hline /t"i.ya/ & borde, orilla \\
\hline /k"i.ti/ & ¿quién? \\
\hline /q"i. $\lambda \mathrm{a} /$ & cenizas \\
\hline /p'i.qi/ & cabezas \\
\hline$/ t^{\prime} i . \chi \mathrm{i} /$ & 1. paquete formado con tientos de cuero \\
\hline /c'i.na/ & $\begin{array}{l}\text { 2. malla de cuero para llevar carga } \\
\text { culo }\end{array}$ \\
\hline$/ \mathrm{k}^{\prime} \mathrm{i} . \lambda \mathrm{i} /$ & carboncillo \\
\hline /q'i.pi/ & $\begin{array}{l}\text { manta doblada en forma de bolsa } \\
\text { para llevar carga a la espalda }\end{array}$ \\
\hline$/ \mathrm{si} . \lambda \mathrm{u} /$ & garra, uña \\
\hline /xi.la/ & hermano \\
\hline$/ \mathrm{mi} . \lambda \mathrm{u} /$ & cierta sal usada para teñir lanas \\
\hline & y para calmar el dolor de muelas \\
\hline /ni.na/ & fuego \\
\hline /ñi.q'i/ & barro \\
\hline /li.k'i/ & 1. grasa 2. gordo \\
\hline
\end{tabular}

incluida la semiconsonante /w/, como en:
/wi.la/
1. sangre 2. rojo

No aparecieron instancias de /i/ precedida de $/ \lambda$ / en sílaba inicial, pero sí en sílaba final, como en:

$$
/ \mathrm{k}^{\prime} \mathrm{i} . \lambda \mathrm{i} / \quad \text { carboncillo }
$$

El único caso de /i/ precedida por /y/ ocurre en sílaba medial en un préstamo hispánico: /wa.yi.ta/ chal, chalón

La vocal /i/ puede aparecer seguida en la misma sílaba por la mayor parte de las consonantes codales de la lengua, como en:

$\begin{array}{ll}\text { /c'is. } \lambda \mathrm{i} / & \text { sucio, manchado } \\ \text { /c"ix.c"i/ } & \text { granizo } \\ \text { /wi } x . r u / & \text { chueco, torcido }\end{array}$




$\begin{array}{ll}\text { /cim.pu/ } & \text { flecos hechos de hilitos de lana } \\ \text { /xin.k'a/ } & \text { prisa, apuro } \\ \text { /cil.qi/ } & \text { paso, tranco, zancada } \\ \text { /pir.qa/ } & \text { muro, pared }\end{array}$

incluida la semiconsonante /w/ como en:

$$
\text { /k'iw.ca/ hígado }
$$

pero no se han registrado secuencias intrasilábicas del tipo /iy/ o /C+iy/. Tampoco han aparecido secuencias intrasilábicas del tipo $/ \mathrm{i} \lambda / \mathrm{o} / \mathrm{C}+\mathrm{i} \lambda /$.

Sílabas de cualquier constitución interna, con /i/ en el foco, pueden aparecer en todas posiciones, o sea, inicial, como en:

$\begin{array}{ll}\text { /i.na.ca/ } & \text { quizás } \\ \text { /ir.pa/ } & \text { pollito de gallina a punto de romer el cascarón } \\ \text { /p'i.qi/ } & \text { cabeza } \\ \text { /pir.qa/ } & \text { muro, pared }\end{array}$

medial (sólo del tipo CV o CVC), como en:
/xi.p"i. $\lambda \mathrm{a} /$
tripas
/wi.c'in.k"a/
cola, rabo

o final (sólo del tipo CV), como en:
/pu.si/
cuatro

La vocal /a/ puede aparecer precedida en la misma sílaba por cualquier consonante, como en:

\begin{tabular}{|c|c|}
\hline /pa.ra/ & frente \\
\hline /ta.qi// & todos \\
\hline /ca.ka/ & puente \\
\hline /ka.yu/ & pie, pierna \\
\hline /qa.la/ & piedra \\
\hline$/ \mathrm{p}$ "a.sa/ & $\begin{array}{l}\text { pasta comestible preparada con tierra caliza, } \\
\text { agua y sal, y que sirve para untar las tapas }\end{array}$ \\
\hline /t"a.ya/ & 1. viento 2 . viento \\
\hline /c"a.ma/ & grano grueso, a medio moler \\
\hline /k"a.ra/ & salado \\
\hline /q"a.na/ & luz, claridad \\
\hline /t'a.p"a/ & desabrido, sin sal \\
\hline /c'a. $\lambda \mathrm{a} /$ & arena \\
\hline /k'a.wa/ & zanjón, quebrada poco profunda \\
\hline /q'a.ñu/ & sucio, mugriento \\
\hline /sa.wu/ & telar \\
\hline /xa.qi// & persona \\
\hline /ma.ra/ & año \\
\hline
\end{tabular}


de lana

Tampoco han apareci-

den aparecer en todas

de romer el cascarón

cualquier consonante,

la con tierra caliza, ra untar las tapas

funda

$\begin{array}{ll}\text { /na.ya/ } & \text { yo } \\ \text { /ñasa/ } & \text { nariz } \\ \text { /la.p'a/ } & \text { piojo } \\ \text { / } \lambda \text { a.xa/ } & \text { herida } \\ \text { /wa.ña/ } & \text { seco } \\ \text { /ya.pu/ } & \text { chacra }\end{array}$

No se dieron casos de /p'/ ante /a/ en sílaba libre inicial, pero sí en sílaba inicial trabada, como:

$$
\text { /p'ar.pa/ flameante }
$$

o en sílaba libre final, como:

$$
\text { la.p'a/ piojo }
$$

La vocal /a/ ocurre trabada por cualquier consonante trabante de la lengua, por ejemplo,

\begin{tabular}{|c|c|}
\hline /c'as.ka/ & cabellera desgreñada y sucia \\
\hline /nax.ra/ & pezuña \\
\hline /lax.ra/ & lengua \\
\hline /xam.p'i/ & tostado de cereales, de habas o de quinua \\
\hline /wan.q'u/ & cuye \\
\hline /mal.q'a/ & garganta \\
\hline /caג.wa/ & pescado \\
\hline /mar.ka/ & pueblo, poblado \\
\hline
\end{tabular}
las continuas, como en:

incluidas las dos semiconsonantes, como en:

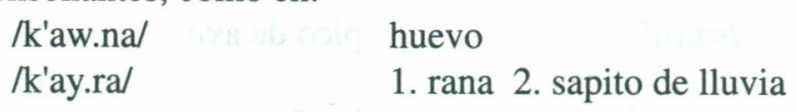

Una sílaba, de cualquier tipo, con /a/ en el foco, puede aparecer en toda posición, o sea, inicial, como en:

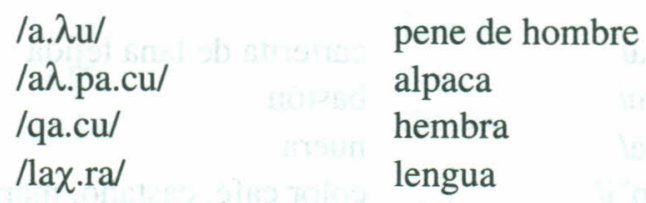

medial (sólo de la forma CV o CVC), como en:

$\begin{array}{ll}\text { /un.ka. } \lambda \mathrm{a} / & \text { cierta especie de pato silvestre } \\ \text { /q'a.sar. } \chi \mathrm{a} / & \text { sarna }\end{array}$

o final (sólo de la forma CV), como en: /la.k'u.ta/ pelo 


$\begin{array}{ll}\text { /na.ya/ } & \text { yo } \\ \text { /ñasa/ } & \text { nariz } \\ \text { /la.p'a/ } & \text { piojo } \\ / \lambda \text { a.xa/ } & \text { herida } \\ \text { /wa.ña/ } & \text { seco } \\ \text { /ya.pu/ } & \text { chacra }\end{array}$

No se dieron casos de /p'/ ante /a/ en sílaba libre inicial, pero sí en sílaba inicial trabada, como:
/p'ar.pa/
flameante

o en sílaba libre final, como:
/la.p'a/
piojo

La vocal /a/ ocurre trabada por cualquier consonante trabante de la lengua, por ejemplo, las continuas, como en:

$\begin{array}{ll}\text { /c'as.ka/ } & \text { cabellera desgreñada y sucia } \\ \text { /nax.ra/ } & \text { pezuña } \\ \text { /lax.ra/ } & \text { lengua } \\ \text { /xam.p'i/ } & \text { tostado de cereales, de habas o de quinua } \\ \text { /wan.q'u/ } & \text { cuye } \\ \text { /mal.q'a/ } & \text { garganta } \\ \text { /ca } \lambda . w a / & \text { pescado } \\ \text { /mar.ka/ } & \text { pueblo, poblado }\end{array}$

incluidas las dos semiconsonantes, como en:
/k'aw.na/
huevo
/k'ay.ra/
1. rana 2. sapito de lluvia

Una sílaba, de cualquier tipo, con /a/ en el foco, puede aparecer en toda posición, o sea, inicial, como en:

\begin{tabular}{|c|c|}
\hline$/ a . \lambda \mathrm{u} /$ & pene de hombre \\
\hline /a入.pa.cu/ & alpaca \\
\hline /qa.cu/ & hembra \\
\hline /lax.ra/ & lengua \\
\hline
\end{tabular}

medial (sólo de la forma CV o CVC), como en:

$\begin{array}{ll}\text { /un.ka. } \lambda \mathrm{a} / & \text { cierta especie de pato silvestre } \\ \text { /q'a.sar. } \chi \mathrm{a} / & \text { sarna }\end{array}$

o final (sólo de la forma CV), como en:

/la.k'u.ta/ pelo


La vocal / u / aparece precedida en la misma sílaba por cualquier consonante, como en:

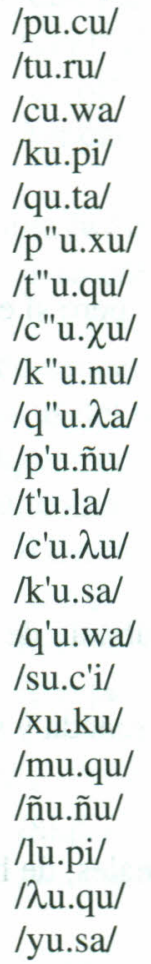
sobras corderito macho pocillo de greda de uso ceremonial derecha

laguna

puquio, ojo de agua

baile

orina

nieve

maleza

cántaro

tola, arbusto altiplánico

gorro de lana, delgado, con orejeras chicha

coba, un arbusto aromático altiplánico

suche, un pez de agua dulce parecido al bagre búho, lechuza

1. puño 2. nudo 3. protuberancia senos, ubre

1. calor (del sol) 2. claridad, luz (del sol) corazón dios

No se encontraron casos de /u/ precedida por /n/ en sílaba inicial, pero sí en sílaba final, como en:

lo mismo con $/ \mathrm{r} /$ :

$$
\text { /k"u.nu/ nieve }
$$

$\mathrm{y} \operatorname{con} / \mathrm{w} /$ :

$$
\text { /su.ru/ pico de ave }
$$

/sa.wu/ telar

La vocal /u/ aparece seguida de la mayor parte de las consonantes trabantes de la lengua, como en:

$\begin{array}{ll}\text { /c'us.pa/ } & \text { carterita de lana tejida } \\ \text { /t"ux.ru/ } & \text { bastón } \\ \text { / } \mathrm{u} \text { u.ca/ } & \text { nuera } \\ \text { /c'um.p"i/ } & \text { color café, castaño, marrón } \\ \text { /pun.ku/ } & \text { puerta } \\ \text { /tul.qa/ } & \text { yerno } \\ \text { /xur.k"u/ } & \text { traje femenino tradicional }\end{array}$

incluida la semiconsonante /y/ como en:

$$
\text { /xuy.k"u/ ciego }
$$

pero no se encontraron casos de vocal / $\mathrm{u} /$ trabada por la semiconsonante / w /. 
Sílabas de cualquier constitución interna, con / $/ \mathrm{k}$ en el foco, pueden aparecer en todas las posiciones, es decir, inicial, como en:

$\begin{array}{ll}\text { /u.qa.ra/ } & \text { sordo } \\ \text { /un.na. } x \mathrm{a} / & \text { cara, rostro } \\ \text { /c'u. } \chi \text { u/ } & \text { tos } \\ \text { /xun.t'u/ } & \text { caliente }\end{array}$

medial (solo del tipo CV o CVC), como en:

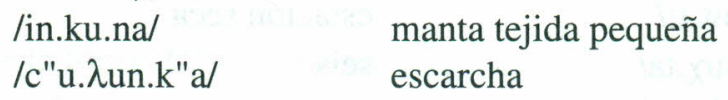

o final (solo del tipo CV), como en:

/pir.pin.tu/ mariposa

La consonante /p/ aparece en posición frontal ante /i, a, u/ en sílaba inicial, como en:

$\begin{array}{ll}\text { /pi.ra/ } & \text { pecho } \\ \text { /pa.ya/ } & \text { dos } \\ \text { /pu.si/ } & \text { cuatro } \\ \text { /pir.qa/ } & \text { muro, pared } \\ \text { /par.pa/ } & \text { médula, tuétano } \\ \text { /pun.ku/ } & \text { puerta }\end{array}$

en sílaba medial del tipo CV, como en:
/a.pi. $\lambda \mathrm{a} /$
oca, tubérculo comestible
/am.pa.ra/
mano
/pu.kul.pu.ku/
un ave silvestre altiplánica

o del tipo CVC solo ante /i/:

/pir.pin.tu/ mariposa

y en sílaba final (solo del tipo CV), como en:

$\begin{array}{ll}\text { /ku.pi/ } & \text { derecha } \\ \text { /ta.pa/ } & \text { nido } \\ \text { /ya.pu/ } & \text { chacra }\end{array}$

La consonante /t/ aparece en posición frontal ante /i, a, u/ en sílaba inicial, como en:

$\begin{array}{ll}\text { /ti.ti/ } & \text { gato montés } \\ \text { /ta.qi/ } & \text { todos } \\ \text { /tu.ru/ } & \text { corderito macho }\end{array}$


en sílaba medial del tipo CV, como en:

$\begin{array}{ll}\text { /q"a.ti.ta/ } & \text { papa cocida con cáscara } \\ \text { /t'am.ta.ta/ } & \begin{array}{l}\text { 1. fermentado (líquido, alimentos) } \\ \text { 2. orina fermentada a la que se agrega ceniza } \\ \text { y se utiliza para lavar el pelo } \\ \text { cóndor }\end{array}\end{array}$

y en sílaba final (sólo de la forma CV), como en:

$\begin{array}{ll}\text { /aw.ti/ } & \text { estación seca } \\ \text { /sux.ta/ } & \text { seis } \\ \text { /q'u.tu/ } & \text { coto, bocio }\end{array}$

La consonante / c / aparece en posición frontal ante /i,a,u/ en sílaba inicial, como en: /ci.ñi/ diente de leche

/ca.ca/

1. hombre 2. esposo

lcu.wa/

pocillo de greda de uso ceremonial

y en sílaba medial, como en:

$\begin{array}{ll}\text { /a.ci. } \lambda \mathrm{u} / & \text { rata } \\ / \mathrm{ma} . \mathrm{ca} . q \mathrm{a} / & \text { nuevo (dicho de las cosas) } \\ \text { /a.cu.ku/ } & \text { ratón }\end{array}$

y en sílaba final (sólo del tipo CV), como en:

$\begin{array}{ll}\text { /mi.ci/ } & \text { gato } \\ \text { /ay.ca/ } & \text { carne } \\ \text { /pu.cu/ } & \text { sobras }\end{array}$

La consonante / $\mathrm{k}$ / aparece en posición frontal ante /i, a, u/ en sílaba inicial, como en:

/ki.wu.la/

/ka.yu/

/ku.pi/

y en sílaba medial, como en:

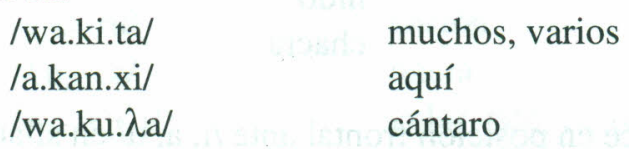

y en sílaba final (sólo del tipo CV), como en:

/kaw.ki/
/kan.ka/
/si.ku/

¿dónde?

asado, carne asada

zampoña, flauta de Pan 
La consonante /q/aparece en posición frontal ante /i, a, u/ en sílaba inicial, como en:

$\begin{array}{ll}\text { /qi.na/ } & \text { quena, un tipo de flauta andina } \\ \text { /qa.la/ } & \text { piedra } \\ \text { /qu.ca/ } & \text { cocha, laguna pequeña }\end{array}$

en sílaba medial no apareció ante /i/ pero sí ante /a, u/, como en:

$\begin{array}{ll}\text { /yu.qa. } \lambda \mathrm{a} / & \text { niño } \\ \text { /tun.qu.ru/ } & \text { tráquea y laringe }\end{array}$

y en sílaba final (sólo de la forma CV), como en:

$\begin{array}{ll}/ \text { xa.qi/ } & \text { persona } \\ / \text { mar.qa/ } & \text { brazada, cantidad de carga contenida } \\ & \text { en los brazos } \\ & \text { corazón }\end{array}$

La consonante /p"/ aparece en posición frontal ante /i, a, u/ en sílaba inicial, como en:

$$
\begin{aligned}
& \text { /p"i.c"u/ } \\
& \text { /p"a.sa/ } \\
& \text { /p"u.xu/ }
\end{aligned}
$$$$
\text { pestañas }
$$$$
\text { pasta comestible preparada con tierra caliza, }
$$
agua y sal, y que sirve para untar las papas puquio, ojo de agua

En sílaba medial está registrada sólo ante /i, a/, como en:

$$
\begin{array}{ll}
\text { /xi.p"i. } \lambda \text { a/ } & \text { tripas } \\
\text { /c'i.p"a.ma/ } & \text { cierta sal que se usa como detergente }
\end{array}
$$

y en sílaba final no apareció ante /u/, sí ante /i, a/, como en:

$$
\begin{array}{ll}
\text { /xuy.p"i/ } & \text { helada } \\
\text { /t'a.p"a/ } & \text { desabrido, sin sal }
\end{array}
$$

Ante /u/ sólo está documentada en:

$$
\text { /c"u.p"u/ t tumor maxilar }
$$

que es la forma metatizada de /p"u.c"u/.

La consonante /c"/ aparece en posición frontal ante /i, a, u/ en sílaba inicial, como en:

$$
\begin{array}{ll}
\text { /c"i.ya/ } & \text { cuarta, medida de longitud } \\
\text { /c"a.ma/ } & \text { grano grueso, a medio moler } \\
\text { /c"u. } \chi \text { u/ } & \text { orina }
\end{array}
$$

en sílaba medial está documentada sólo ante /a/, en:

$$
\text { /p"i.c"a. } \chi a / \quad \text { alfiler hecho de espina de cactus }
$$




$\begin{array}{ll}\text { /ñi.q'i/ } & \text { barro } \\ \text { /mus.q'a/ } & \text { dulce } \\ \text { /lu.q'u/ } & \text { gusano }\end{array}$

Se puede considerar que las interruptas (oclusivas y africadas) como clases, no aparecen en psición codal, aunque algunos de sus miembros $(/ \mathrm{c}, \mathrm{k}, \mathrm{t} /)$ aparecen ocasionalmente $( \pm$ $1 \%$ cada una ) trabando sílaba.

La consonante /s/ aparece en posición frontal ante /i, a, u/ en sílaba inicial, como en:

$\begin{array}{ll}/ \text { si. } \lambda \mathrm{u} / & \text { garra, uña } \\ / \text { sa.wu/ } & \text { telar } \\ \text { /su. } \lambda \mathrm{u} / & \text { feto }\end{array}$

en sílaba medial sólo está documentada ante /i, a/, como en:

$\begin{array}{ll}\text { /a.si.ru/ } & \text { culebra, víbora } \\ \text { /q'a.sar. } \chi \text { a/ } & \text { sarna }\end{array}$

y en sílaba final, como en:

$\begin{array}{ll}\text { /p"ax.si/ } & \text { luna, mes } \\ \text { /kim.sa/ } & \text { tres } \\ \text { /a.ña.su/ } & \text { chingue, zorrino }\end{array}$

Aparece en posición codal tras /i, a, u/, como en:

$\begin{array}{ll}\text { /c'is. } \lambda \mathrm{i} / & \text { sucio, manchado } \\ \text { /c'as.ka/ } & \text { cabellera desgreñada y sucia } \\ \text { /c'us.pa/ } & \text { carterita de lana tejida }\end{array}$

La consonante /x/ aparece en posición frontal ante /i, a, u/ en primera sílaba, como en:

$\begin{array}{ll}\text { /xi.p'i/ } & \text { polvo tostado del tronco de la quinua } \\ / \mathrm{xa} . \lambda \mathrm{u} / & \text { lluvia } \\ \text { /xu.ku/ } & \text { búho, lechuza }\end{array}$

en sílaba interna está documentada sólo ante /a/ como en:
/pa.xa. $\lambda \mathrm{i} /$
flor

y ante $/ \mathrm{u} /$ en préstamos hispánicos:

/li.xu.na/ puma

y en sílaba final, como en:

$\begin{array}{ll}/ \mathrm{mi} . x \mathrm{/} / & \text { 1. hembra estéril de llama o alpaca } \\ / \lambda \text { a.xa/ } & \text { 2. mujer estéril } \\ / \text { p"u.xu/ } & \text { herida } \\ \text { puquio, ojo de agua }\end{array}$


Aparece trabando a /i, a, u/, como en:

$\begin{array}{ll}\text { /c"ix.c"i/ } & \text { granizo } \\ \text { /nax.ra/ } & \text { pezuña } \\ \text { /t"ux.ru/ } & \text { bastón }\end{array}$

La consonante $/ \chi /$ no aparece en posición frontal en sílaba inicial, pero sí de sílaba final ante /i, a, u/, como en:
$/ t^{\prime} \cdot \chi^{\mathrm{i} /} /$
1. paquete formado con tientos de cuero
2. malla de cuero para llevar carga
/pat. $\chi \mathrm{a} /$
altiplano
/q'i. $\chi$ u/
rayo

Aparece en posición codal tras /i, a, u/, como en:

$\begin{array}{ll}\text { /wix.ru/ } & \text { chueco, torcido } \\ \text { /lax.ra/ } & \text { lengua } \\ \text { /sux.ta/ } & \text { seis }\end{array}$

La consonante $/ \mathrm{m} /$ aparece en posición frontal ante $/ \mathrm{i}, \mathrm{a}, \mathrm{u} /$ en sílaba inicial, como en:

/mi.c'a/ mezquino, tacaño

/ma.ya/ uno (numeral)

/mu.qu/

1. puño 2. nudo 3. protuberancia

en sílaba medial, como en:
/i.mi. $\lambda \mathrm{a} /$
niña
/ca.ma.xa/
oscuridad de la noche
/may.mu.ru/
riñón

y en sílaba final apareció en la muestra sólo ante /a, i/, como en:

/war.mi/

/k'a.ma/

1. mujer 2. esposa

muela cariada

Aparece trabando a /i, a, u/, como en:
/cim.pu/
/xam.p'i/
flecos hechos con hilitos de lana
/c'um.p"i/
maíz tostado
color café, color castaño, marrón

La consonante /n/ aparece en posición frontal ante /i, a/ en sílaba inicial, como en:

$\begin{array}{ll}\text { /ni.na/ } & \text { fuego } \\ \text { /na.ya/ } & \text { yo }\end{array}$

y en sílaba interna, como en:

/si.ni.xa/

pantano

/qi.na.ya/

nube que se desplaza de Este a Oeste 
$\mathrm{y}$ tras /i, a, u/, como en:

$\begin{array}{ll}\text { /ya.ni/ } & \text { canal, acequia } \\ \text { /t'u.na/ } & \text { material desmenuzado } \\ \text { /a.xa.nu/ } & \text { cara, rostro }\end{array}$

Aparece trabando a /i, a, u/, como en:

$\begin{array}{ll}\text { /xin.k'a/ } & \text { prisa, apuro } \\ \text { /k'an.wa/ } & \text { huevo } \\ \text { /tun.qu/ } & \text { maíz }\end{array}$

La consonante / $\tilde{n} /$ aparece en posición frontal ante /i, a, u/ en sílaba inicial, como en:

$\begin{array}{ll}\text { /ñi.q'i/ } & \text { barro } \\ \text { /ña.k'u.ta/ } & \text { pelo } \\ / \text { ñu.ñu/ } & \text { senos, ubres }\end{array}$

en sílaba medial ha sido encontrada ante /a, $\mathrm{u} /$, como en:
/xa.ña.cu/
garañón
/c'u.ñu.la/
frío, helado

y en sílaba final, ante /i, a/, como en:
/c'i.ñi/
liendre
/q"i.ña/
queña, un arbusto altiplánico
/c'u.ñu/
chuño, papa sometida a la acción del hielo

Aparece trabando a /i, a/, como en:
/xiñ.cu/
orejas
lañ.ca/
demasiado

La consonante / 1 / aparece en posición frontal ante /i, a, u/ en sílaba inicial, como en: /li.k'i/ 1. grasa 2.gordo

/la.p'a/ piojo

/lu.qa/ brazada, medida de longitud

En posición frontal de sílaba interna aparece en la muestra ante /i, a/, como en:

$\begin{array}{ll}\text { /c"i.c"i.lin.k"a/ } & \text { mosca, moscardón } \\ \text { /xi.la.ta./ } & \text { hermano }\end{array}$

En posición frontal de sílaba final aparece en la muestra ante /i, a/, como en:
/kum.pu.li/ insecto
/wi.la/
1. sangre 2. rojo

Aparece trabando a /i, a, u/, como en:

/cil.qi/

paso, tranco, zancada

/mal.q'a/

garganta

/pul.q"u/

especie de zapatilla 
La consonante $/ \lambda /$ aparece en posición frontal de sílaba inicial sólo ante /a, u/, como en:

$\begin{array}{ll}/ \lambda \mathrm{a} . \mathrm{xa} / & \text { herida } \\ / \lambda \mathrm{u} . \mathrm{qu} / & \text { corazón }\end{array}$

en sílaba interna aparece ante $/ \mathrm{i}, \mathrm{a}, \mathrm{u} /$, como en:

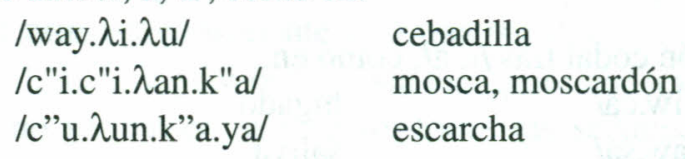

y en sílaba final, como en:

$\begin{array}{ll}/ \mathrm{k}^{\prime} \mathrm{i} . \lambda \mathrm{i} / & \text { carboncillo } \\ / \mathrm{c}^{\prime \prime} \mathrm{i} . \lambda \mathrm{a} / & \text { cuarta, medida de longitud } \\ / \mathrm{c}^{\prime} \mathrm{u} . \lambda \mathrm{u} / & \text { gorro de lana }\end{array}$

En la muestra aparece en posición codal tras /a, u/, como en:
/waג.pa/
gallina
/suג.ka/
hermano menor, hermana menor

La consonante / $\mathrm{r}$ / aparece en posición frontal ante /i, a, u/ sólo en sílaba interna, como en:

$\begin{array}{ll}\text { /pa.ri.na/ } & \text { flamenco } \\ \text { /a.ra.ma/ } & \text { noche } \\ \text { /ku.ru.ru/ } & \text { ombligo }\end{array}$

y en sílaba final, como en:

$\begin{array}{ll}\text { /la.ri/ } & \text { zorro } \\ \text { /c'a.ra/ } & \text { negro } \\ \text { /p'ux.ru/ } & \text { quebrada poco profunda }\end{array}$

Aparece en posición trabante tras /i, a, u/, como en:

$\begin{array}{ll}\text { /ir.pa/ } & \begin{array}{l}\text { pollito de gallina a punto de romper } \\ \text { el cascarón }\end{array} \\ \text { /par.pa/ } & \text { médula, tuétano } \\ \text { /ur.qu/ } & \text { macho }\end{array}$

La semiconsonante /w/ aparece en posición frontal ante /i, a/ en sílaba inicial, como en: /wix.ru/ chueco, torcido

/war.mi/ 1. mujer 2. esposa

y en sílaba medial, como en:

$\begin{array}{ll}\text { /xa.wi.ra/ } & \text { río } \\ \text { /a.wa.yu/ } & \text { manta tejida usada para llevar carga }\end{array}$ 
en sílaba final ocurre frontal ante /i, a, u/, como en:
/ñi.wi/
canal, acequia de regadío
/k'a.wa/
zanjón, quebrada poco profunda
/ki.wu/
colmillo

Aparece en posición codal tras /i, a/, como en:

$\begin{array}{ll}\text { /k'iw.ca/ } & \text { hígado } \\ \text { / } \lambda \text { aw.sa/ } & \text { saliva }\end{array}$

La semiconsonante / y / aparece en posición frontal ante /a, u/, en sílaba inicial, como en:

$\begin{array}{ll}\text { /ya.pu/ chacra } \\ \text { lyux.c'a/ } & \text { nuera }\end{array}$

y en sílaba medial, como en:
/wa.ya.xa/
bolsa, talega
/wa.yi.ta/
chal, chalón

y en sílaba final, como en:

$\begin{array}{ll}/ p^{\prime i} \text { ya/ } & \text { agujero } \\ / \mathrm{p} \text { "u.yu/ } & \text { pluma }\end{array}$

Aparece trabando a /a, u/, como en:

$\begin{array}{ll}\text { /ay.ca/ } & \text { carne } \\ \text { /cuy.ma/ } & 1 . \text { bofes } 2 \text {. corazón }\end{array}$

De la distribución examinada se desprende que las interruptas están restringidas a la posición frontal, en tanto que las fricativas, las resonantes y las semiconsonantes pueden ser frontales o codales. En otras palabras, las 26 consonantes pueden iniciar sílaba, pero sólo 11 pueden cerrar sílaba, lo que está en consonancia con la mayor frecuencia del tipo silábico CV y la menor frecuencia del tipo CVC.

Una restricción importante afecta a las consonantes $/ \chi, \mathrm{r} /$ que pueden aparecer en posición frontal solamente en sílaba no inicial. Aparentemente, esta restricción no está vinculada a factores accidentales -como el tamaño o la orientación de la muestra utilizada- sino más bien es un rasgo estructural de la lengua.

Ninguna vocal aparece restringida al contexto de alguna consonante o clase de consonantes. Ninguna consonante aparece restringida al contexto de alguna vocal en particular, pero las semiconsonantes presentan restricciones de coocurrencia con sus contrapartidas vocálicas, en particular en posición trabante: secuencias intrasilábicas del tipo */(C)iy/o*/(C)uw/ no han sido encontradas; por otra parte, /y,w/ en posición frontal ante /i, u/ respectivamente, ocurren muy rara vez. No hay restricción a la coocurrencia de las semiconsonantes en posición frontal 0 codal con la vocal /a/. 


\subsubsection{Grupos consonánticos internos}

Salvo rara excepción, todos los grupos consonánticos que se producen en el interior de la palabra, corresponden a la concurrencia de la consonante codal de una sílaba con la consonante inicial de la sílaba siguiente: $/(\mathrm{C}) \mathrm{CV}$.CV/. En principio, entonces, en todo grupo consonántico interno, la primera consonante será una fricativa, una resonante o una semiconsonante /s, x, $\chi, \mathrm{m}, \mathrm{n}, \tilde{\mathrm{n}}, 1, \lambda, \mathrm{r}, \mathrm{w}, \mathrm{y} / \mathrm{y}$ la segunda cualquier consonante/semiconsonante de la lengua. En la práctica, no se dan en la muestra todas las secuencias teóricamente posibles. Así, por ejemplo, la única secuencia de consonantes idénticas que aparece es $/ \mathrm{Vn}$.nV/, una sola vez en:

$$
\text { /un.na. } \chi \text { a/ cara, rostro }
$$

Secuencias registradas de consonantes diferentes son:

1. /...s.p.../, como en:

/c'us.pa/ carterita de lana tejida

2. /...s.t.../, como en:

/k"is.ti/ ¿quién?

3. /...s.k.../, como en:

/c'as.ka/ cabellera sucia, desgreñada

4. /...s.k".../, como en:

/xis.k"u/ ojotas

5. /...s.q.../, como en:

/p"is.qi/ quinua machacada

6. /...s.q'.../, como en:

/mus.q'a/ dulce

7. /...s. $\chi$.../, como en:

/mus. $\chi$ a/ dulce

8. /...s.n.../, como en:

/p"is.na/ liviano

9. /...s. $\lambda . . . /$, como en:

$/ c$ 'is. $\lambda \mathrm{i} / \quad$ sucio, manchado

10. /...x.t.../, como en:

/ $\lambda$ ux.ta/ lejía en moldecitos para acompañar la coca

11. /...x.t'.../, como en:

/ $\lambda$ ux.t'a/ lejía en moldecitos para acompañar la coca

12. /...x.c.../, como en:

/su.rux.ci/ mal de altura, mal de la puna

13. /...x.c".../, como en:

/c"ix.c"i/ granizo

14. /...x.ג.../, como en:

$/ c$ 'ix. $\lambda \mathrm{i} / \quad$ sucio, manchado 
15. /...x.r.../, como en:

/c'ux.ru/, conchita alargada

16. /...x.t.../, como en:

$/$ sux.ta/ seis

17. I/........../, como en:

$/ \lambda \mathrm{u} \chi . c^{\prime} \mathrm{a} /$ nuera

18. /.....ñ.../, como en:

/c'ux.ña/ verde

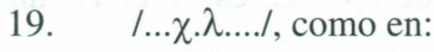

$/ c u \chi . \lambda \mathrm{u} /$ mazorca del maíz

20. /... $\chi . r . . . /$, como en:

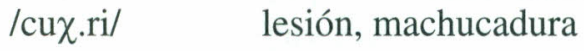

21. /...m.p.../, como en:

/cim.pu/ flecos hechos de hilitos de lana

22. /...m.p".../, como en:

/c'um.p"i/ color café, castaño, marrón

23. /...m.p'.../, como en:

/xum.p'i/ sudor

24. /...m.t.../, como en:

/t'am.ta.ta/ orina fermentada

25. /...m.s.../, como en:

/kim.sa/ tres

26. /...n.t.../, como en:

/in.ti/ sol

27. /...n.t".../, como en:

/t"an.t"a/ viejo, inservible

28. /...n.t'.../, como en:

/xun.t'u/ caliente

29. /...n.k.../, como en:

/pun.ku/ puerta

30. /...n.k".../, como en:

/cun.k"a/ barba, bigote

31. /...n.k'.../, como en:

/xan.k'a/ prisa, apuro

32. I...n.q.../, como en:

/cin.qi/ vulva

33. /...n.q".../, como en:

/man.q"a/ 1. interior, adentro 2. abajo

34. /...n.q'.../, como en:

/wan.q'u/ cuy, cuye

35. /...n.x.../, como en:

/a.kan.xi./ aquí 
36. /...n.w.../, como en:
/k'an.wa/
huevo

37. /...ñ.c.../, como en:
/añ.ca/
desmasiado

38. /...ก̃...../, como en:

/q"iñ.wa/ queñua, un arbusto altiplánico

39. /...l.q.../, como en:

/tul.qa/

yerno

40. /...1.q".../, como en:

/pul.q"u/ especie de zapatilla fabricada del cuero entero de la pierna de los animales

41. /...1.q'.../, como en:
/mal.q'a/
garganta

42. /.....p.../, como en:
/aג.pa.cu/
alpaca

43. /.....c.../, como en:

/a $\lambda . c i / \quad$ nieto, nieta

44. /.....k.../, como en:

$/ \mathrm{ka} \lambda . \mathrm{ku} / \quad$ amargo

45. /... ...../, como en:

/caג.wa/ pescado

46. /...r.p.../, como en:

/par.pa/ médula, tuétano

47. /...r.k.../, como en:

/mar.ka/ pueblo, poblado

48. /...r.k".../, como en:

/xur.k"u/ traje femenino tradicional

49. /...r.q.../, como en:

/ur.qu/ macho

50. /...r.s.../, como en:

/pir.sa.ra/ un tipo de frazada tejida a telar

51. /...r. $\chi \ldots . . /$, como en:

/q'a.sar. $\chi a /$ sarna

52. /...r.m.../, como en:

/war.mi/ 1. mujer 2. esposa

53. /...w.t.../, como en:

law.ti/ estación seca

54. /...w.c.../, como en:

/k'iw.ca/ hígado

55. /...w.k.../, como en:

/aw.ki/ $\quad$ 1. padre 2. abuelo 3. anciano

56. /...w.k'.../, como en:

/xiw.k'i/ tostador 
57. . /...w.q'.../, como en:

/xiw.q'i/ humo

58. /...w.s.../, como en:

/ $\lambda$ aw.sa/ saliva

59. /...w.n.../, como en:

/k'aw.na/ huevo

60. /...w.ñ.../, como en:

/q"iw.ña/ queñua, un arbusto altiplánico

61. /...w.1.../, como en:

/kiw.la/ perdiz pequeña, codorniz

62. /...w. ..../, como en:

/q"iw. $\lambda \mathrm{a} /$ gaviota

63. /...w.r.../, como en:

/qaw.ra/ llama

64. /...у.p".../, como en:

/xuy.p"i/ helada

65. /...y.c.../, como en:

/ay.ca/ carne

66. /...y.k.../, como en:

/tay.ka/ madre

67. /...y.k".../, como en:

/xuy.k"u/ ciego

68. /...y.q.../, como en:

/lay.qa/ brujo

69. /...y.q".../, como en:

/qay.q"a/ ¿cuánto?

70. /...y.m.../, como en:

/cuy.ma/ 1. bofes 2 . corazón

71. /...y.n.../, como en:

/way.na/ muchacho, hombre joven

72. /...y.ñ.../, como en:

/way.ñu/ huaino, cierto tipo de música para canto y baile

73. /...y.ג.../, como en:

/way. $\lambda \mathrm{i} . \lambda \mathrm{u} / \quad$ cebadilla, un tipo de pasto para el ganado

74. /...y.r.../, como en:

/k'ay.ra/ 1. rana 2. sapito de lluvia

75. /...y.w.../, como en:

/uy.wa/ ganado

\subsubsection{Reglas de silabeo}

Sin excepción observada, cada consonante/semiconsonante forma sílaba con la vocal que la sigue. Dos consonantes contiguas pertenecen, en principio, a sílabas separadas, con excepción de palabras como: 


$\begin{array}{ll}\text { /c"a. } \chi w a / & \text { chancado, triturado de piedra } \\ \text { /lu.rya/ } & \text { papelillo } \\ \text { /q"i.ñwa/ } & \text { queñua, un arbusto altiplánico } \\ \text { /wa.tya/ } & \text { guiso preparado en un hoyo excavado en la tierra }\end{array}$

en las que las que aparece un grupo consonántico (consonante + semiconsonante) en el frontis de la segunda sílaba. En toda otra ocurrencia registrada de consonante + semiconsonante, éstas están separadas por frontera silábica, como en:

$$
\text { /caג.wa/ pescado }
$$

Se encontraron tres palabras en las que aparecen contiguas tres consonantes, en todas ellas las últimas dos consonantes siguen la pauta general, o sea, pertenecen a sílabas separadas:

$\begin{array}{ll}\text { /ams.ta/ } & \text { cuesta, pendiente } \\ \text { /awx.ci/ } & \text { suegro } \\ \text { /cilq.ta/ } & \text { paso, tranco, zancada }\end{array}$

No hay secuencias de dos vocales silábicas contiguas, con excepción de cuatro palabras:

$\begin{array}{ll}\text { /ta.ik.ci/ } & \text { suegra } \\ \text { /c'i.a.ra/ } & \text { negro } \\ \text { /ki.u.la/ } & \text { perdiz pequeña, codorniz } \\ \text { /c'i.a.ra.na/ } & \text { mojado }\end{array}$

En toda otra secuencia de segmentos fonéticamente vocálicos, sólo uno es silábico. Este puede ser el primero, como en :

$$
\text { luy.wa/ ganado }
$$

o el segundo, como en:

/wa.ña/ seco

o el del medio, como en:

/way.ñu/ huaino

\subsubsection{Rasgos suprasegmentales}

En una palabra todas las sílabas que la componen se pronuncian con aproximadamente la misma longitud, intensidad y altura de tono, excepto la penúltima sílaba que es un punto más larga, alta e intensa, y la última, un punto más breve, baja y laxa.

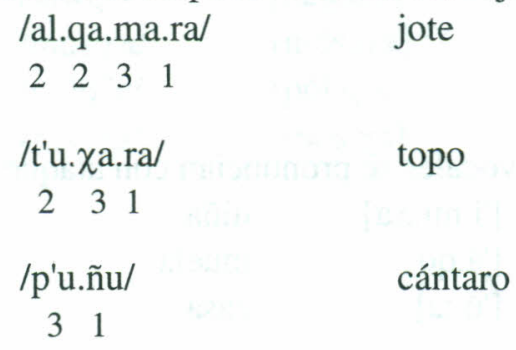


Se puede concluir que la lengua es de ritmo silábico, con acento de longitud, intensidad y altura fijo en la penúltima sílaba, con pequeño margen de diferenciación entre la sílaba tónica y la o las sílabas átonas. En estas condiciones el acento no cumple función contrastiva, sino más bien demarcativa en el sentido de que puede servir como criterio adicional para definir la palabra simple, como toda secuencia de sílabas delimitada por el contorno 3-1. Así en:

$$
\begin{aligned}
& \text { /xa.ra.ran.k"u/ lagartija } \\
& \begin{array}{llllll}
2 & 2 & 3 & 1
\end{array}
\end{aligned}
$$

hay una palabra simple, pero en:

$$
\begin{aligned}
& \text { /ta".ya.xa.ma.c'i/ cierta ave silvestre altiplánica } \\
& \begin{array}{llllll}
3 & 1 & 2 & 3 & 1
\end{array} \quad \text {. }
\end{aligned}
$$

hay dos palabras simples unidas por composición, y en:

$$
\begin{aligned}
& \text { /qa.la.qa.la/ pedregal } \\
& 3131
\end{aligned}
$$

hay una reduplicación de una palabra simple, /qa.la/ 'piedra', y en:

$$
\begin{aligned}
& \text { /k"a.ya.a.nu.qa.ra.xan.q'u.wa/ aquel perro blanco-es } \\
& \begin{array}{llllllllll}
3 & 1 & 2 & 2 & 3 & 1 & 2 & 3 & 1
\end{array}
\end{aligned}
$$

hay un enunciado compuesto por tres palabras simples.

En fonología los compuestos se diferencian de las frases por el tipo de juntura, continua en aquéllos y discontinua (/\#/) en éstas:

$$
\begin{aligned}
& \text { /a.rax.pa.ca/ cielo } \\
& 311 \\
& \text { /ur.qu \# qaw.ra/ macho de llama } \\
& \begin{array}{llll}
3 & 1 & 3 & 1
\end{array}
\end{aligned}
$$

\subsection{Variación alofónica}

En general, los fonemas aymara son muy estables en su realización fonética de norma, la que está afectada por relativamente pocos cambios contextual o posicionalmente regulados.

\subsubsection{Vocales}

En posición inicial absoluta las vocales se pronuncian con ataque duro:

$\begin{array}{lll}\text { /imi } \lambda \mathrm{a} / & \text { ['i.mí. } \lambda \mathrm{a} \text { ] } & \text { niña } \\ \text { /aqu/ } & \text { ['á.qo] } & \text { muela } \\ \text { /uta/ } & \text { ['ú.ta] } & \text { casa }\end{array}$


El ataque duro aparece también en los pocos casos de vocal inicial de sílaba interna, como en:

$$
\text { /c'iara/ [c'i.'a.ra] negro }
$$

Las vocales altas, $/ \mathrm{i}, \mathrm{u} /$, suelen pronunciarse medias, $([\mathrm{e}, \mathrm{o}])$ en contacto con consonante uvular (/q, q", q', $\chi /)$ precedente, como en:

\begin{tabular}{|c|c|c|}
\hline /qina/ & [qé.na] & quena, un tipo de flauta andina \\
\hline /quca/ & [qó.ca] & cocha, laguna pequeña \\
\hline /q"ipa/ & [q"é.pa] & atrás \\
\hline /q"uc"i/ & [q"ó.c"i] & charco \\
\hline /q'iñca/ & [q'eñ.ca] & cerco de ramas \\
\hline /q'uwa/ & [q'ó.wa] & un arbusto aromático altiplánico \\
\hline /pat'a i/ & 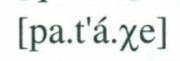 & camastro \\
\hline /xaхu/ & [xá.ұo] & amargo, picante \\
\hline
\end{tabular}

o siguiente, como en:

\begin{tabular}{|c|c|c|}
\hline /ciqa/ & [cé.qa] & verdad, verdadero \\
\hline /luqa/ & [ló.qa] & brazada, medida de longitud \\
\hline /c"iq"a/ & [c"é.q"a] & 1. ala 2. pluma \\
\hline /xuq"u/ & [xó.q"o] & bofedal \\
\hline /piq'ara/ & [pe.q'á.ra] & calvo, pelado \\
\hline /luq'u/ & [ló.q'o] & gusano \\
\hline /wix.ru/ & [wéx.ro] & chueco, torcido \\
\hline /c'uxña/ & [c'óx.ña] & verde \\
\hline
\end{tabular}

la consonante $/ \chi /$ baja a $/ \mathrm{i}, \mathrm{u} /$ precedentes y siguientes, de donde éstas resultan pronunciadas $[\mathrm{e}, \mathrm{o}]$ :

[t'é. $\chi \mathrm{e}]$

[só. $\chi 0]$

[ñé. $\chi 0]$

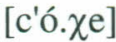

El descenso producido por las consonantes uvulares puede propagarse a /i, u/ no contiguas, situadas en sílaba precedente, o sea, separadas de la consonante uvular por una consonante trabante, como puede verse en:

\begin{tabular}{|c|c|c|}
\hline /cilqi// & [cél.qe] & paso, tranco, zancada \\
\hline /tulqa/ & [tól.qa] & yerno \\
\hline /xiwq'i/ & [xéun.q'e] & humo \\
\hline /musq'a/ & [mós.q'a] & dulce \\
\hline /pulq"u/ & [pól.q"o] & zapatilla \\
\hline /mus $\chi a$ / & [mós.xa] & dulce \\
\hline
\end{tabular}


No se produce dscenso vocálico por influencia de consonante uvular hacia sílaba siguiente, como puede verse en:

$\begin{array}{lll}\text { /qunkura/ } & \text { [qon.kú.ra] } & \text { rodilla } \\ \text { /qururu/ } & \text { [qo.rú.ro] } & \text { ombligo } \\ \text { /q'uruta/ } & \text { [q'o.rú.ta] } & \text { testículos }\end{array}$

\subsubsection{Semiconsonantes}

Las semiconsonantes tienen articulación vocálica alta anterior (/y/) y posterior $(/ \mathrm{w} /)$, y distribución consonántica, es decir, ocurren en el frontis ([j, w]) o en la coda de la sílaba ([ i, u $]$ ] $)$ como en:

$\begin{array}{lll}\text { /ya.pu/ } & \text { [já.po] } & \text { chacra } \\ \text { /yu.qa/ } & \text { [jó.qa] } & \text { hijo } \\ \text { /wa.k'a/ } & \text { [wá.k'a] } & \text { faja } \\ \text { /wi.la/ } & \text { [wíla] } & \text { 1. sangre 2. rojo } \\ \text { /ay.ca/ } & \text { [ái.ca] } & \text { carne } \\ \text { /aw.ki/ } & \text { [áu.ke] } & \text { 1. padre 2. abuelo 3. anciano } \\ \text { /kiw.la/ } & \text { [kíu.la] } & \text { perdiz pequeña, codorniz } \\ \text { /xuy.ra/ } & \text { [xúi.ra] } & \text { quinua cruda }\end{array}$

Nótese que hay restricción para la coocurrencia en la misma sílaba de las semiconsonantes /y, w/ con sus contrapartidas vocálicas /i, u/.

En posición frontal /y, w/ tienen realizaciones consonánticas alternantes secundarias, palatal levemente fricativa ([y]) y bilabial levemente fricativa ([b]), respectivamente, como en:

\begin{tabular}{|c|c|c|}
\hline /ya.pu/ & [já.po] [yá.po] & chacra \\
\hline /wa.k'a/ & [wá.k'a] [bá.k'a] & faja \\
\hline /yu.qa/ & [jó.qa] [yó.qa] & hijo \\
\hline /wi.c'u/ & [wí.c'u] [Đí.c'u] & diarrea \\
\hline /k'a.wa/ & [k'á.wa] [k'á.ba] & zanjón \\
\hline /xa.wi.ra/ & [xa.wí.ra] [xa.bí.ra] & río \\
\hline /sa.wu/ & [sá.wu] [sá.wo] [sá.bo] & telar \\
\hline /pa.ya/ & [pá.ja] [pá.ya] & dos \\
\hline /xa.yu/ & [xá.jo] [xá.yo] & sal común \\
\hline
\end{tabular}

La realización bilabial fricativa sonora $[\mathrm{b}]$ del fonema /w/ está documentada en posición codal una sola vez, en:

$$
\text { /k'iwca/ [k'ín.ca }] \sim\left[k^{\prime} \text { ił.ca }\right] \quad \text { hígado }
$$


No se encontraron realizaciones consonánticas de /y/ en posición codal, las que sólo aparecen marginalmente en posición frontal. En ningún item apareció solamente la realización consonántica.

Hay palabras en las cuales nunca se registró la realización bilabial fricativa sonora [ $\exists]$ del fonema $/ \mathrm{w} /$, entre otras:

\begin{tabular}{|c|c|c|}
\hline /awayu/ & siempre [a.wá.ju] & manta tejida \\
\hline /awica/ & siempre [a.wí.ca] & abuela \\
\hline /k'anwa/ & siempre [k'án.wa] & huevo \\
\hline /lawita/ & siempre [la.wí.ta] & mazamorra de quinua \\
\hline /q"iñwa/ & siempre [q"éñ.wa] & queñua, un arbusto altiplánico \\
\hline /wac"a/ & siempre [wá.c"a] & $\begin{array}{l}\text { dedo o dedos excedentes en } \\
\text { una llama o alpaca }\end{array}$ \\
\hline /wakuגa/ & siempre [wa.ku. $\lambda \mathrm{a}]$ & cántaro \\
\hline /waגpa/ & siempre [wád.pa] & gallina \\
\hline /wit"u/ & siempre [wí.t"o] & animal mocho de la cola \\
\hline
\end{tabular}

El caso contrario, o sea, siempre la realización [ఈ], se registró en tres palabras:

\begin{tabular}{|c|c|c|}
\hline /ñiwi/ & siempre [ñí.be] & canal, acequia de regadío \\
\hline /q'urawa/ & siempre [q'o.rá.Đa] & honda \\
\hline /wixro/ & 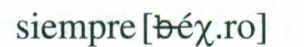 & chueco, torcido \\
\hline
\end{tabular}

\subsubsection{Consonantes}

Las oclusivas puras, /p, t, k, q/ presentan realizaciones sonoras en el mismo punto, cuando están precedidas de consonante nasal, de donde resultan los siguientes alófonos: [b, d, ǵ, g], como en:

$\begin{array}{lll}\text { /ampara/ } & \text { [am.pá.ra] [am.bá.ra] } & \text { mano } \\ \text { /inti/ } & {[\text { ín.te] } \sim[\text { [í.de] }} & \text { sol } \\ \text { /punku/ } & {[\text { púń.ko] } \sim[\text { pún.gó }} & \text { puerta } \\ \text { /tunqu/ } & {[\text { tón.qo] } \sim[\text { tón.go] }} & \text { maíz }\end{array}$

Está documentada también la sonorización de la fricativa palatal sorda / $\mathrm{x} /$ precedida de consonante nasal, de donde resulta una fricativa palatal sonora [q́⿴囗十 como en:

$$
\begin{array}{ll}
\text { /akanxi/ } & \text { [a.káń.xe] [a.káń.ǵe] } \quad \text { aquí } \\
\text { /q"anatanxi/ } & \text { [q"a.na.táń.xe] } \sim \text { [q"a.na.táń.ǵe }] \text { claridad del amanecer }
\end{array}
$$


Es posible que los grupos [ńǵ] y [ńǵ] se reduzcan a una nasal palatal [ń], como en: /p"at"anka/ [p"a.t"áń.ka] [p"a.t"áń.ǵa] [p"a.t"á.j́a] guatitas, callos /sansanxi/ [san.sáń.xe] [ [san.sáń.ǵe] $\sim$ [san.sá.ýe] ruido

La sonorización de las oclusivas puras /p, t, k, g/ y de la fricativa palatal /x/ precedidas de consonante nasal, ocurre algo menos de la mitad de los casos en que el grupo en cuestión se presenta. Así, en algunas palabras la sonorización no está documentada, como en:

$\begin{array}{lll}\text { /cimpu/ } & \text { siempre [cím.po] } & \text { flecos hechos de hilitos de lana } \\ \text { /pirpintu/ } & \text { siempre [pir.pín.to] } & \text { mariposa } \\ \text { /anku/ } & \text { siempre [án..ko] } & \text { nervio } \\ \text { /cinqi/ } & \text { siempre [cén.qe] } & \text { vulva }\end{array}$

Aparecieron pocos ítemes en los cuales sólo se escuchó la realización sonora, como en:

/cinki/

/ñusantata/

/waqanqa/

/kuntiri/ siempre [ciń.ǵe] vulva

siempre[ñu.san.dá.ta] podrido

siempre [wa.qán.qa] agua desabrida

siempre[kun.dé.re] cóndor

En los casos en que alternan realizaciones sordas y sonoras, se aprecia predominio de la realización de norma, o sea, sorda, en el norte (Provincia de Parinacota), en tanto que hacia el sur (Provincia de Iquique) aumenta la frecuencia de la sonorización. Así, /ampara/ 'mano-brazo' se pronuncia en el norte habitualmente con oclusiva bilabial sorda, [am.pá.ra], y sólo excepcionalmente con oclusiva bilabial sonora, [am.bá.ra], y a la inversa en el sur. En ningún área se observó reacción negativa ante la realización secundaria.

La africada alveopalatal pura /c/ destaca dentro de las otras obstruyentes puras (/p, t, k, q/) por no estar afecta a la sonorización opcional tras consonante nasal, así hay:
/añca/
siempre [áñ.ca]
nunca *[añ.ỹa]
/入añcu/
siempre [ $\lambda a ́ n ̃ . c o]$
nunca $*[\lambda$ añ.ŷo $]$
mojado

Las interruptas aspiradas palatal, /k"/, y uvular, /q"/, tienen realizaciones secundarias africadas en sus mismos puntos, $\left[\mathrm{k}^{\mathrm{X}}\right]$ y $\left[\mathrm{q}^{\chi}\right]$ respectivamente, como en:

\begin{tabular}{|c|c|c|}
\hline /c'ik"i/ & [c'í.k"e] [c'í.k $\left.\mathrm{x}_{\mathrm{e}}\right]$ & duro \\
\hline /sunk"a/ & [súń.k"a] [súń. $\mathrm{k}^{\mathrm{X}} \mathrm{a}$ ] & barba, bigote \\
\hline / p"uk"u/ & [p"ú.k"o] [p"ú.k ${ }^{\mathrm{x}_{\mathrm{o}}}$ ] & olla \\
\hline /aq"i/ & [á.q"e] [á.qхe] & montaña cortada a pique \\
\hline /c"iq"a/ & [c"é.q"a] [c"é.q $\left.\chi_{a}\right]$ & 1. ala 2. pluma \\
\hline
\end{tabular}


La fricativización de la aspiración ocurre mayormente en posición medial. En posición inicial sólo se ha encontrado $\left[\mathrm{q}^{\prime \prime}\right] \sim[\mathrm{q} \chi]$ en pocas palabras, como:

\begin{tabular}{|c|c|}
\hline /q"i $\lambda \mathrm{a} /$ & {$[q " e ́ . \lambda a] \sim[q \chi e ́ . \lambda a]$} \\
\hline /q"ana/ & [q"á.na] [qXá.na] \\
\hline
\end{tabular}

Está registrada la fricativización de la aspiración de /k"/ inicial:
/k"uc"i/
[k"ú.c"e] [k $\left.\mathrm{X}^{\mathrm{X} . c " e}\right]$
1. basura 2.cerdo

En la mayor parte de las ocurrencias de /k", q"/ la fricativización de la aspiración no ha sido observada, como en:

$\begin{array}{lll}\text { /xik"ina/ } & \text { siempre [xi.k"í.na] } & \text { espalda } \\ \text { /cirk"a/ } & \text { siempre [cír.k"a] } & \text { dedos excedentes en una llama o alpaca } \\ \text { /ñuk"u/ } & \text { siempre [ñ́.k"o] } & \text { bozal o mordaza } \\ \text { /manq"a/ } & \text { siempre[mán.q"a] } & \text { 1. interior 2. adentro } \\ \text { /pulq" u/ } & \text { siempre[pól.q"o] } & \text { zapatilla } \\ \text { /q"ipa/ } & \text { siempre[q"é.pa] } & \text { atrás }\end{array}$

Se ha registrado un pequeño número de casos de fricativización en el mismo punto de las oclusivas puras palatal /k/ y uvular /q/ y de la oclusiva aspirada palatal /k"/, todas ellas en posición medial. El resultado es una fricativa palatal $[\mathrm{x}]$ alternante con $[\mathrm{k}]$ y $\left[\mathrm{k}^{\prime \prime}\right]$ o una fricativa uvular $[\chi]$, alternante con [q], como puede apreciarse en:

\begin{tabular}{|c|c|c|}
\hline /pataka/ & [pa.tá.ka] [pa.tá.xa] & cien \\
\hline /puraka/ & [pu.rá.ka] [pu.rá.xa] & guata, vientre \\
\hline /taikci/ & [ta.ík.ce] [ta.íx.ce] & suegra \\
\hline /awkci/ & [áunk.ce] [áunx.ce] & suegro \\
\hline / $\lambda \mathrm{ukta} /$ & {$[\lambda$ úk.ta $] \sim[\lambda$ úx.ta $]$} & $\begin{array}{l}\text { lejía en moldecitos para } \\
\text { acompañar la coca }\end{array}$ \\
\hline /macaqa/ & [ma.cá.qa] [ma.cá.xa] & nuevo, dicho de las cosas \\
\hline /p"ic"aqa/ & [p"i.c"á.qa] [p"i.c"á.ða] & alfiler hecho de espina de cactus \\
\hline /wayaqa/ & [wa.já.qa] [wa.já.xa] & bolsa, talega \\
\hline /qamaqi/ & 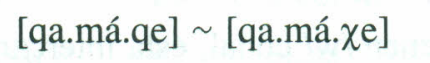 & zorro \\
\hline /anuqara/ & 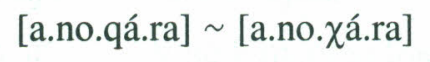 & perro \\
\hline /c'uqi/ & 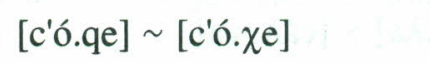 & papa \\
\hline /muruqu/ & 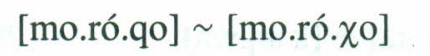 & redondo \\
\hline /paqalqu/ & 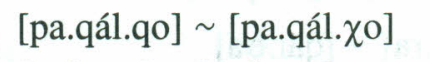 & siete \\
\hline /musqa/ & [mós.qa] [mós.ұa] & dulce \\
\hline /yuqc'a/ & 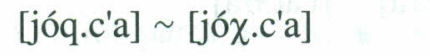 & nuera \\
\hline
\end{tabular}




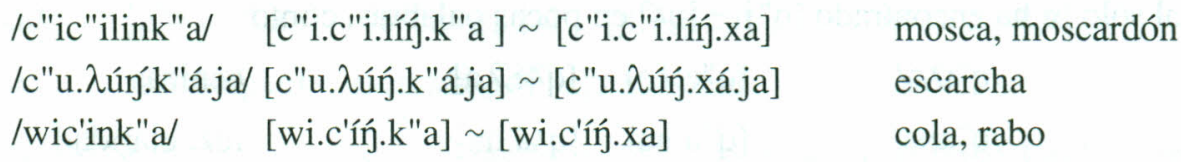

Como las fricativas palatal $[\mathrm{x}]$ y uvular $[\chi]$ tienen estatus fonémico en la lengua, $/ \mathrm{x} / \mathrm{y}$ $|\chi|$, los casos presentados han sido tratados aquí como variación en el léxico, no como variación en la realización de los fonemas /k, q, k"/, de modo que un ítem dado, sea 'perro', está registrado con dos configuraciones fonemáticas: /anuqara/ y /anuxara/, y otro, sea 'cien', como /pataka/ y /pataxa/.

La nasal alveolar /n/ se realiza palatal ['́] ante consonante palatal, /k, k”, k', x/, como en:

$\begin{array}{lll}\text { /anku/ } & \text { [áń.ko] } & \text { nervio } \\ \text { /c'ank"a/ } & \text { [c'án.k"a] } & \text { hilitos largos de lana dispuestos como flecos } \\ \text { /link'u/ } & \text { [lín.k'o] } & \text { ondulado con curvas } \\ \text { /sansanxi/ } & \text { [san.sáń.xe] } & \text { ruido }\end{array}$

y se realiza uvular [n] ante consonante uvular, /q, q", q'/, como en:

\begin{tabular}{|c|c|c|}
\hline /tunqu/ & [tón.qo] & maíz \\
\hline $\begin{array}{l}\text { /manq"a/ } \\
\text { /wang'a/ }\end{array}$ & [mán.q"a] & 1. interior 2 . adentro \\
\hline
\end{tabular}

La vibrante $/ \mathrm{r} /$ se realiza siempre como simple $[\mathrm{r}]$, y en dos ítemes presenta una variante fricativa rehilada, $[\overline{\mathrm{r}}]$ :

\begin{tabular}{|c|c|c|}
\hline /asiru/ & [a.sé.ro] [a.sé.̄̄o] & culebra, víbora \\
\hline /waranqa/ & [wa.ráń.qa] [wa.̄̄áń.qa] & mil \\
\hline
\end{tabular}

La realización fricativa rehilada es de norma en posición incial de préstamos hispánicos, como:

$$
\text { /rutaña/ [ [ [ u.tá.ña }] \quad \text { rogar }
$$

\subsubsection{Metátesis}

En algunos ítemes que contienen /w/ codal, ésta intercambia su posición con la consonante siguiente, como en:

\begin{tabular}{|c|c|c|}
\hline /caw $\lambda \mathrm{a} /$ & 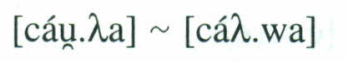 & pescado \\
\hline /k'awna/ & [k'áun.na] [k'áp.wa] & huevo \\
\hline /qawra/ & [qáun.ra] [qár.ba] & llama \\
\hline /t'awra/ & [t’áu.ra] [t'ár.ba] & lana \\
\hline
\end{tabular}


En un ítem la metátesis produjo una estructura silábica anómala:

$$
\text { /qiwña/ [q"éun.ña] [q"éñ.wa] [q"é.ñwa] queñua }
$$

el último ítem es anómalo porque contiene una sílaba con un grupo consonántico en el frontis.

En general, la metátesis no tiene lugar si la consonante que sigue a /w/ es obstruyente:

\begin{tabular}{|c|c|c|}
\hline /awti/ & $\begin{array}{l}\text { siempre [áu.t.ti] } \\
\text { no * [át.wi] }\end{array}$ & estación seca \\
\hline /ciwci/ & $\begin{array}{l}\text { siempre [cíu.ci] } \\
\text { no }{ }^{*} \text { [cic.wi] }\end{array}$ & pollito de gallina recién nacido \\
\hline /xiwk'i/ & $\begin{array}{l}\text { siempre [xíu.k'e] } \\
\text { no * [xík.we] }\end{array}$ & tostador \\
\hline /xiwq'i/ & $\begin{array}{l}\text { siempre [xéun.q'e] } \\
\text { no * [xéq'.we] }\end{array}$ & humo \\
\hline / $\lambda$ awsa/ & $\begin{array}{c}\text { siempre }[\lambda \text { áu.u.sa }] \\
\text { no * }[\lambda \text { ás.wa }]\end{array}$ & saliva \\
\hline
\end{tabular}

Se han observado también casos de metátesis de sílabas enteras, como en:

$$
\begin{array}{ll}
/ \text { c'u. } \lambda \text { u/ / } \lambda \text { u.c'o/ } & \text { gorro de lana } \\
/ \text { c"u.p"u/ /p"u.c"u/ } & \text { tumor maxilar }
\end{array}
$$

En /c'u. $\lambda \mathrm{u} / /$ / $/ \lambda$ u.c'u/ se ha producido un contraste nuevo: 'gorro de lana delgado, con orejas' (/c'u $\lambda \mathrm{u} /)$ vs. 'gorro pasamontañas grueso que cubre el rostro y el cuello' (/ $\left.\lambda u u^{\prime} u /\right)$, contraste que no es aceptado por todos los hablantes consultados.

Se han observado algunos casos de caída de /x/ inicial absoluta ante /a, u/, como en:

$\begin{array}{lll}\text { /xaq"i/ } & {[\text { xá.q"e] [á.q"e] }} & \text { montaña cortada a pique } \\ \text { /xawayu/ } & {[\text { xa.wá.jo] } \sim \text { [a.wá.jo] }} & \text { manta tejida } \\ \text { /xurk"u/ } & {[\text { xúr.k"o] [úr.k"o] }} & \text { traje femenino tradicional }\end{array}$

que han sido tratados como variación léxica y presentados con dos configuraciones fonemáticas cada uno, así:

$$
\begin{array}{ll}
\text { /aq"i/ /xaq"i/ } & \text { montaña cortada a pique } \\
\text { /awayu/ /xawaju/ } & \text { manta tejida } \\
\text { /xurk"u/ /urk"u/ } & \text { traje femenino tradicional }
\end{array}
$$

\subsection{Fonología y gramática}

\subsubsection{Fonología y morfología}

El silabismo presentado en los párrafos anteriores se modifica en la flexión nominal y verbal en el siguiente sentido: hay sufijos, verbales y nominales, los llamados "sufijos fuertes" 
en los estudios aymara, que producen caída de la vocal inmediatamente precedente. En algunos casos la caída vocálica deja consonantes obstruyentes en posición codal, como en:

$$
\text { /maq'tawa/ comiste, has comido }
$$

donde aparece /q'/ en posición codal de la primera sílaba (/maq'/). La raíz para 'comer' es /maq'a/, pero la última /a/ cae al concurrir el sufijo /maq'ta/, al que se añade el sufijo verbal enfático -/wal: /maq'(a)-ta-wa/.

La caída vocálica motivada por los sufijos fuertes produce grupos consonánticos en el interior de la palabra, inexistentes en las raíces solas, como en:

$$
\text { /sart } \chi \text { a/ ya fui, ya he ido }
$$

donde aparece el grupo /rt / / producido por caída de la última /a/ de la raíz /sara/ 'ir', debida a la concurrencia del sufijo -/ta/ 'I persona/pretérito perfecto', de donde /sarta/, el que su vez pierde su última /a/ por efecto del sufijo - $\chi \mathrm{a} /$ 'terminativo': /sar(a)-t(a)- $\chi \mathrm{a} /$.

Se pueden producir grupos de obstruyentes, que retienen bien su identidad fonológica:

$$
\text { /maq'ktati/ /maq'xtati/ tu no comiste }
$$

donde la raíz /maq'a/ 'comer' pierde su última /a/ por efecto del sufijo negativo -/ka/ -/xa/; la forma resultante /maq'ka/ /maq'xa/ pierde su última /a/ por efecto de -/tati/ 'II persona singular/pretérito perfecto negativo':

$$
\text { /maq'(a)k(a)tati/ /maq'(a)x(a)tati/ }
$$

Una situación similar se presenta en la flexión nominal, como se puede apreciar en: /taqpaca/ todos juntos

donde se encuentra una /q/ en posición codal, posición en la que normalmente /q/ no se da en las raíces solas. La raíz 'todos' es /taqi/ y pierde su última vocal, /i/, al concurrir el sufijo -/pa$\mathrm{cal}$ 'en conjunto':

$$
\text { /taq(i)paca/ }
$$

Igualmente:

/ukatxa/ después de eso, a continuación, luego

la raíz /uka/ 'despues' recibe el sufijo -/ta/ que indica el punto de partida. La forma resultante

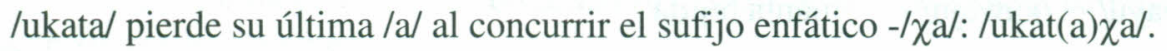

\subsubsection{Fonología y sintaxis}

En las oraciones se observa una tendencia consistente a elidir la última vocal de las palabras componentes, exceptuándose la última palabra, la que siempre conserva su vocal:

/qalt'i $\chi$ aramat sartañani/_ mañana de noche nos levantaremos 
de las tres palabras componentes, las dos primeras pierden su última vocal en habla casual. La raíz /qalt'i/ 'mañana' recibe el sufijo enfático $-/ \chi a$ /, cuya última vocal cae, quedando /qalt'i $\chi$ /. La raíz /arama/ 'noche' recibe el sufijo -/ta/ 'punto de partida', resultando la forma /aramata/, cuya última vocal también cae, con lo que la forma final queda /aramat/. En pronunciación deliberada, se recuperan las vocales elididas:

\section{/qalt'ixa aramata sartañani/}

Es consistente la caída de la última vocal del complemento directo, como puede apreciarse en:

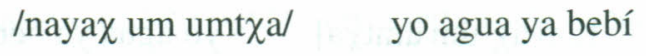

donde la raíz para 'agua', /uma/, pierde su última vocal, /a/, porque es el complemento directo de la oración:

$$
\begin{array}{cc}
\text { Complemento Directo } & \text { Verbo } \\
\text { um(a) } & \text { umtxa }
\end{array}
$$

La primera palabra, /naya /, también presenta caída de la última vocal. La forma completa es /naya $\chi a /$, de /naya/ 'yo' con el sufijo enfático -/ $\chi \mathrm{a} /$. La forma completa regresa con toda facilidad en habla lenta o deliberada, en cambio, la vocal elidida en el complemento directo no reaparece en pronunciación pausada y deliberada. Se puede concluir que la elisión de la última vocal del complemento directo es un fenómeno morfosintáctico ("sustracción de fonemas") que funciona como marca de acusativo.

La elisión o caída de vocales, sea fonológica, sea morfosintáctica, produce en el interior de la oración palabras agudas y consonantes finales, ambas desconocidas en el léxico aislado:

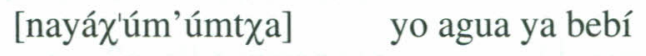

Grupos consonánticos finales de palabra, por cierto inexistentes en las raíces solas, siempre terminadas en vocal, pueden producirse por combinación de la acción de los sufijos fuertes con la elisión vocálica, como puede apreciarse en:

$$
\text { /kuns alta/ ¿qué compraste? }
$$

la partícula interrogativa /kuna/ ¿qué? ¿cómo?’ recibe el sufijo -/sa/ que marca enunciados interrogativos, por cuya acción pierde la última vocal /a/, de donde resulta /kunsa/, forma que pierde su última vocal por elisión fonológica, de donde queda /kuns/, con un grupo consonántico final /ns/.

En la frase nominal los determinadores (por ejemplo, raíces nominales en función adjetiva) largos, o sea, de tres y más sílabas, pierden sistemáticamente su vocal final, como en los ejemplos siguientes:

/yuqa $\lambda$ wawal muchacho bebé, es decir bebé de sexo masculino

La raíz para 'muchacho' es /yuqa $\lambda \mathrm{a}$ /, cuya /a/ final cae cuando ingresa como adjetivo en una frase. La caída de vocal final no se presenta en determinadores cortos, o sea, de hasta dos sílabas, como en: 
Los determinadores bisilábicos terminados en /ya/, por ejemplo, el demostrativo /k"aya/ 'aquel', o los numerales /maya/ 'un, uno', /paya/ 'dos', pierden la sílaba /ya/ y alargan la vocal de la primera sílaba, como en:

$\begin{array}{ll}\text { /mä urqu/ } & \text { un macho } \\ \text { /pä qawra/ } & \text { dos llamas } \\ \text { /k"ä anuqara/ } & \text { ese perro }\end{array}$

En el interior de la oración la "liaison" está inhibida por el ataque duro, ['V], de la vocal inicial de palabra, así en:

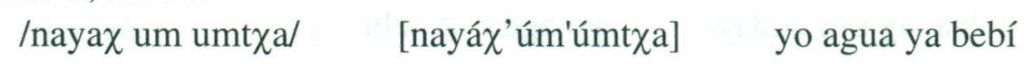

la consonante final de cada palabra está fonéticamente separada de la vocal inicial de la palabra siguiente por el corte producido por el ataque vocálico duro. Este también minimiza las posibilidades de sinalefa, de modo que normalmente hay hiato entre la vocal final de una palabra y la vocal inicial de la palabra siguiente, como en:

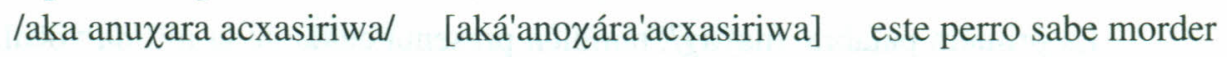

\subsubsection{La entonación oracional}

Es típica la inflexión cadente $(\downarrow)$ antes de pausa breve $(/)$ o larga $(/ /)$, tanto en oraciones afirmativas, como:

[xumáxa q"aruróxa markáru sarantáwa $\downarrow$ ] tu mañana al pueblo vas a ir

o interrogativas, como:

[k"ítis xáqes púri $\downarrow] \quad$ ¿qué persona llegó? (i.e. ¿quién llegó?)

o imperativas, como:

[qont'ásim $\downarrow$ ] ¡siéntese!

ya que aparentemente las diferencias de índole (afirmación, interrogación, aseveración, hipótesis, etc.) se marcan más que por la entonación por morfemas libres o por sufijos o por una combinación de ambos. Así, en:

[kúns páta $\downarrow$ ] ¿qué cocinaste?

la índole interrogativa de la oración está marcada léxicamente por /kuna/ ‘quién?' y morfológicamente por medio del sufijo -/sa/. Del mismo modo en:

[aká anoqára xánq'ówa $\downarrow$ ] este perro es blanco

el sufijo -/wa/ marca a /xanq'u/ 'blanco' como información focal, en contraste con la afirmación llana: [aká anoqára xánq'o $\downarrow$ ] este perro es blanco

La caída vocálica deja en el interior del enunciado subgrupos terminados en inflexión no cadente $(\rightarrow)$, como en:

[xumáste markár $\rightarrow$ / ís alír saránta $\downarrow$ ] tú al pueblo ropa a comprar irás 
Si no ocurre la caída vocálica los subgrupos terminan en inflexión cadente $(\downarrow)$, como en: [xumáste kutańxatáwa markáta $\downarrow /$ ukatx maqasiñane $\downarrow / /$ ] tú regresarás del pueblo, entonces comeremos

\subsection{Análisis fonémico}

\subsubsection{Inventario de fonos}

La descripción fonológica presentada en la Sección I, partió del siguiente inventario de fonos vocálicos:

\section{Cuadro 1}

Fonos Vocálicos

\begin{tabular}{|c|c|c|c|}
\hline & \multicolumn{2}{|c|}{ No redondeada } & Redondeada \\
\hline Alta & $\mathrm{i}$ & & $\mathrm{u}$ \\
\hline Media & $\mathrm{e}$ & & $\mathrm{o}$ \\
\hline Baja & & $\mathrm{a}$ & \\
\hline & Anterior & Central & Posterior \\
\hline
\end{tabular}

y del siguiente inventario de fonos consonánticos:

Cuadro 2

Fonos Consonánticos

\begin{tabular}{|c|c|c|c|c|c|c|c|c|c|c|}
\hline & & & & & & & & & & \\
\hline & sd & sn & & sn & & & sd & $\mathrm{sn}$ & & sn \\
\hline $\begin{array}{l}\text { Oclusiva } \\
\text { pura } \\
\text { aspirada } \\
\text { glotal }\end{array}$ & $\begin{array}{l}\text { p, } \\
\text { p, } \\
\text { p' }\end{array}$ & b & $\begin{array}{l}\mathrm{t} \\
\mathrm{t}^{\prime} \\
\mathrm{t}^{\prime}\end{array}$ & d & & & $\begin{array}{l}\mathrm{k} \\
\mathrm{k}, \\
\mathrm{k},\end{array}$ & ǵ & $\begin{array}{l}\text { q, } \\
\text { q, } \\
\text { q, }\end{array}$ & $\mathrm{g}$ \\
\hline $\begin{array}{l}\text { Africada } \\
\text { pura } \\
\text { aspirada } \\
\text { glotal }\end{array}$ & & & & & $\begin{array}{l}\text { c } \\
c^{\prime} \\
c^{\prime}\end{array}$ & & $\mathrm{kx}$ & & $q^{X}$ & \\
\hline Fricativa & & $b$ & & $\bar{r}$ & & $\mathrm{y}$ & $x$ & & $\mathrm{X}$. & \\
\hline Nasal & & $\mathrm{m}$ & & $\mathrm{n}$ & & $\tilde{\mathrm{n}}$ & & ń & & J \\
\hline Lateral & & & & 1 & & $\kappa$ & & & & \\
\hline Vibrante & & & & r & & & & & & \\
\hline
\end{tabular}




\subsubsection{Interpretación del fono [a]}

El fono vocálico [a] fue interpretado como vocal fonémica /a/ porque aparece en el foco silábico solo o precedido de cualquier consonante de la lengua o seguida de cualquier consonante trabante de la lengua.

\subsubsection{Asignación de los fonos vocálicos altos a fonemas vocálicos vs. fonemas consonánticos}

Los fonos vocálicos altos $[\mathrm{i}, \mathrm{u}]$ fueron asignados a fonemas vocálicos /i, $\mathrm{u} /$, cuando aparecieron en el foco de la estructura silábica, o sea, en las configuraciones [V], [VC.], [.CV.] y [.CVC.]. En cambio, cuando aparecieron en posición frontal, [j, w], o codal [i, un] se los consideró fonemas consonánticos. Dentro de las consonantes forman un grupo aparte, semiconsonantes, descrito en términos articulatorios típicamente vocálicos. Esto significa que las semiconsonantes son vocales articulatorias distribuidas como consonantes. Así, [i, u] focales son las vocales fonémicas $/ \mathrm{i}, \mathrm{u} /$ respectivamente; $[\mathrm{j}, \mathrm{w}]$ frontales y $[\mathrm{i}, \mathrm{u}]$ codales son las semiconsonantes /y, w/ respectivamente. Los fonemas /i, u/ se comportan como /a/, o sea, pueden estar precedidos de cualquier consonante de la lengua y pueden estar seguidas de cualquier consonante codal de la lengua. Los fonemas /y, w/ se comportan como cualquier otra consonante de la lengua, o sea, pueden aparecer precediendo a /a/ o siguiendo a /a/.

La interpretación consonántica de los fonos vocálicos no silábicos, frontales o codales, tienen apoyo adicional:

-en posición frontal /y/ tiene dos realizaciones: una vocálica de norma [j] y otra consonántica como alternante secundaria [y] fricativa alveopalatal sonora: /y/ ([j] [y] [i]).

En posición frontal alternan [j] [y]; en posición codal sólo [i] ; -en posición frontal /w/ tiene dos realizaciones: una vocálica de norma $[\mathrm{w}]$ y otra consonántica como alternante secundaria $[\mathrm{b}]$ fricativa bilabial sonora: $/ \mathrm{w} /([\mathrm{w}] \sim[\mathrm{b}] \sim[\mathrm{u}])$.

En posición frontal alternan $[\mathrm{w}] \sim[\mathrm{G}]$; en posición codal sólo [uㅣ]; en la palabra aymara aislada el acento cae siempre en la penúltima vocal, de modo que en palabras como:

$$
\begin{array}{ll}
\text { [ái.ca] } & \text { carne } \\
\text { [áun].ti] } & \text { estación seca }
\end{array}
$$

las vocales articulatorias $[i, u]$ no son la penúltima vocal. La penúltima vocal es la que lleva el acento, o sea, la [a], los fonos [i, un] están pautados como cualquier consonante codal, por ejemplo, $[\lambda]$ lateral alveopalatal, en:

$$
\text { [án.c"i] nieto, nieta }
$$

que tiene la misma configuración silábica que:

[ái.ca]

[áu.ti]

de modo que fonémicamente las tres palabras son:

$$
\text { /a } \lambda c^{\prime \prime} \text { // /ayca/ /awti/ }
$$


donde no se marca el acento fijo en la penúltima vocal, ni la frontera silábica, la que predeciblemente corre entre dos consonantes contiguas.

Esta solución es la seguida por Harmelink (1985: Clave de simbología fonética), quien las llama "semivocales" (la diferencia es sólo terminológica) incluidas en la carta consonántica, y las describe como labial [w] y alveopalatal [y]. Es también la solución de Hardman (Hardman et al. 1988: 36), donde /w/ es una semiconsonante labial sonora y /y/ es una semiconsonante alveopalatal sonora, que "contrastan con las vocales fonéticamente similares / $\mathrm{u} / \mathrm{e} / \mathrm{i} / \mathrm{y}$ también entre sî".

Clair-Vasiliadis (1976:149-50) hace un análisis diferente. Distingue [i] "voyelle d'ouverture minimale antérieure" y [j] "semi-consonne". Marca también una [e] fonética, pero no es pertinente a esta discusión ya que se trata de una variante de [i]. En el área posterior distingue [u] "voyelle d'ouverture minima-postérieure" y [w] "semi-consonne". Marca también una [o] alternante con [u]. Sin decir en qué sentido [i] y [j] son distintas entre sí ni en qué sentido [u] y [w] son distintas entre sí, concluye que [i] y [j] son realizaciones del mismo fonema /i/ y que [u] y [w] son realizaciones del mismo fonema /u/, sobre la base de que las realizaciones vocálicas [i, u] nunca aparecen ante otra vocal y las realizaciones semiconsonánticas sólo aparecen ante vocal. Aunque él no lo dice, queda claro que consideró que ésta era distribución complementaria, suficiente para adscribir cada par de fonos a un solo fonema.

Frente a este análisis hay que notar que no ofrece solución para el problema planteado por la posición fija del acento en la penúltima vocal: no está dicho de qué manera en /xaira/ 'paresseux' o en /xeuq'e/ 'fumée' (ejemplos y transcripción suyas) se llega a la acentuación correcta /xáira/ y /xéuq'e/, o sea, cómo se bloquea la acentuación en la /i/ o la /u/ (*/xaíra/, */xeúq'e/) las que en la presentación de Clair-Vasiliadis aparecen como antepenúltima vocal, es decir, en la posición en la que debe recaer el acento. Tampoco dice Clair-Vasiliadis cómo él obtiene el silabeo correcto (/wai.ra/, /xeu.q'e/ bisílabos), y no el silabeo incorrecto (/wa.i.ra/, xe.u.q'e/ trisílabos) sugerido por su interpretación vocálica de /i, u/. Estos problemas se presentan porque el analista no distinguió entre naturaleza articulatoria -cuestión fonética- y pautamiento silábico -cuestión fonémica; ni entre vocal articulatoria (o "vocoide") y vocal distribucional ("vocal" en sentido fonémico, por aparecer en la cima silábica). Los problemas señalados desaparecen si se reconoce que [i, u], vocales fonéticas (o "vocoides"), se distribuyen (a) en la cima silábica (vocoides silábicos); o (b) en el frontis o en la coda silábica (vocoides no silábicos). En la distribución (a) [i, u] son vocales fonémicas, /i, u/; en la distribución (b) son consonantes fonémicas que tienen la particularidad de ser articulatoriamente vocálicas, /y, w/, descritas como semiconsonantes. Así, /i/ y /u/ están en contraste como vocales vs. consonantes con /y/y/w/ respectivamente.

\subsubsection{Asignación de los fonos [e, o] a los fonemas $/ i, u /$}

Los fonos [i, e] fueron asignados como alófonos a un fonema único /i/ por su contigüidad fonética y su distribución no contrastante. En posición final absoluta de palabras aisladas aparece normalmente [e] y en algunos casos aparecen [e] o [i] en alternancia. En contacto con consonante uvular precedente o siguiente aparece normalmente [e]; [i] no aparece normalmente en esta posición; [e] excluye a [i] a distancia cuando en la sílaba inmediatamente siguiente hay una consonante uvular. La siguiente es una generalización estadísticamente segura: /i/ ([e] [i]). 
Ocurre [e] (1) en contacto directo con consonante uvular precedente o siguiente; (2) o a distancia cuando hay consonante uvular en la sílaba inmediatamente siguiente. En posición absoluta [e] alterna con [i]. En los demás casos, ocurre sólo [i].

Los fonos $[\mathrm{u}, \mathrm{o}]$ fueron asignados a un fonema único /u/ por su contigüidad fonética y su distribución no contrastante: $/ \mathrm{u} /([\mathrm{o}] \sim[\mathrm{u}])$.

Ocurre [o] (1) en contacto directo con consonante uvular; (2) a distancia cuando hay consonante uvular en la sílaba inmediatamente siguiente. En posición final absoluta [o] alterna con [u]. En los demás casos ocurre sólo [u].

Nótese que la distribución de los alófonos de /u/ es congruente con la distribución de los alófonos de /i/.

Se llegó así a la siguiente agrupación fonemática de los fonos vocálicos:

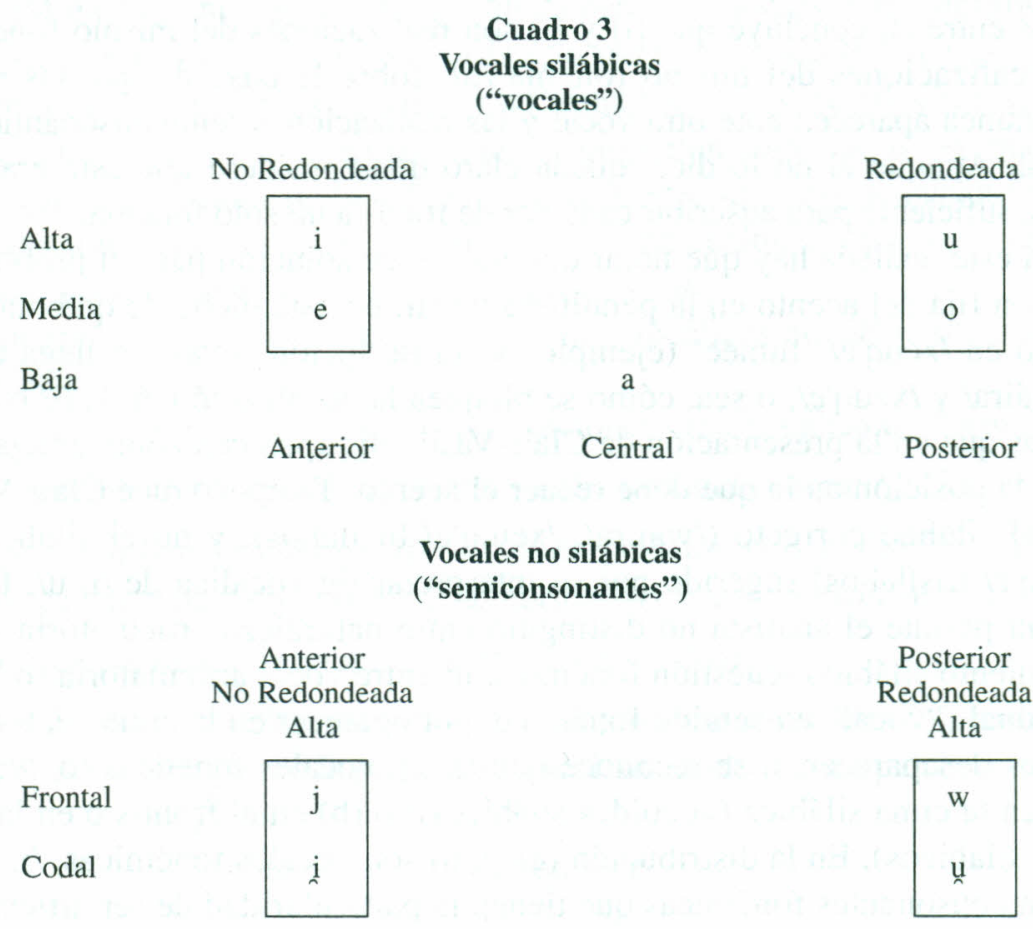

1.4.5. Interpretación de fonos oclusivos sordos puros vs. oclusivos aspirados vs. oclusivos glotalizados

Estos ocurren en los puntos bilabial [p, p", $\left.\mathrm{p}^{\prime}\right]$, alveolar [t, t", $\left.\mathrm{t}^{\prime}\right]$, palatal [k, k", k'] y uvular [ q, q", q']. Cada uno de estos fonos fue asignado últimamente a un fonema en términos de su distribución en contextos análogos, de donde resultaron 12 fonemas : /p, p", p, t, t", t', k, $\mathrm{k}^{\prime \prime}, \mathrm{k}^{\prime}, \mathrm{q}, \mathrm{q} ", \mathrm{q} /$.

El detalle es el siguiente. Sobre la base de la distancia articulatoria se separaron los tres fonos bilabiales [p, p", $\mathrm{p}^{\prime}$ ] de los tres alveolares [t, t", $\left.\mathrm{t}^{\prime}\right]$. A su vez, estos fueron separados del grupo formado por los palatales [k, k", k'] y uvulares [q, q", q']. Cada fono palatal fue considerado fonéticamente similar a su correspondiente uvular y por lo tanto, formando pares sospe- 
chosos cuyo estatus fonémico debía ser domostrado. Los fonos de cada grupo (bilabial, alveolar, palatal, uvular) fueron considerados fonéticamente similares entre sí. Se llegó así a los siguientes conjuntos de pares sospechosos:

\section{Cuadro 4}

Pares sospechosos de oclusivas

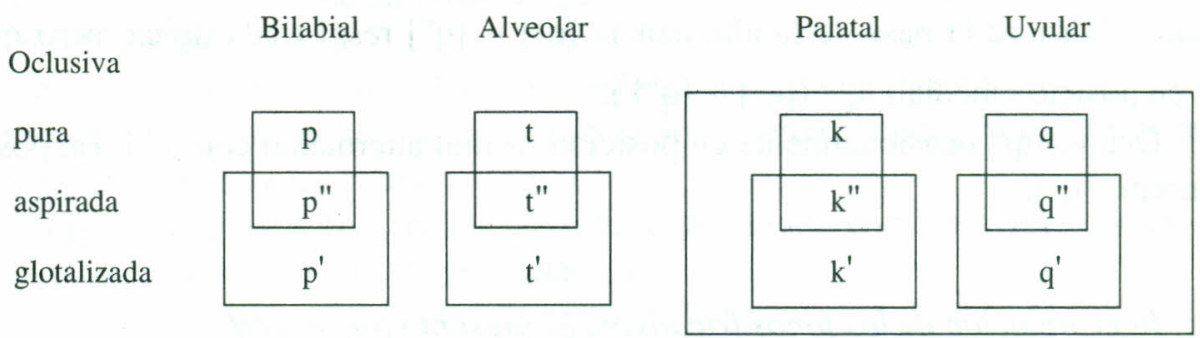

La observación de la distribución reveló que todos los fonos ocurrían ante /a/, que todos los bilabiales, alveolares y palatales ocurrían ante /i/, manifestado [i] y ante /u/, manifestado [u]; y que los uvulares ocurrían ante /i/; manifestado [e]; y ante /u/, manifestado [o]. Esta distribución se consideró evidencia suficiente para adjudicar estatus fonémico separado a cada fono.

1.4.6. Interpretación de los fonos oclusivos sonoros bilabial, alveolar, palatal y uvular

Cada uno de estos fonos fue asignado al correspondiente fonema oclusivo puro:

$\begin{array}{lll}{[\mathrm{b}]} & \mathrm{a} & / \mathrm{p} / \\ {[\mathrm{d}]} & \mathrm{a} & / \mathrm{t} / \\ {[\mathrm{g}]} & \mathrm{a} & / \mathrm{k} / \\ {[\mathrm{g}]} & \mathrm{a} & / \mathrm{q} /\end{array}$

sobre la base de que los fonos sonoros alternan con los sordos tras consonante nasal:

$\begin{array}{rlrl}/ \mathrm{p} / & & ([\mathrm{b}] \sim[\mathrm{p}]) \\ / \mathrm{t} / & & ([\mathrm{d}] \sim[\mathrm{t}]) \\ / \mathrm{k} / & & ([\mathrm{g}] \sim[\mathrm{k}]) \\ / \mathrm{q} / & ([\mathrm{g}] \sim[\mathrm{q}])\end{array}$

Tras consonante nasal los fonos sordos [p, t, k, q] alternan con los sonoros [b, d, g, g]. En todo otro contexto sólo ocurren los fonos sordos.

\subsubsection{Interpretación de los fonos africados}

A los tres fonos africados alveopalatales sordos (puro [c], aspirado [c"] y glotalizado [c']) se les asignó el estatus de fonema separado, /c, c", c'/, a partir de su distribución amplia: los tres ocurren ante las tres vocales, $/ \mathrm{i}, \mathrm{a}, \mathrm{u} /$. 
El fono africado palatal sordo $\left[\mathrm{k}^{\mathrm{x}}\right]$ fue considerado alófono del fonema oclusivo palatal aspirado /k"/ sobre la base de la alternancia $\left[\mathrm{k}^{\star}\right] \sim\left[\mathrm{k}^{\prime \prime}\right]$ registrada típica, pero no exclusivamente, en posición medial: /k"/ ([kx $\left.~\left[\mathrm{k}^{\prime \prime}\right]\right)$.

Ocurre ocasinalmente $\left[\mathrm{k}^{\mathrm{x}}\right]$ en posición medial alternando con [k"]. En posición inicial es de norma [k"].

El fono africado uvular sordo $\left[\mathrm{q}^{\chi}\right]$ fue considerado alófono del fonema oclusivo uvular aspirado [q"] sobre la base de la alternancia $\left[\mathrm{q}^{\chi}\right] \sim[\mathrm{q} "]$ resgistrada típica, pero no exclusivamente en posición medial: /q"/ ([q $\chi] ~[q "])$.

Ocurre $\left[\mathrm{q}^{\chi}\right]$ ocasionalmente en posición medial alternando con [q"]. En posición inicial es de norma [q"].

\subsubsection{Interpretación de los fonos fricativos. El presunto fonema $/ v /$}

El fono fricativo bilabial sonoro [ฤ] se consideró como alternante consonántica del fonema semiconsonántico /w/ en el frontis silábico: /w/ ([ø] [w] [uㅅ] $)$.

Ocurre $[\nvdash]$ en posición frontal en variación libre con $[w]$. En posición codal es de norma [u].

El fono más similar a [ฤ] es el oclusivo bilabial sonoro [b], interpretado aquí como realización alternante de /p/ tras consonante nasal, por ser éste el único contexto en que /b/ apareció. El fricativo $[\mathrm{b}]$, en cambio, apareció constantemente alternando con $[\mathrm{w}]$ frontal y esporádicamente con [u] codal. Harmelink (1985: 11) registra dos variantes para [w]: la oclusiva bilabial sonora [b] y la fricativa bilabial sonora [ฤ] "como en [wila] - [bila] - [bila] rojo...vaca, [waka] - [baka] [baka]". Hemos encontrado frecuentemente la alternancia $[w] \sim[\mathrm{b}]$, como en /wila/ [wíla] [ఈila]. La fricativa puede ser más cerrada o más abierta, pero no suele presentar el firme cierre y retención que caracteriza a las oclusivas. No nos consta la ocurrencia del fono oclusivo [b] en alternancia con el fono labiodental fricativo [v], registrados por Clair-Vasiliadis (1976: 147) como variantes alofónicas de su presunto fonema $/ \mathrm{v} /$, descrito como "labiodentale fricative, sonore, oral", no confirmado por ningún otro descriptor:

En position initiale absolute, el [el fonema /v/] se réalise souvent [subrayado nuestro] comme une occlusive bilabiale sonore:/'vila/ [bíla] "sang"

para "sangre" hemos escuchado como pronunciación de norma [wila] o [Đíla]. No descartamos la posibilidad de una realización espuria con fricativa labiodental sonora [v], pero no nos consta como hecho sistemático. El par mínimo aducido por Clair-Vasiliadis (1976:147):

$$
/ \mathrm{v} \sim \mathrm{u} / \text { : /" vasa/ "lieu désolé" }
$$

/'uasa/ "ma Ĩs ou blé cuit à demi”" 
es en realidad un caso de homofonía: ambos ítemes tienen exactamente la misma pronunciación:

\begin{tabular}{|c|c|c|}
\hline /wasa/ & [wása] [łása] & desierto, despoblado \\
\hline /wasa/ & [wása] [bása] & grano sancochado \\
\hline
\end{tabular}

pero no hemos escuchado una fricativa labiodental sonora [v] en ninguno de los ítemes, ni en ninguna otra palabra del corpus. Así las cosas, consideramos infundada la inclusión de un fone$\mathrm{ma} / \mathrm{v} /$, aunque no se descarta la posibilidad de que aparezcan realizaciones esporádicas y ocasionales $[\mathrm{v}]$ del fonema $/ \mathrm{w} /$.

$\mathrm{Al}$ fono [s] fricativo ápico-alveolar sordo se le asignó estatus fonémico /s/ por su distribución amplia -ocurre con todas las vocales, en posición frontal y codal- y por su distanciamiento fonético con respecto a las demás fricativas.

El fono [y] alveopalatal fricativo sonoro fue considerado como variante consonántica del fonema semiconsonántico /y/ en el frontis silábico:

$$
\mathrm{ly} /(\mathrm{j}] \sim[\mathrm{y}] \sim[\mathrm{i}])
$$

Ocurre [j] en posición frontal en variación libre con [y]. En posición codal es de norma [i].

Los fonos fricativos sordos palatal $[\mathrm{x}]$ y uvular $[\chi]$ fueron considerados fonemas separados $/ \mathrm{x} /$ vs. $/ \chi /$ sobre la base de su ocurrencia en contextos análogos: ambos ocurren con todas las vocales, en posición frontal y codal. En contacto con /x/ las vocales /i, u/ se articulan altas $[\mathrm{i}, \mathrm{u}]$; en contacto con $/ \chi /$ las vocales $/ \mathrm{i}, \mathrm{u} / \mathrm{se}$ articulan medias $[\mathrm{e}, \mathrm{o}]$.

$\mathrm{El}$ análisis produjo, tres fonemas en la serie fricativa: /s, $\mathrm{x}, \chi /$.

\subsubsection{Interpretación de los fonos nasales}

Los fonos nasales bilabial [m], alveolar [n] y alveopalatal [ñ] fueron considerados fonemáticos por no presentar restricciones de contexto en su distribución.

El fono nasal palatal [ń] aparece únicamente ante consonante palatal, contexto en el cual no ocurre ningún otro fono nasal. Sobre la base de esta distribución [ń] fue asignado al fonema $/ \mathrm{n} /: / \mathrm{n} /([\hat{n}] \sim[\mathrm{n}])$.

Ocurre [ń] ante consonante palatal, en otros contextos sólo ocurre [n].

Se dio el mismo tratamiento al fono nasal uvular [n], el que aparece solamente ante consonante uvular, contexto en el cual ningún otro fono nasal ocurre. Así, [ฤ] fue asignado al fonema $/ \mathrm{n} /$, el que quedó en definitiva así: $/ \mathrm{n} /([\mathfrak{n}] \sim[\mathrm{\eta}] \sim[\mathrm{n}])$

Ocurre [ń] ante consonante palatal; ocurre [n] ante consonante uvular. En otros contextos sólo ocurre [n].

La asignación de [ń] y [ $\eta$ ] a /n/ ha sido arbitraria ya que de hecho, estos dos fonos están en distribución complementaria no sólo con [n] sino también con [m] y [ñ], de modo que bien pudieron ser adscritos a $/ \mathrm{m} / \mathrm{o}$ a $/ \tilde{\mathrm{n}} /$. Si se los adscribió a $/ \mathrm{n} /$ fue por un argumento estadístico, no metodológico: $/ \mathrm{n} /$ es mucho más frecuente que $/ \mathrm{m} / \mathrm{o} / \tilde{\mathrm{n}} /$ en posición trabante. Esta fue la solución seguida en Salas y Valencia (1988) y terminantemente rechazada por Clair-Vasiliadis (en comunicación personal a Alba Valencia) con argumentación que no hemos entendido. 
En definitiva, en el análisis nuestro, hay tres fonemas nasales: bilabial $/ \mathrm{m} /$, alveolar $/ \mathrm{n} /$ y alveopalatal $/ \tilde{\mathrm{n}} /$.

\subsubsection{La nasal velar [ $\mathrm{\eta}]$}

Un fono nasal muy similar a [ $\mathrm{\eta}$, descrito por los observadores como nasal velar (ClairVasiliadis 1976: 49, Harmelink 1985: 10-3), del todo correspondiente al que hemos descrito más arriba como nasal uvular, queda como problema abierto cuyos términos pueden ser planteados así: en el sector de Isluga (área altiplánica de la Provincia de Iquique) el fono [n] presenta la siguiente distribución:

(a) ante consonante homorgánica, que es la distribución normal en todo el territorio aymara;

(b) ante vocal /a/, la que obviamente no constituye un contexto asimilante, y por lo tanto sugiere que $[\mathrm{\eta}]$ es un fono de ocurrencia irrestricta, de donde se desprende estatus fonémico /y/. Esta es la interpretación de Clair-Vasiliadis (1976: 148-9), la que presentada sin mayor discusión, suena convincente. Harmelink (1985: 12-3) hace notar, sin embargo, que la nasal velar [ $\mathrm{n}$ ] aparece sólo en el sufijo [na] 'posesivo de $1^{\mathrm{a}}$ persona singular', como en:

$$
\begin{array}{ll}
\text { [uta] } & \text { casa } \\
\text { [uta-na] } & \text { mi casa }
\end{array}
$$

y en el sufijo [na] ' 1 a persona singular del futuro indicativo', como en:

$$
\begin{array}{ll}
\text { [sara] } & \text { raíz de 'ir' } \\
\text { [sara-na] } & \text { yo voy a ir, yo iré }
\end{array}
$$

Hamerlink observa que ésta es una particularidad del aymara de Chile, ya que en aymara central "los dos ejemplos anteriores serían [utaxa] mi casa y [saraxa] yo iré" (1985:12). Coincidimos en lo principal con la presentación de Harmelink, pero notando que (1) formas como [sarana] 'yo iré', yo voy a ir' alternan con formas como [sara $a$ ], como en:

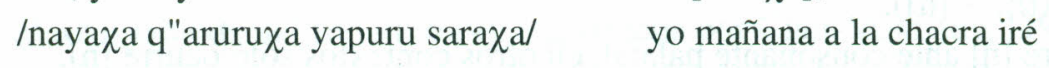

registrado en Chujlluta (Parinacota) y con formas sin sufijo abierto. Así, en el siguiente ejemplo, también de Chujlluta, la raíz es /kut'a/ 'regresar' (infinitivo /kut'aña/) y /wa/ es un sufijo enfático:

$$
\text { /q"aruruða mayampi kut'awa yapuru/ mañana otra vez regresaré a la chacra }
$$

de modo que la forma "limpia" de la $1^{\text {a }}$ persona singular del futuro en el ejemplo es /kut'a/; y

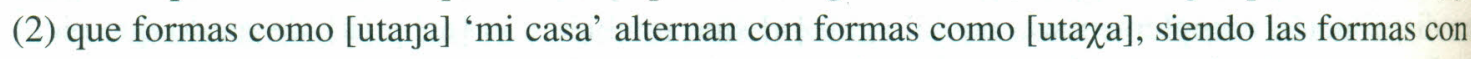
nasal [n] más frecuentes en el altiplano iquiqueño que en el altiplano parinacontense.

Hay que hacer notar que [na] 'sufijo posesivo de $1^{\text {a }}$ persona singular' ([uta-na] 'mi casa') y [na] 'sufijo de $1^{\text {a }}$ persona singular del futuro' ([sara-na] 'yo iré') son las únicas ocurren- 


\subsubsection{Interpretación de los fonos laterales}

Los fonos laterales alveolar [1] y alveopalatal $[\lambda]$ se consideraron fonemas separados /1/ vs. $/ \lambda /$ en razón de su distribución amplia. Ambos ocurren en posición frontal ante /i, a, u/; y en posición codal /// aparece trabando a /i, a, $\mathrm{u} / ; \mathrm{y} / \lambda / \mathrm{a} / \mathrm{a}, \mathrm{u} /$. Quedan entonces, dos fonemas laterales: alveolar $/ / /$ y alveopalatal $/ \lambda /$.

\subsubsection{Interpretación del fono fricativo rehilado $[\bar{r}]$}

El fono alveolar vibrante simple $[\mathrm{r}]$ y el fono fricativo alveolar rehilado $[\overline{\mathrm{r}}]$ se consideraron alófonos del mismo fonema /r/, cuya manifestación de norma es el vibrante simple [r], pero que en un ítem /asiru/ 'culebra' alterna con [ [ $\mathrm{r}$ ]: [asíro] [aséro]. El sistema incluye, entonces, un solo fonema vibrante / $\mathrm{r} /$.

\subsubsection{El golpe glotal}

Harmelink (1985: Clave de simbología fonética) añade en nota al pie de página "A glottal Stop [ '] also ocurrs". La única ocurrencia de una oclusiva glotal que hemos encontrado ha sido una alternante esporádica de /q/, en realidad un hapax (una sola vez, en un solo ítem, en un solo informante):

$$
\text { /maqa/ [máqa] [mála] 'comida' }
$$

Se ha registrado sí el ataque duro [ '] como característica sistemática de la realización de las vocales en posición inicial de palabra. Ni la oclusiva glotal [?] ni el ataque vocálico duro [ '] fueron considerados aquí como fonemas de la lengua. 


\subsubsection{Los fonemas consonánticos}

Se llegó en definitiva a la siguiente agrupación fonemática de los fonos consonánticos:

\section{Cuadro 5}

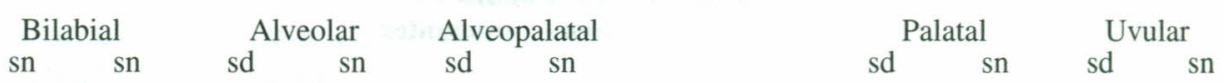

Oclusiva

pura
aspirada
glotalizada
Africada
pura
aspirada
glotalizada
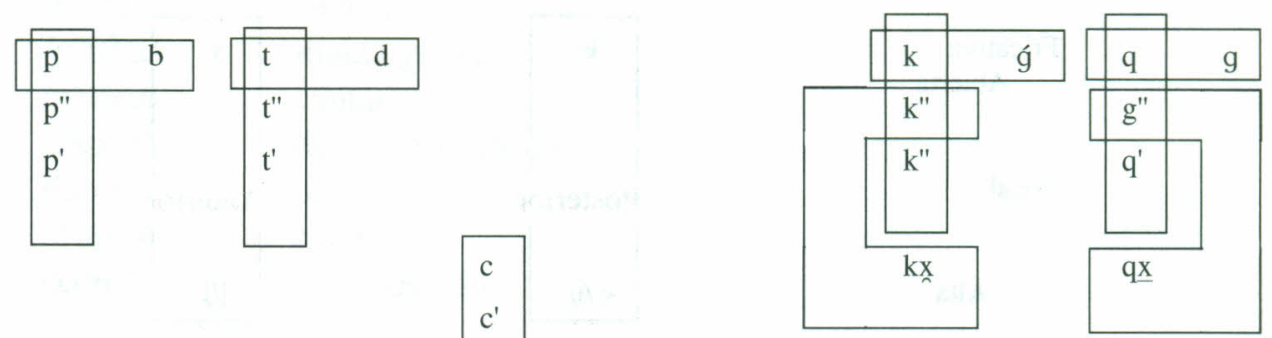

Fricativa

Nasal

Lateral

Vibrante simple

Semiconsonante
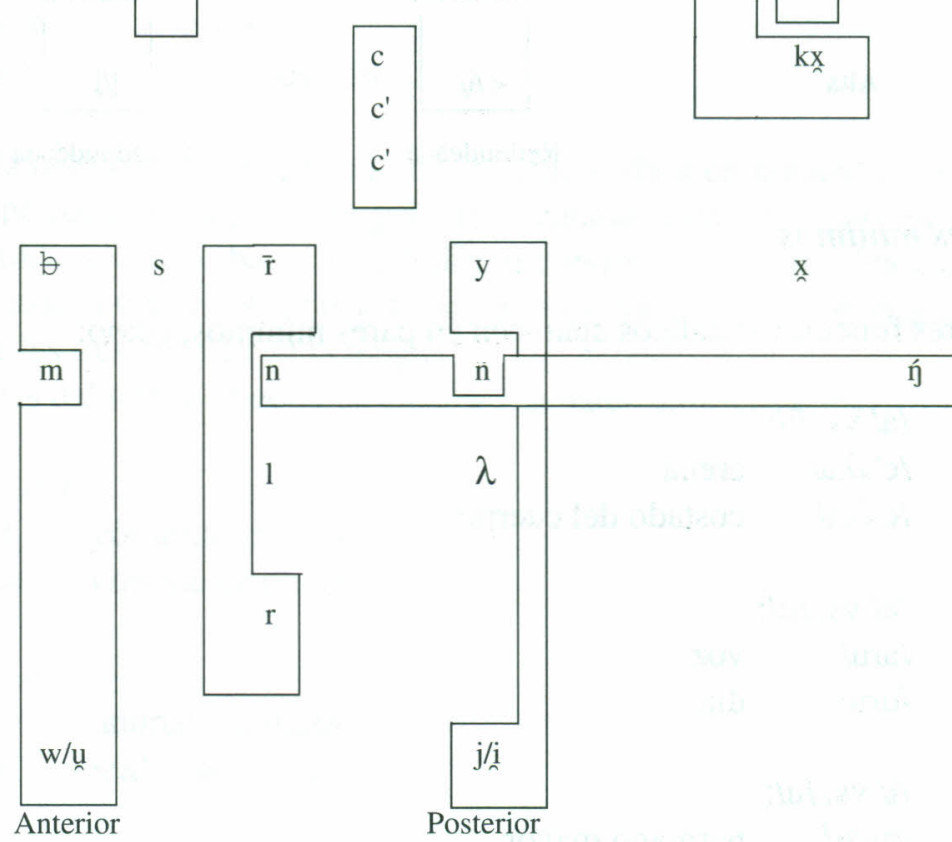

y la siguiente agrupación fonemática de fonos vocálicos silábicos:

\section{Cuadro 6}

\section{Fonos vocálicos silábicos}

No redondeada

Redondeada

Alta

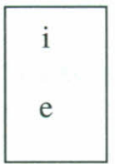

Media

o

Baja

a

Anterior

Central

Posterior 
Por su parte los fonos vocálicos altos no silábicos $[j, w]$ frontales y [i, un] fueron agrupados con las consonantes articulatoriamente más próximas [y, b], formando un tipo especial de consonantes fonémicas, las semiconsonantes:

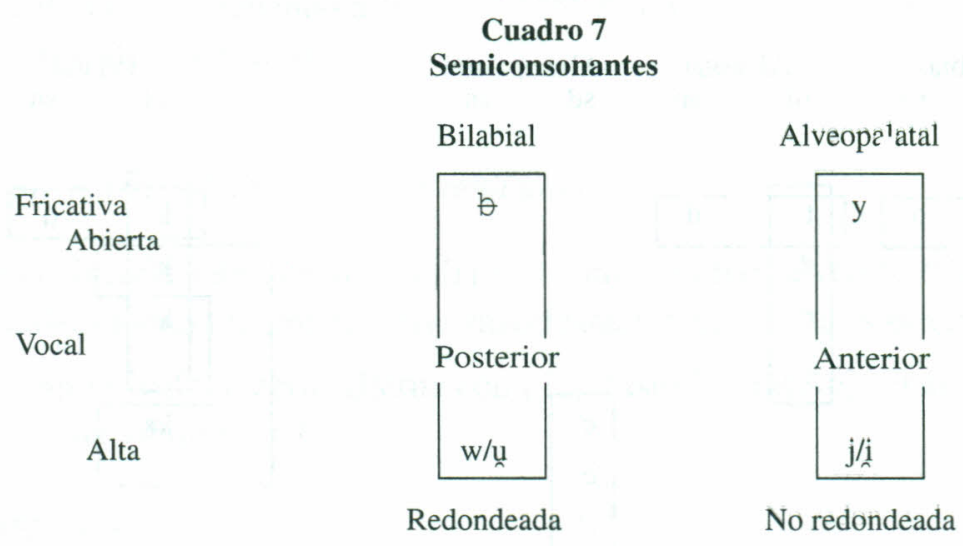

\subsubsection{Pares mínimos}

Los tres fonemas vocálicos aparecen en pares mínimos, como:

/a/ vs. /i/:

/c'àa/ arena

/c'i $\lambda \mathrm{a} /$ costado del cuerpo

/a/ vs. /u/:

laru/ voz

/uru/ día

/i/ vs. /u/:

/picu/ hermano mayor

/pucu/ sobras

Entre los fonemas de la serie interrupta se encuentran pares mínimos, como los siguientes del orden bilabial:

/p/ vs. /p"/

/picu/ hermano menor

/p"icu/ pestañas

$/ \mathrm{p} / \mathrm{vs} . / \mathrm{p} /$

/parpa/ médula, tuétano

/p'arpa/ flameante 
No aparecen pares mínimos /p"/vs. /p'/, pero la separación fonémica entre ellos se desprende de su distribución en contextos análogos, como:

$\begin{array}{ll}\text { /p"V/vs. /p'V/ } & \\ \text { /p"asa/ } & \text { pasta comestible hecha de barro } \\ \text { /p'arpa/ } & \text { médula } \\ \text { /p"isi/ } & \text { gato } \\ \text { /p'iqi/ } & \text { cabeza } \\ \text { /p"u } \mathrm{pu} \text { / } & \text { manta gruesa } \\ \text { /p'uñu/ } & \text { cántaro } \\ \text { /t'ap"a/ } & \text { desabrido, sin sal } \\ \text { /lap'a/ } & \text { piojo } \\ \text { /c'ap"i/ } & \text { espina } \\ \text { /ximp'i/ } & \text { maíz tostado }\end{array}$

lo que muestra que la distribución [p"] / [p'] no está vinculada a un contexto vocálico dado, y por lo tanto no son perfectamente posibles palabras aymaras como */p'asa/ (en contraste con /p"asa/ 'pasta comestible hecha de barro') */p"iqi/ (en contraste con /p'iqi/ 'cabeza') o */p'usa/ (en contraste con /p"usa/ 'instrumento musical de viento'), ya que están atestiguadas ocurrencias de /p"/ y /p'/ ante las tres vocales de la lengua.

En los fonemas del orden alveolar se encuentran pares mínimos como:

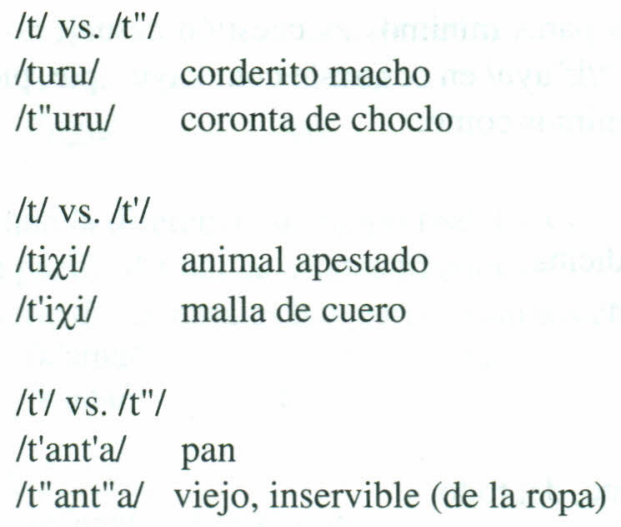

Entre los fonemas del orden alveopalatal se encuentran los siguientes pares mínimos:

/c/ vs. /c"/

/waca/ cabra

/wac"a/ dedo(s) excedente(s) en una llama o alpaca

/c/ vs. /c'/

/xaca/ lágrima

/xac'a/ grande, alto

/c"/vs. /c'/ 


\section{/c"ama/ grano grueso \\ /c'ama/ fuerza}

Entre los fonemas del orden palatal aparecen los siguientes pares mínimos:

$/ \mathrm{k} / \mathrm{vs} . / \mathrm{k}^{\prime} /$

/laka/ boca

/lak'a/ suelto

$/ \mathrm{k}^{\prime \prime} / \mathrm{vs} . / \mathrm{k}^{\prime} /$

/k"asa/ eructo

/k'asa/ basura

No aparecen pares mínimos $/ \mathrm{k} / \mathrm{vs}$. /k"/, pero la separación fonémica entre ellos puede afirmarse a partir de la ocurrencia de ambos en contextos análogos, como:

$\begin{array}{ll}\text { /kayu/ } & \text { pie, pierna } \\ \text { /k"aya/ } & \text { aquél } \\ \text { /puku/ } & \text { espinas, abrojos } \\ \text { /p"uk"u/ } & \text { olla } \\ \text { /kawki/ } & \text { ¿dónde? } \\ \text { /c'arki/ } & \text { charqui }\end{array}$

lo que revela que la distinción [k] / [k"] no está vinculada a un contexto vocálico dado, y por lo tanto el que no hayan sido encontrados pares mínimos es cuestión casual, no estructural; por ejemplo, es posible una palabra aymara */k"ayu/ en contraste con /kayu/ 'pie, pierna'.

En el orden uvular hay pares mínimos como:

/q/ vs. /q"/

/qu $\lambda \mathrm{a} /$ remedio, medicina

/q"u $\lambda \mathrm{a} /$ pasto, maleza

/q/ vs. /q'/

/qala/ piedra

/q'ala/ completamente, del todo

/q"/ vs. /q'/

/q"ara/ mañana

/q'ara/ calvo, pelado

Entre palatales y uvulares ocurren los siguientes pares mínmos:

/k/ vs. /q/

/marka/ pueblo

/marqa/ brazada

/k"/ vs. /q"/ 


/k"asa/ eructo
/q"asa/ estanque
/k'/vs. /q'/
/xiwk'i/ tostado
/xiwq'i/ humo

No se encontraron pares mínimos entre la fricativa palatal sorda $/ \mathrm{x} / \mathrm{y}$ la fricativa uvular sorda $\mid \chi /$, pero (a) el contraste entre ambos órdenes (palatal vs. uvular) está probado a propósito de /k/ vs. /q/, /k"/ vs. /q"/, /k'/ vs. /q'/; y (b) en posición codal han sido encontradas tras la vocal hu/, como en:

$$
\begin{array}{ll}
\text { /t"ux.ru/ } & \text { bastón } \\
\text { /c'ux.ña/ } & \text { verde }
\end{array}
$$

y tras la vocal /a/ como en:

$$
\begin{array}{ll}
\text { /naxra/ } & \text { pezuña } \\
\text { /laxra/ } & \text { lengua }
\end{array}
$$

y en posición frontal de sílaba no inicial aparecen ante las tres vocales, como en:

$\begin{array}{ll}\text { /wic'inxa/ } & \text { cola, rabo } \\ \text { /q'asar } \chi \text { a/ } & \text { sarna } \\ \text { /mixi/ } & \text { hembra estéril de llama } \\ \text { /t'i } \chi \text { i/ } & \text { malla de cuero } \\ \text { /c'ixu/ } & \text { sombra } \\ \text { /ñi } \chi \text { u/ } & \text { feo }\end{array}$

lo que sugiere que la diferencia de punto (palatal vs. uvular) no está condicinada por el contexto, de donde se puede afirmar su estatus fonémico.

En la serie de las nasales hay pares mínimos entre $/ \mathrm{m} / \mathrm{y} / \mathrm{n} /$ :

$$
\begin{array}{ll}
\text { /k'ama/ muela cariada } \\
\text { /k'ana/ } & \text { trenzas }
\end{array}
$$

y entre $/ \mathrm{n} / \mathrm{y} / \tilde{\mathrm{n}} /:$

$$
\begin{array}{ll}
\text { /q"ana/ luz, claridad } \\
\text { /q'aña/ } & \text { sucio, mugriento }
\end{array}
$$

También hay pares mínimos entre / 1 / y / $\mathrm{r} /$ como en:

$/ t$ 'ili/ perro de talla pequeña

/t'iri/ cicatriz

El fonema alveopalatal $/ \lambda$ está en contraste con la fricativa alveopalatal sonora [y], manifestación del fonema /y/ en posición frontal, como en:

$$
\begin{array}{ll}
\text { /xaגu/ lluvia } \\
\text { /xayu/ } & \text { sal común }
\end{array}
$$


Consideramos superfluo aducir pares mínimos entre fonos que no presentan entre sí similitud, como [c] / [s] ([cúdo] 'gorro de lana'/ [súio] 'feto'). En estos casos, un par mínimo no prueba nada nuevo: sobre la base del distanciamiento fonético tales fonos deben ser asignados en principio a fonemas separados. Para la posición opuesta Cf. Clair-Vasiliadis 1976, quien utiliza sistemáticamente el par mínimo como prueba de estatus fonémico, entre dos fonos cualesquiera, tengan o no similitud fonética, lo que sugiere que para él la similitud fonética no es una exigencia que deban presentar los alófonos de un fonema único.

\subsubsection{Fluctuación de fonemas}

Es relativamente frecuente que fonos articulatoriamente contiguos, de probada separación fonémica, se presenten en variación libre en uno o varios ítemes dados.

Entre los fonemas vocálicos han aparecido los siguientes casos de fluctuación:

$$
\begin{array}{ll}
\text { /a/ /u/: } & \\
\text { /acaku/ /acuku/ } & \text { ratón } \\
\text { /arama/ /aruma/ } & \text { noche } \\
\text { /qunqura/ /qunquru/ } & \text { rodilla } \\
\text { /q"aña/ /q"añu/ } & \text { sucio } \\
\text { /laq'u/ /luq'u/ } & \text { gusano } \\
\text { /a/ /i/: } & \\
\text { /xamp'i/ /ximp'i/ } & \text { maíz tostado } \\
\text { /xank'a/ /xink'a/ } & \text { prisa, apuro } \\
\text { /ñak'uta/ /ñik'uta/ } & \text { pelo } \\
& \\
\text { /u/ /i/: } & \\
\text { /qunquru/ /qunquri/ } & \text { rodilla }
\end{array}
$$

Entre los fonemas consonánticos es frecuente la fluctuación entre oclusivos y fricativos homorgánicos, como en:

$$
\begin{aligned}
& \text { /q } / \sim|\chi| \text {, sólo en posición medial: }
\end{aligned}
$$

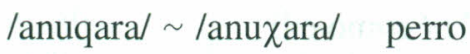

$$
\begin{aligned}
& \text { /c'uqi/ /c'u } \chi \text { i/ papa } \\
& \text { /macaqa/ /maca } a \text { a/ nuevo } \\
& \text { /qamaqi/ /qamaxi/ zorro } \\
& \text { /paqalqu/ /paqal } \chi \mathrm{u} / \quad \text { siete } \\
& \text { /tawaqu/ /tawa } \chi \text { u/ muchacha }
\end{aligned}
$$




\begin{tabular}{|c|c|}
\hline 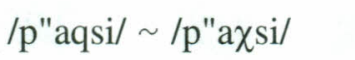 & luna, mes \\
\hline /p"ic"aqa/ /p"icaxa/ & alfiler hecho de espina de cactus \\
\hline /wayaqa/ /wayaxa/ & bolsa \\
\hline /yuqc'a/ /yu хc'a/ & nuera \\
\hline
\end{tabular}

En /muqsa/ /mus $\chi a /$ 'dulce' hay además metátesis.

$/ \mathrm{k} / \sim / \mathrm{x} /:$

/pataka/ /pataxa/ cien

$\mid \lambda \mathrm{ukt}^{\prime} \mathrm{a} / \sim / \lambda \mathrm{uxt}^{\prime} \mathrm{a} / \quad$ lejía en moldecitos

/taikci/ $\sim$ /taixci/ suegra

$/ \mathrm{k}^{\prime \prime} / \sim / \mathrm{x} /$ :

/c"ic"ilink"a/ /c"ic"ilinxa/ mosca, moscardón

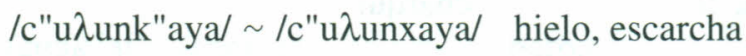

/wic'ink"a/ /wic'inxa/ cola, rabo

Otros casos de fluctuación se presentan entre oclusivas aspiradas y puras, como:

$$
\begin{aligned}
& / \mathrm{p} " / \sim / \mathrm{p} /
\end{aligned}
$$

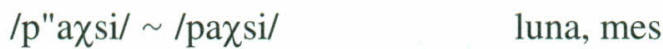

$$
\begin{aligned}
& / \mathrm{t} " / \sim / \mathrm{t} / \\
& \text { /t"apa/ /tapa/ nido } \\
& / \mathrm{k}^{\prime \prime} / \sim / \mathrm{k} /
\end{aligned}
$$

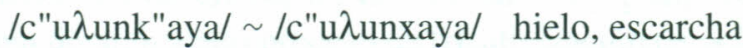

$$
\begin{aligned}
& \text { /cunk"a/ /cunka/ barba } \\
& \text { /k"unu/ /kunu/ nieve } \\
& \text { /q"/ /q/ } \\
& \text { /c"iq"a/ /c"iqa/ 1. ala 2.pluma } \\
& / \mathrm{c} " / \sim / \mathrm{c} / \\
& \text { /c"unk"a/ /cunk"a/ barba } \\
& \text { /kuc"i/ /kuci/ 1. basura 2.cerdo } \\
& \text { /xinc"u/ /xincu/ orejas }
\end{aligned}
$$

Otros casos de fluctuación se presentan entre oclusivas glotalizadas y puras, como: $/ \mathrm{p}^{\prime} / \sim / \mathrm{p} /$

/ximp'i/ /ximpi/ maíz tostado 


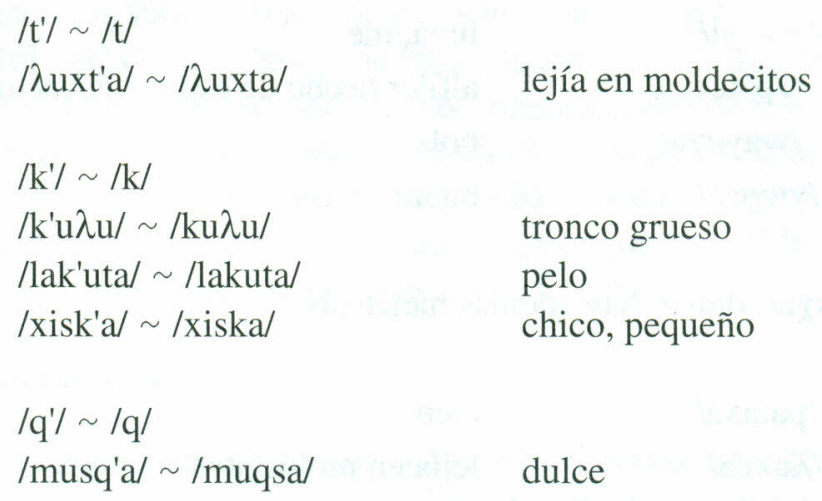

en este caso también hay metátesis.

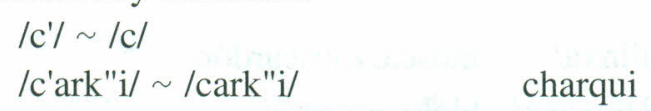

También aparece fluctuación entre oclusivas glotalizadas y aspiradas, como: $/ t^{\prime} / \sim / t^{\prime \prime} /$

/t'uk"a/ /t"uk"a/ flaco

$/ \mathrm{k}^{\prime} / \sim / \mathrm{k}^{\prime \prime} /$

/xak'u/ /xak"u/ harina

$/ \mathrm{c}^{\prime} / \sim / \mathrm{c} " /$

/c'unk"a/ /c"unk"a/ barba

También entre palatales y uvulares, como:

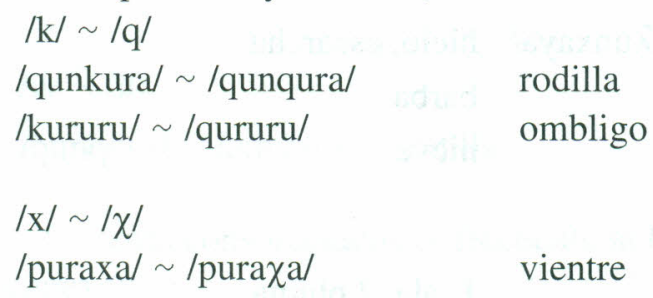

Entre alveolares y alveopalatales aparecieron:

\begin{tabular}{|c|c|}
\hline $\begin{array}{l}\text { /nasa/ /ñasa/ } \\
\text { /inkuna/ } \sim \text { /inkuña/ } \\
/ 1 / \sim / \lambda /\end{array}$ & $\begin{array}{l}\text { nariz } \\
\text { manta tejida }\end{array}$ \\
\hline /lak'uta/ / / ak'uta/ & pelo \\
\hline /c'ulu/ /c'u $\lambda \mathrm{u} /$ & gorro de lana \\
\hline$/$ paqalqu/ /paqa $\lambda$ qu/ & siete \\
\hline
\end{tabular}


Se registró fluctuación entre $/ \lambda /$ y $/ y /$ :

\begin{tabular}{|c|}
\hline /入арu/ /yapu/ \\
\hline / $\lambda$ atunka/ /yatunka/ \\
\hline /גaq'a/ /yaq'a/ \\
\hline / $\lambda$ awsa/ /yawsa/ \\
\hline$/ \lambda$ uqc'a/ /yu $\chi c^{\prime} a /$ \\
\hline
\end{tabular}

Hay unos pocos casos de fluctuación en que la motivación fonética no es tan obvia:

$\begin{array}{ll}/ \mathrm{k} / \sim / \lambda / & \\ / \mathrm{ka} \lambda \mathrm{aka} / \sim / \mathrm{ku} \lambda \mathrm{a} \lambda \mathrm{a} / & \text { hermana } \\ / \mathrm{c} / \sim / \mathrm{s} / & \\ / \text { cunk"a/ } / \text { sunk"a/ } & \text { barba } \\ / \text { mici } / \sim / \text { misi/ } & \text { gato }\end{array}$

pero para Harmelink (1985:15), siguiendo a Briggs (1976), en esta fluctuación está involucrada una "diferencia en el grado de contracción", pero no hemos encontrado evidencia del paso intermedio $*[\check{s}]$ :

$$
\text { [mice }]>*[\text { miše }]>[\text { mise }]
$$

Algunas de estas fluctuaciones pueden ser interpretadas en términos de procesos articulatorios, tales como:

- fricativización de oclusivas: /q $/ \sim / \mathrm{X} /, / \mathrm{k} / \sim / \mathrm{x} / \mathrm{y} / \mathrm{k} " / \sim / \mathrm{x} /$; es posible que este proceso pase un paso intermedio de africación de la oclusiva y posterior pérdida de la oclusión inicial, comparable al bien documentado proceso de fricativización de oclusiva aspirada palatal y uvular:

$$
\begin{aligned}
& {\left[\mathrm{k}^{\prime \prime}\right]>\left[\mathrm{k}^{\mathrm{x}}\right]>[\mathrm{x}]} \\
& {\left[\mathrm{q}^{\prime \prime}\right]>\left[\mathrm{q}^{\chi}\right]>[\chi]}
\end{aligned}
$$

- simplificación de oclusiva: /p"/ /p/,/t"/ /t/,/k"/ /k /, /q"/ / / / y /c"/ / /c/; $\mathrm{y} / \mathrm{p}^{\prime} / \sim / \mathrm{p} /, / \mathrm{t}^{\prime} / \sim / \mathrm{t} /, / \mathrm{k}^{\prime} / \sim / \mathrm{k} /, / \mathrm{q}^{\prime} / \sim / \mathrm{q} / \mathrm{y} / \mathrm{c}^{\prime} / \sim / \mathrm{c} /$;

- intercambiabilidad entre órdenes muy cercanos: $/ \mathrm{k} / \sim / \mathrm{q} /,|\mathrm{x} / \sim| \chi|,| \mathrm{n} / \sim / \tilde{\mathrm{n}} /, / \mathrm{l} / \sim \mid \lambda /$, $|\lambda| \sim / \mathrm{y} /$.

No hemos podido vincular estas fluctuaciones a una localización dada, lo que sugiere que no se trata de dialectalismos, sino de un rasgo aymara general, como ya ha sido señalado por Harmelink (1985: 15) para Chile y para Bolivia siguiendo a Briggs (1976).

Como es impredecible en qué otros ítemes podría aparecer nuevamente una fluctuación documentada en un número dado de casos, sea /c/ /s/: /cuank"a/ /sunk"a/, /mici/ /misi/, 
tampoco qué otros pares de fonemas podrían aparecer en fluctuación en un corpus mayor, hemos optado aquí por considerar las fluctuaciones de fonemas como hechos del léxico, o sea, datos para el diccionario.

\subsection{Aymara central y aymara chileno. Fonología}

A lo que hemos podido observar, en la fonología no hay grandes diferencias que separen profundamente al aymara chileno del aymara central. Así, el inventario de fonemas es el mismo, con excepción del supuesto fonema /v/ encontrado por Clair-Vasiliadis (1976: 147,151), y del dudoso fonema nasal uvular $/ \mathrm{y} /$ registrado en algunas áreas del territorio chileno (V. ClairVasiliadis 1976:149, 151 y Hamerlink 1985: 12), en Tarata, Perú, y en Carangas, Oruro, Bolivia (según Briggs 1976 y 1980, citada por Hardman et al. 1988:65). También hay correspondencia casi total en los parámetros articulatorios de contraste entre los fonemas y en las reglas de realización alofónica. Algunos procesos morfofonémicos que hemos podido observar en el área estudiada, presentan también correspondencia con el aymara central. El examen de los textos que presentamos aquí deja entrever una morfología nominal y verbal muy similar. Todo esto deja lugar a la conclusión de que el aymara moderno es una lengua que ostenta un alto grado de cohesión interna, en el sentido de que presenta un rango bajo de variación dialectal dentro de un territorio extenso y con una masa poblacional apreciable, estimada en unos tres millones de personas (V. Hardman et al. 1988: 1, 13).

\subsubsection{El inventario de fonemas, parámetros de contraste y realización alofónica}

El inventario de fonemas del aymara central presentado en Hardman et al. 1988: 28 contiene tres vocales: $i, a$, $u$; y 26 consonantes: $p, t, c h, k, q, p^{\prime \prime}, t^{\prime \prime}, c h^{\prime \prime}, k^{\prime \prime}, q^{\prime \prime}, p^{\prime}, t^{\prime}, k^{\prime}, q^{\prime}, s, j$, $x, m, n, \tilde{n}, l, l l, w, r, y$; y un suprasegmental descrito como alargamiento vocálico ( $\ddot{v}$ ). En este inventario las unidades segmentales son las mismas que aparecen en el aymara de Chile, solo que están representadas en un sistema de transcripción diferente, más viable para efectos prácticos que el que hemos usado aquí, más cercano al uso académico clásico en la presentación y discusión de sistemas fonológicos:

\subsubsection{Vocales}

Las tres vocales están descritas (pp. 36-8) como no redondeadas: anterior / i /, central / a /, y posterior / u /. Queda indicado que / u / es "no redondeada, excepto en el habla de los bilingües" (p. 36). Si desprendemos que en los bilingües es redondeada, el sistema vocálico coincide con el del aymara chileno. Todos nuestros informantes son bilingües y en todos ellos la vocal posterior se manifestó redondeada, como en el castellano. Como sea, la función bilabial no es contrastiva, ya que (a) las tres vocales son deslabializadas, como en el aymara monolingüe, o (b) la labialización (redondeamiento) está fijamente asociada a la vocal posterior, como en el aymara bilingüe. Está fuera de discusión el que en ambos dialectos la altura de la lengua no es contrastiva. En el aymara descrito por Hardman y sus colaboradores, las vocales anterior / i / y posterior / u / presentan un amplio campo de dispersión gradual y continua entre realizaciones más altas, tipo $[\mathrm{i}, \mathrm{u}]$ y más bajas, tipo $[\varepsilon$, o] (V. p.27), distribuidas mayormente en variación libre, 
"es decir, que no está condicionada por los elementos que conforman el ambiente fonético" (V. p. 37), aunque no se descarta la posibilidad de que exista un condicionamiento no advertido (V. p. 64, nota 6). En el aymara chileno la situación parece darse en términos algo más estables: para las vocales anterior y posterior, /i, u/, la realización que encontramos de norma es alta [i, u], muy similar al castellano /i/ en /si/ 'si' o /u/ en /su/ 'su', o sea, altas y cerradas. En posición fonal es normal que bajen hasta $[\mathrm{e}, \mathrm{o}]$, similares al castellano /e/ en /seko/ 'seco' y /o/ en /sópa/ 'sopa', o sea, medias y cerradas; [e, o] son también de norma en contacto directo con consonante uvular o a distancia con consonante uvular en la sílaba siguiente:

\section{Cuadro 8}

1. $\left\{\begin{array}{c}\mathrm{i} \\ \mathrm{u}\end{array}\right\} \rightarrow\left\{\begin{array}{l}\mathrm{e} \\ \mathrm{o}\end{array}\right\} / \#\left\{\begin{array}{r}\text { C Uvular } \\ \text { C Uvular }\end{array}\right\}$

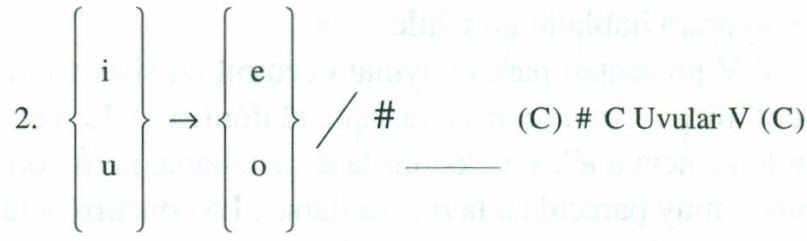

El descenso de /i, $\mathrm{u} /$ en contacto directo con consonante uvular está registrado para el aymara central en Hardman (Hardman et al. 1988: 38), pero como incremento gradual en la apertura, no como en Chile, donde parece tratarse más bien de tipos fonéticos diferentes en un grado entero: / i / ([i] [e]), / u / ([u] [o]). En aymara central la influencia de la consonante sobre el grado de apertura de la vocal, funciona " tanto progresiva como regresivamente, aunque la influencia progresiva es más fuerte" (pp. 37-8). En el aymara chileno, el descenso de un grado entero en la altura de la vocal ocurre en contacto directo con consonante uvular precedente o secuente, y a distancia la consonante uvular afecta sólo regresivamente. No hemos observado elevación vocálica en el ambiente de /ñ/ y /y/ (p.38); así /ñuñu/ 'pecho' aparece en la realización de norma: [ñuñu]; /ñiqi/ 'barro' es pronunciado [ñéq'e]; /xayu/ 'lluvia' es pronunciado [xáyo] y /wayita/ es [wayéta]. Tampoco se ha observado descenso vocálico por efecto del acento: /isi/ 'ropa' es pronunciado [íse] y /uru/ 'día' es [úro]. La vocal inicial es alta cerrada,

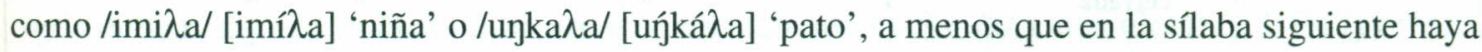
consonante uvular, como en /iqiqu/ [eqéqo] 'muñeco de barro' o /uqara / [oqára] 'sordo'.

No encontramos en aymara chileno centralización y relajación $a$ [a] en [ə] o [ $\Lambda$ ], documentada como ocasional en aymara central (Hardman et al. 1988: 38).

El corpus examinado para esta descripción no mostró el ensordecimiento vocálico descrito para el aymara central en Hardman et al. 1988: 39, lo que es explicable porque se trata de un proceso de relajación de la tensión articulatoria vocálica que difícilmente podría aparecer en palabras aisladas pronunciadas muy deliberadamente o en textos producidos a velocidad de dictado lento y enfático. 
No encontramos casos de alargamiento vocálico con valor fonemático. Así, para el par mínimo /caka/ 'puente' vs. /ca:ka/ 'tronco seco de quinua' (Hardman et al. 1988: 39), tenemos acá /caka/ 'puente' vs. /caxa/ 'tallo de la quinua'. Está bien documentado en Chile el alargamiento de la vocal /a/ vinculado a la caída de la sílaba /ya/ en /maya/ 'un, uno' /paya/ 'dos' /k"aya/ 'aquel', tal como en aymara central (V. Hardman et al. 1988: 40).

No conocemos bien la flexión verbal del aymara de Chile, de modo que de momento no podemos decir nada seguro con respecto al alargamiento vocálico gramatical, o sea, con valor de suprafijo, pero hemos observado que formas de la flexión verbal registradas para el aymara central con alargamiento vocálico, por ejemplo, $1^{a}$ persona plural inclusivo, grupo pequeño, en futuro indicativo -/ña:ni/, se realiza en Parinacota sin un alargamiento que podamos advertir a simple oído como en:

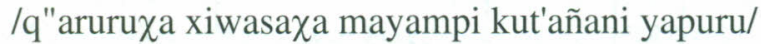

mañana nosotros otra vez regresaremos a la chacra

en la forma verbal no se aprecia en la /a/ de la flexión (-/ñani/) un alargamiento comparable al que aparece en la reducción de /maya/ en /ma:/ o /paya/ en /pa:/. Por ahora todo lo que se puede decir es que el alargamiento vocálico con función gramatical, tan claro en el aymara central, debe ser investigado en el aymara hablado en Chile.

Cotari et al. 1978:V presentan para el aymara central un sistema de tres vocales fonológicas: $i$ (con su variante alofónica $e$ ), $a, u$ (con su variante alofónica $o$ ). La vocal i está descrita "como la $i$ castellana, pero con tendencia a $e$ "; y $u$ "como la u castellana, pero con tendencia a $o$ ". La variante $e$ está descrita como "muy parecida a la $o$ castellana". La concurrencia de $e$ y $o$ está presentada así: "las variantes alofónicas de $i$ y $u$ ( $e$ y $o$ respectivamente) ocurren antes o después de jj, q, qh, q', o por influencia de estos sonidos a través de $1, \mathrm{n}, \mathrm{r}$ y s". Registran alargamiento vocálico con valor fonemáticos en el léxico (el alargamiento fonémico simple de Hardman et al.1988:39).

Como ya fue dicho más arriba, en el aymara chileno las vocales fonéticas [i, e, u, o] tienden a ser cerradas en todo contexto. Si entendemos correctamente, para los autores las vocales altas en aymara central $(i, u)$ son más abiertas, $[u, u]$, que en el aymara chileno; y las vocales medias $(e, o)$ pueden ser cerradas, $[e, o], o$ abiertas $[\varepsilon, 0]$, en tanto que en aymara chileno son siempre cerradas $([\mathrm{e}, \mathrm{o}])$ :

\section{Cuadro 9}

Vocales fonéticas en aymara chileno y central

\begin{tabular}{|c|c|c|c|c|c|c|c|}
\hline & & Anterior & Central & Posterior & Anterior & Central & Posterior \\
\hline Alta & $\begin{array}{l}\text { cerrada } \\
\text { abierta }\end{array}$ & $\mathrm{i}$ & & $\mathrm{u}$ & $\mathrm{i}$ & & $\mathrm{u}$ \\
\hline Media & $\begin{array}{l}\text { cerrada } \\
\text { abierta }\end{array}$ & $\mathrm{e}$ & & o & $\begin{array}{l}\mathrm{e} \\
\varepsilon\end{array}$ & & $\begin{array}{l}0 \\
0\end{array}$ \\
\hline Baja & & & a & & & $\mathrm{a}$ & \\
\hline
\end{tabular}


La distribución de los alófonos $e$ (de $i)$ y $o($ de $u$ ) es la misma que en el aymara chileno: los sonidos representados por $j j, q, q$ ", $q$ ', son los mismos llamados aquí "uvulares":

$\begin{array}{ll}\text { jj } & \chi \\ \text { q } & \text { q } \\ \text { q" } & \text { q" } \\ \text { q' } & \text { q' }^{\prime}\end{array}$

abren a $i, u$ contiguas en $e, o$ respectivamente. La observación de que estas consonantes bajan las vocales "a través de $l, n, r, s$ " sugiere que en el aymara estudiado por los autores las consonantes uvulares abren la $i$ o $u$ situadas en sílaba anterior, tal como en aymara chileno: la única manera en que las consonantes $l, n, r, s$ puedan servir de puente entre una consonante uvular y una vocal, es regresiva:

\section{Cuadro 10}

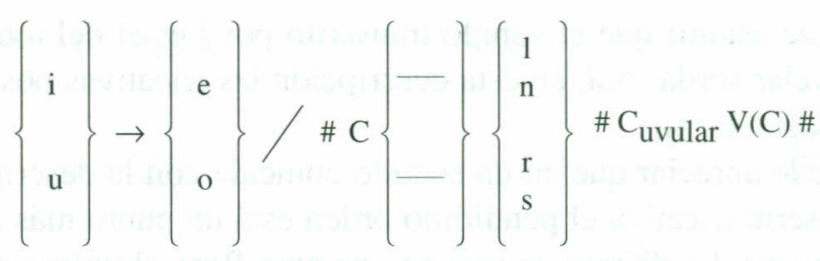

\subsubsection{Consonantes}

En lo que respecta al consonantismo central y chileno, el número de unidades es el mismo, 26 fonemas, distribuidos en una red casi idéntica de coordenadas de series y órdenes. Así, hay 18 obstruyentes, 15 de las cuales son interruptas (12 oclusivas y 3 africadas) y 3 son continuas (fricativas). Hay seis resonantes: nasales (3), laterales (2) y vibrante (1). Hay, finalmente dos semiconsonantes. La ocurrencia de voz tiene la misma distribución: las obstruyentes son sordas y las resonantes y semiconsonantes son sonoras.

En los dos dialectos coinciden la mayor parte de los órdenes: bilabial, alveolar, alveopalatal. La mayor diferencia está en que en Chile contrastan palatales y uvulares ("postvelares" es otra opción terminológica), y en aymara central la situación se ve algo más compleja: para Hardman (Hardman et al. 1988: 31-2), los órdenes contrastantes son (1) velar y postvelar en la serie oclusiva, y (2) en la serie fricativa contrastan una uvular $/ \mathrm{x} / \mathrm{y}$ una glotal $/ \mathrm{j} /$. En la presentación de Cotari et al. 1978:V, en el área posterior hay j, jj, $k, k^{\prime \prime}, k^{\prime}, q, q^{\prime \prime}, q^{\prime}$. Las dos primeras, $j$ y jj, están referidas a la pronunciación de $j$ en castellano: $j$ "como en castellano", o sea, fricativa velar sorda; y $j j$ "como la $j$ castellana, pero con la parte posterior de la lengua levantada hacia la parte trasera del velo del paladar y con bastante fricción" de donde puede interpretarse como fricativa postvelar sorda. Para ellos, entonces, en el área posterior de la serie obstruyente contrastan velares y postvelares. La misma descripción en Herrero et al. 1987: 7. Para Ross (1963: 9-10) las oclusivas posteriores son palatales: 


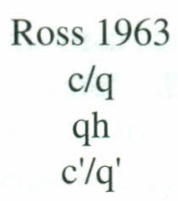

y postvelares (o uvulares):

Ross 1963
k
kh
$\mathrm{k}^{\prime}$

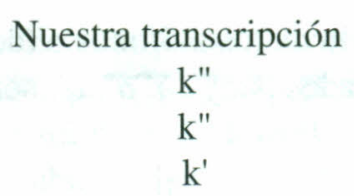

Nuestra transcripción

$$
\begin{aligned}
& \text { q" } \\
& \text { q" } \\
& \text { q' }
\end{aligned}
$$

En las fricativas, el sonido transcrito por $j j$ es descrito en referencia a $j$ castellana, en términos que podrían interpretarse como fricativa postvelar o uvular:

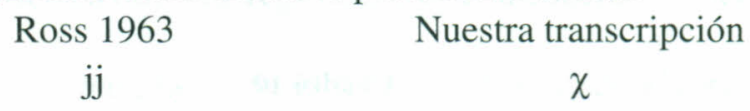

Hay que asumir que el sonido transcrito por $j$ es el del todo similar a la $j$ castellana, 0 sea, fricativa velar sorda. Así, en esta descripción las fricativas posteriores contrastan como velar (j) contra postvelar (jj).

Se puede apreciar que en un sentido coincide con la descripción de Hardman y colaboradores: en la serie fricativa el penúltimo orden está un punto más atrás que el penúltimo orden en la serie oclusiva. La diferencia está en que para Ross el último orden es el mismo para oclusivas y fricativas: ambas postvelares.

El aymara chileno presenta contraste entre palatales y postvelares (o uvulares) tanto en la serie oclusiva:

$\begin{array}{cc}\text { Palatales } & \begin{array}{c}\text { Postvelares } \\ \text { (uvulares) }\end{array} \\ \text { k" } & q^{\prime \prime} \\ \text { k" } & q^{\prime \prime} \\ \text { k' } & \text { q' }^{\prime}\end{array}$

como en la serie fricativa:

$\begin{array}{cc}\text { Palatales } & \begin{array}{c}\text { Postvelares } \\ \text { (uvulares) }\end{array} \\ \mathrm{x} & \chi\end{array}$

o sea, el penúltimo orden (palatal) y el último orden (postvelar o uvular) son los mismos para la serie oclusiva y la serie fricativa. En nuestra percepción, el fonema aymara / $/$ fricativo palatal aparece en un campo articulatorio anterior al punto velar: si consideramos típicamente velar a la pronunciación castellana de /x/, como en /xáro/ 'jarro', /xénte/ 'gente', /xitáno/ 'gitano'/, el fonema aymara $/ \mathrm{x} /$ oscila entre pre-palatal, ante / i / y post-palatal, ante /a, u/, no velar como en castellano. Por su parte, en Chile el fonema aymara $/ \chi /$ presenta una realización localizada entre la última parte del velo del paladar y la úvula, o sea, más atrás que /x/ castellana. 


\section{Cuadro 11}

1. Cotari et al. 1978, Herrero et al. 1978.

Oclusiva

pura

aspirada

glotalizada

Fricativa

2. Hardman et al. 1988.

Oclusiva

$$
\begin{aligned}
& \text { pura } \\
& \text { aspirada } \\
& \text { glotalizada }
\end{aligned}
$$

Fricativa

3. Ross 1963.

\section{Oclusiva \\ pura \\ aspirada \\ glotalizada}

Fricativa

\section{Velar \\ Postvelar}

$\mathrm{k}^{\prime \prime}$

$\mathrm{k}^{\prime \prime}$

$\mathrm{k}^{\prime}$

j

q"
q"
q'

$\mathrm{jj}$
Glotal

q"
$q^{\prime \prime}$
$q^{\prime}$

$\mathrm{x}$

j

Velar Postvelar

k"

$\mathrm{kh}$

$\mathrm{k}^{\prime}$

$\mathrm{jj}$

No hemos escuchado realizaciones glotales, tipo [h], del fonema $/ \chi /$.

$\mathrm{Si}$ se considera que el castellano $/ \mathrm{k} /$ es oclusivo velar, situamos al fonema $/ \mathrm{k} /$ del aymara en los puntos pre-palatal ante /i/ y post-palatal ante /a, u/.

El fonema aymara /q/ está realizado detrás del punto velar, entre la última parte del velo del paladar y la úvula. Los fonemas /k", k'/ siguen la localización de / $/$ y los fonemas /q", q'/ la de $/ q /$.

Con este patrón de realización el aymara de Chile se asemeja parcialmente a los dialectos bolivianos aludidos en Hardman et al. 1988: 63 (nota 2) que en las fricativas presentan contraste entre velar y postvelar (o sea, siguen el pautamiento de las oclusivas), con la diferencia de que en Chile (a) en las series oclusiva y fricativa el contraste ocurre entre palatal y postvelar (o uvular); y (b) el fonema chileno $/ \chi /$ fricativo postvelar no presenta un alófono glotal [h], que sí aparece en los dialectos bolivianos observados por Hardman y colaboradores.

En Hardman et al. (1988: 22, 29) se hace notar que en el consonantismo del aymara central hay "una tendencia general de las oclusivas, sobre todo los velares y post-velares aspiradas y glotalizadas, de volverse africadas" (p. 29). Esta tendencia aparece consistentemente en los datos chilenos, pero afecta solo a las oclusivas palatales aspiradas y uvulares aspiradas (debe tenerse presente que palatales y uvulares chilenas corresponden funcionalmente a velares y postvelares centrales de los datos de Hardman). En Chile las oclusivas puras palatal y uvular ostentan más bien una moderada tendencia a la fricativización.

No hemos podido confirmar alófonos del tipo [క̌ s] sibilante alveolar sorda para el fonema / c / africado alveopalatal sordo, señalados en Hardman (Hardman et al. 1988: 30) para el 
aymara central. Hay una sola ocurrencia de / c / ante / t / y en ella se retiene la realización africada alveopalatal sorda.

$$
\text { /xactaña/ [xactáña] estornudo, }
$$

donde en aymara central sería [xaštáña] [xastaña]. Además hay unas pocas palabras en las que concurren [s] y [t] como en [ámsta] 'cuesta, pendiente' o [wistá $\lambda$ a] 'carterita tejida', sin evidencia que recomienda adscribir el fono [s] al fonema / c / y no al fonema / s /.

Tampoco hemos podido confirmar alófonos fricativos alveopalatales o palatales, [šs pa$\mathrm{ra} / \mathrm{s} /$ en el ambiente de /c, y, $\tilde{\mathrm{n}} /$.

Es posible que en los dos últimos puntos discutidos no sea cuestión de diferencia entre el aymara central y el aymara chileno, sino más bien se trate de limitación en nuestros datos, los que no incluyen formas verbales flexionadas.

En Chile el fonema vibrante / $\mathrm{r} /$ se realiza mayormente simple [ $\mathrm{r}$ ]; únicamente en dos ítemes apareció una variante libre fricativa rehilada $[\bar{r}]$, sólo uno de los cuales cumple la condición de que / r / esté en el ambiente de / s /: /asiru/ [aséro] [aséro] 'culebra'; en el otro caso la alternancia apareció $\sin$ / s / en el entorno: /waranqa/ [waránqa] [waránqa] 'mil'.

\subsubsection{Fluctuación de fonemas en aymara central y chileno}

Los casos observados de fluctuación de fonemas en aymara de Chile han sido también documentados en Bolivia por Briggs (1976), citada en Harmelink (1985:15-6).

\subsubsection{Restricciones en la distribución de los fonemas}

En aymara chileno la pauta de distribución de los fonemas es muy similar a la del aymara central. Así, no hay secuencias vocálicas ni en hiato ni en diptongo. Son permisibles secuencias de vocal y semiconsonante, como en /ay $\lambda u$ / 'comunidad vecinal' o /awti/ 'estación seca'; o de semiconsonante y vocal: /yapu/ 'chacra' o /wari/ 'vicuña'; o de semiconsonante, vocal y semiconsonante como en /wayra/ 'viento arremolinado'. Se ha detectado tendencia a restricción en la ocurrencia de las semiconsonantes en contacto directo con vocales altas homorgánicas, del tipo /yi/, /iy/, /wu/ o /uw/. Como los datos constan mayormente de raíces solas, no se ha observado ocurrencia de dos vocales iguales contiguas, que sí se da en aymara central, en vinculación con el alargamiento vocálico (V. Hardman et al. 1988: 41).

Tal como en aymara central, en aymara chileno los fonemas uvular fricativo $/ \chi / y$ vibrante / r / no aparecen en posición frontal de sílaba inicial de palabra. En nuestros datos no hay sufijos, pero hemos escuchado en el altiplano iquiqueño la forma /mama $\lambda \mathrm{a} /$ 'madrecita' que sugiere la existencia de un sufijo (tal vez semifosilizado) -/ $\lambda \mathrm{a}$ / (Cf. Hardman et al. 1988: 42 y 64, nota 7). 


\subsubsection{Frecuencia, estructura de la sílaba y configuración silábica de las palabras}

Las tendencias de frecuencia vocálica y consonántica son, en general las mismas en aymara central y chileno. También son muy similares la estructura de la sílaba y la configuración silábica de las palabras, al menos cuando se trata de raíces solas.

\subsubsection{Fonología, morfología y sintaxis}

Todos los procesos de caída vocálica por efectos de los llamados sufijos fuertes observados hasta ahora en el aymara chileno, corresponden a procesos similares descritos para el aymara central. También se aprecia correspondencia en la elisión de la última vocal de las palabras internas en el grupo fónico, de los determinadores de tres y más sílabas y en la caída de la última sílaba de los determinadores terminados en /ya/ con alargamiento de la vocal precedente. La marca del complemento directo por sustracción de la última vocal ha sido consistemente observada en el aymara chileno.

\subsubsection{Conclusiones}

Se puede concluir que en la fonología el aymara general es una lengua que está bajamente afectada por la variación dialectal. De hecho, observamos más diferencias fonológicas entre el castellano paceño y el castellano ariqueño que entre el aymara de Puno (Perú) y de Parinacota (Chile).

Las únicas diferencias realmente importantes en el sistema fonológico son (a) la presencia de una nasal posterior (descrita como velar o postvelar) de estatus fonémico dudoso, confirmada en algunas áreas de Chile, Perú y Bolivia; (b) la presencia de alófonos sonoros de las oclusivas puras tras consonante nasal que se da normal, pero no exclusivamente en el área sur del territorio aymara chileno, altiplano de la Provincia de Iquique, que es precisamente el área chilena donde aparece $[\eta]$ en contextos no asimilantes.

\subsection{7. ¿Dos áreas en el territorio aymara chileno?}

Harmelink (1985:10-6) llega a la conclusión de que hay dos áreas en el territorio aymara chileno, correspondientes a los dialectos bolivianos centrales y sureños descritos por Briggs (1976). El área sureña (altiplano iquiqueño), está marcada por la aparición de la nasal velar no asimilada, de la alta frecuencia de los alófonos sonoros de las oclusivas puras tras nasal, y del sufijo sociativo -/nti/ [nde] en vez de -/mpi/ [mpi], del aymara central. La distribución de estos rasgos sigue un modelo de graduatum o continuum, con los extremos claramente definidos y un área intermedia, situada en los alrededores del poblado de Guallatire, en donde alternan las formas centrales y sureñas. Entre Guallatire y Visviri, en el extremo norte, se extiende el área central. Allí son minoritarios los alófonos sonoros de las oclusivas puras, "las incidencias de la nasal velar en otros ambientes fuera de los asimilatorios fueron inexistentes" (Harmelink 1985: 14) y se usa el sociativo -/mpi/. 
Nuestras observaciones confirman la división sugerida por Harmelink, sólo que nosotros preferiríamos, hablando en términos del territorio aymara chileno, llamar "área norte" al área central de Harmelink y Briggs, y reservar el nombre de aymara central para el dialecto del Lago Titikaka.

Harmelink hace notar que en la precordillera "no se encontró evidencia sustancial que indicara grandes diferencias" con el uso altiplánico (1985: 14). Los datos de Harmelink proceden del poblado de Socoroma. Nuestros datos precordilleranos, procedentes del poblado de Belén, confirman del todo la observación de Harmelink.

\subsection{Aymara central y aymara chileno}

\subsubsection{Léxico}

Harmelink hace una breve presentación de algunas diferencias léxicas entre el aymara central y el aymara chileno (1985: 16-7), Lista de elicitación preliminar y listas representativas de Chile y Bolivia). Observa que en Chile /tata/ es 'padre' y en Bolivia es 'señor' y /mama/ es 'madre' y en Bolivia es 'señora'. Nuestros datos confirman la observación de Harmelink en lo que respecta a Chile, pero hay que tener presente (a) que en aymara central /tata/ también significa 'padre' y /mama/ también 'madre' y (b) que en Chile en el uso más respetuoso /tata/ también significa 'señor' y /mama/ también significa 'señora'. Así, no hay diferencia sustantiva en la semántica de estos dos ítemes.

Para Harmelink /qalti/ es 'mañana' en Chile, como en: /qalti qama/ 'ihasta mañana!' y en Bolivia 'mañana' es /q"ara/ como en: /q"arur qama/ 'ihasta mañana!', pero ambos ítemes aparecieron en nuestros datos: /qalt'i/ y /q"ara/, el primero de uso menos frecuente. Así, en el uso más frecuente hay coincidencia entre el aymara central y el aymara chileno.

Harmelink, siguiendo a Manuel Mamani (Universidad de Tarapacá, Arica), registra para 'venir' /xutaña/ en Bolivia y /puriña/ en Chile, pero al parecer la diferencia es sólo idiosincrática de Mamani, ya que en Chile y en Bolivia se usan ambos y en contraste: /puriña/ es 'llegar' y /xuntaña/ es 'venir'. Así, tampoco es ésta una verdadera diferencia entre Chile y Bolivia.

Los 44 ítemes de la lista de elicitación preliminar de Harmelink revelaron un alto grado de correspondencia entre cinco localidades chilenas (poblados de Parinacota, Socoroma, Guallatire, Guytane y Villablanca) y La Paz, Bolivia. Sólo hubo ligeras diferencias en 11 palabras:

Localidades chilenas

1. padre

madre

abuelo

4. maíz tostado

barba tata

mama

acici

tonqo

ximp'i

cunka

sunka
La Paz

awki

tayka

acaci

xamp'i

sunk"a 


$\begin{array}{lll}\text { dulce } & \begin{array}{l}\text { c"unk"a } \\ \text { mosqa } \\ \text { mosq'a } \\ \text { xaca }\end{array} & \text { mosq"a } \\ \text { grande } & \text { xac'a } \\ \text { pelo } & \begin{array}{l}\text { nakuta } \\ \text { lakuta } \\ \text { c'ara } \\ \text { c'iyara }\end{array} & \text { ñakuta } \\ \text { negro } & \text { ciyara } \\ \text { nido } & \begin{array}{l}\text { cu } \lambda \text { unka } \\ \text { cu } \lambda \text { unkaya }\end{array} & \text { tapa } \\ \text { hielo } & \text { cu } \lambda \text { unka } \lambda a\end{array}$

pero incluso estas diferencias aparecen bastante atenuadas en nuestros datos:

1. padre. Está registrado /tata/ y también /awki/, este último con dos significados de superficie: 'padre' y 'abuelo', que en realidad corresponden a un solo significado profundo: 'pariente masculino ascendente lineal'; también está documentado el significado translaticio 'anciano'. El uso es el mismo en Bolivia;

2. madre. Están resgistrados en Chile /mama/ y /tayka/. El uso es el mismo en Bolivia;

3. abuelo. Están registradas en Chile /acaci/ y /acici/, con dos significados vinculados: 'anciano' y 'abuelo'; este último parece ser un translaticio. Al menos algunas localidades chilenas conciden con La Paz;

4. maíz tostado. Hemos encontrado consistentemente /tunqu/ [tónqo] con el significado de 'maíz'; para 'maíz tostado' tenemos /xamp'i/ /ximp'i/; para Bolivia los diccionaros registran /xamp'i/ como 'tostado de cereales';

5. barba. Conocemos /c"unk"a/ /cunk"a/ /sunk"a/, aunque muy esporádicamente se han escuchado formas sin aspiración: /k/ y no /k"/. Hay coincidencia entre algunas localidades chilenas y La Paz;

6. dulce. Hemos escuchado /musq'a/ /mus $\chi$ a/ y la forma metatizada /muqsa/. Hay coincidencia entre algunas formas chilenas y la forma boliviana /musq'a/; no es imposible que algún uso chileno incluya la forma metatizada /mus $\chi$ a/ documentada para Bolivia;

7. grande. En Chile tenemos solo /xac'a/, en contraste con /xaca/ 'lágrima', coincidiendo totalmente con el uso paceño;

8. pelo. Hemos escuchado /lak'uta/ / $\lambda$ ak'uta/ /ñak'uta/ /ñik'uta/, muy esporádicamente alguna de estas formas con $/ \mathrm{k} /$ en vez de $/ \mathrm{k}^{\prime} /$. Para Bolivia: /ñik'uta/ coincidiendo con el uso de algunas localidades chilenas;

9. negro. Tenemos /c'ara/ /c'iara/ /c'ayara/; algunos usos chilenos coinciden con la forma boliviana /c'iara/;

10. nido. Hemos escuchado/tapa/, igual que en Bolivia;

11. hielo. Hemos registrado /c"u $\lambda$ unk"aya/ /c"u $\lambda$ unk"a/ /c"u $\lambda$ unxaya/ "escarcha, hielo'; así en el uso más frecuente el aymara chileno coincide con el uso boliviano registrado en los diccionarios: /c"u $\mathrm{u} u n k " a y a /$. 
Las listas representativas de Chile y Bolivia de Harmelink contienen 170 ítemes con las respuestas de Guallatire (en el sector medio del altiplano de la Provincia de Parinacota) y de La Paz, Bolivia. Para los efectos de esta discusión hemos elegido 70 ítemes, de los cuales los siguientes revelaron diferencias (el primer ítem corresponde a Guallatire, el segundo a La Paz):

1. noche /arama/ \# /xayp'u/, en nuestros datos hay /arama/ /aruma/, este último es igual a la forma boliviana en Cotari et al. para quienes /xayp'u/ es 'tarde, desde el mediodía hasta el atardecer';

2. mañana /qalti/ \# /q"aruru/, diferencia ya discutida más arriba, en el párrafo anterior; pasado mañana /xurpi/ \# /xurp'uru/, la respuesta boliviana que recibió Harmelink es realmente /xurp'(i)/ contraído con la forma /uru/ 'día'; la forma de Cotari et al. es /xur$\mathrm{pi} /$, o sea idéntica a la forma chilena;

3. año /mamara/ \# /mara/, la respuesta de Guallatire que recibió Harmelink es en realidad /mara/, fundido con /mä(ya)/ 'un, uno', de modo que aquí no hay una verdadera diferencia entre ambas localidades;

4. barba /cunka/ \#/sunk"a/ ya discutida en el párrafo anterior;

5. pierna /cara/ \#/c"ara/ Cotari et al. traen /cara/, o sea, igual a la respuesta chilena;

6. tobillo /qunqura/ \# /qunquri/, las dos respuestas recibidas por Harmelink aparecen en Chile con el significado de 'rodilla'; para 'tobillo' conocemos la forma perifrástica /c'ixta-muqu/, y para Bolivia, Cotari et al. registran una perífrasis parecida: /kayu muqu/ 'tobillo', de /kayu/ 'pie y pierna (hasta la rodilla)' y /muqu/ 'abultamiento, protuberancia';

7. pelo /lakuta/ \#/ñikuta/ ya discutido;

8. corazón /cuyma/ \#/c"uyma/, nosotros hemos escuchado /cuyma/, ocasionalmente con una aspiración muy débil: /c"uyma/, con dos significados, 1. bofes; 2. corazón; en este último sentido contrasta con / $\lambda \mathrm{uqu} /$ 'corazón muerto de los animales carneados'; /cuyma/ 'corazón viviente de las personas'. Cotari et al. registran /cuyma/ sin aspiración /c/ y no /c"/;

9. orejas /xinc"u/ \# /xinc"u (naka)/, la respuesta boliviana recibida por Harmelink es realmente /xinc"u/ ya que /naka/ es el pluralizador. Nosotros hemos oído /xiñcu/ sin aspiración, coincidiendo con la forma boliviana resgistrada en Cotari et al.;

10. tierra /c"a $\mathrm{a} \mathrm{a} /$ \# /uraqi/, la diferencia es más aparente que real; nosotros registramos /c'a $\lambda \mathrm{a} /$ como 'arena' y /uraqi/ como 'tierra', en el sentido de "suelo, terreno", coincidiendo con los usos bolivianos registrados por Cotari et al.;

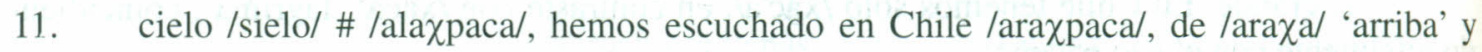
/paca/ 'región';

12. nube /c'iwi/ \# /qinaya/, en p.16, Harmelink anota tres ítemes aymara más o menos correspondientes a 'nube': [qenaya], [urp"u] y [c'ibu], respectivamente 'nubes altas', 'cielos cubiertos' y 'niebla baja'. Nosotros hemos recogido en Chile las cuatro palabras registradas por Harmelink, pero con ligeras diferencias de significado:

/c'iwi/

/c'iwu/

/qinaya/

/urpu/ sombra, área umbría

sombra de un cuerpo

nube que se desplaza de este a oeste

niebla, neblina, camanchaca 
Cotari et al. traen así:
/c'iwi/
sombra, ausencia de sol
/qinaya/
nubes blanquecinas sin presagio de lluvia
/urpu/
1. nubes densas 2. neblina

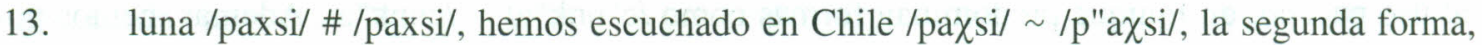
con $/ \mathrm{p} " /$ aspirada, coincide con la información de Cotari et al. para Bolivia;

14. viento /wayra/ \#/t"aya/, nuevamente, la diferencia es más aparente que real: en Chile hemos escuchado /wayra/ y /t"aya/, en contraste: 'viento fuerte, viento arremolinado' vs. 'viento frío' o mejor 'frío dicho del viento';

15. niebla /surka/ \# /urpu (ntata)/, como se vio antes para 'niebla, neblina' hemos encontrado en Chile /urpu/, coincidiendo con el uso paceño;

16. limpio /limpio/ \# /quma/, nosotros tenemos anotado para Chile /q'uma/ 'limpio', coincidiendo con el uso paceño de Cotari et al.;

17. sucio /siste/ \# /k'añu/, hemos escuchado /q"aña/ /q"añu/ /q'aña/ /q'añu/ 'sucio, mugriento' en contraste con /c'is $\lambda \mathrm{i} / \sim$ / $\mathrm{c}$ 'ix $\lambda \mathrm{i} /$ 'sucio, manchado'. Hay buena similitud con los datos bolivianos de Cotari et al. entre otros los siguientes:
/q'añu/
sucio, suciedad
$/ \mathrm{k} " \mathrm{aña} /$
sucio, mugriento
/c'is $\lambda$ i/
sucio, manchado

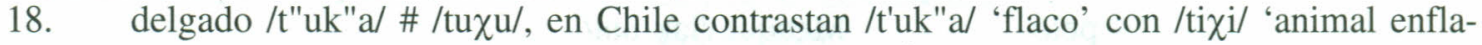
quecido por alguna peste', Cotari et al. registran para Bolivia /t'uk"a/ /t'uka/ 'flaco' y $/$ tu $\chi \mathrm{u} /$ 'flaco (despectivo)';

19. negro /c'ara/ \#/c'iyara/, ya discutido en el párrafo anterior;

20. blanco /xanq'u/ \# /xanqu/, el uso boliviano registrado por Cotari et al. es /xanq'u/ igual a las formas recogidas en Chile;

21. perro /anuqara/ \#/anu/

22. gato /misi/ \# /pisi/, en nuestros datos 'gato' se da /mici/ /misi/ /p"isi/ y las formas correspondientes con el sufijo (¿fosilizado?) -/tu/; para Cotari et al. la forma boliviana es /p"isi/;

23. alpaca /a $\lambda$ pacu/ \# /alpaka/

24. cóndor/kunturi/ \# /kunturi/ en Chile hemos oído además /kuntiri/

25. padre /tata/ \# /awki/

26. madre /mama/ \#/tayka/ ya discutidos en el párrafo anterior.

Los datos de Harmelink complementados con nuestras observaciones confirman para el léxico el alto grado de unidad espacial del aymara ya detectado en la fonología.

Una segunda sugerencia que surge tanto de los datos de Harmelink como de los nuestro, se vincula con la eventual separación del altiplano iquiqueño como un enclave o islote dentro del territorio aymara chileno. Se basa en que la mayor parte de las veces en que un ítem léxico dado presenta variantes en su configuración fonemática, el altiplano iquiqueño se aparta del uso de Parinacota. A su vez, en estos casos el uso parinacoteño tiende a ser similar al uso del aymara central; por ejemplo, 'gato' es /mici/ /misi/ en Iquique y /p"isi/ /p"isitu/ en Pari- 
nacota, coincidiendo con el aymara central /p"isi/, registrado en Cotari et al. Igualmente, para 'pelo' /ñik'uta/ en aymara central, las formas parinacoteñas son /ñik'uta/ /ñak'uta/, en tanto que las formas más divergentes /lak'uta/ / $\lambda$ ak'uta/ son iquiqueñas.

Para 'barba' en Parinacota se oyen con más frecuencia formas como /sunk"a/ idénticas al uso paceño; en Iquique predominan formas como /c"unk"a/ /cunk"a/. Además, hemos podido apreciar que algunas palabras recolectadas en Iquique, no eran comprendidas en Parinacota, pero lo inverso no ocurrió: la gente iquiqueña comprendía todos los ítemes de sus vecinos nortinos. Por ejemplo, la forma iquiqueña /wasa/ 'grano sancochado' no es entendida en Parinacota. En cambio, la forma parinacotense /wisk' aca/ era entendida en Iquique, aunque allí se dice /sik'acu/ 'vizcacha'.

A fin de explorar algo más esta impresión comparamos 171 ítemes recogidos (a) en Mauque, poblado del altiplano iquiqueño; (b) en General Lagos, poblado del altiplano de Parinacota; y (c) en Sipita, Puno (Perú). El sistema fonológico fue el mismo en inventario de fonemas y reglas básicas de realización alofónica. En un 75\% los ítemes fueron iguales en las tres localidades, como:

$\begin{array}{lll}\text { frente } & \text { /para/ } & \text { [pára] } \\ \text { cabeza } & \text { /p'iqi/ } & \text { [p'éqe] } \\ \text { boca } & \text { /laka/ } & \text { [láka] }\end{array}$

En 13 ítemes, Mauque se separa del uso coincidente de General Lagos y Sipita, como en: pelo Mauque /lak'uta/

General Lagos y Sipita /ñik'uta/

espalda Mauque /xik"ina/

General Lagos y Sipita /xik"ane/

ratón Mauque /acuku/

General Lagos y Sipita /acaku/

vientre Mauque/puraxa/

General Lagos y Sipita /puraka/

tráquea-laringe Mauque /t'u $\lambda \mathrm{o} /$

General Lagos y Sipita /tunquru/

rodilla

Mauque/qunquru

General Lagos y Sipita /qunquri/

maíz tostado Mauque /ximp'i/

General Lagos y Sipita /xamp'i/

nuevo Mauque /macaxa/

General Lagos y Sipita /macaqa/

mosca Mauque/c"ic"ilinxa/

General Lagos y Sipita /c"ic"i入ank"a/

cola, rabo Mauque /wic"inxa/

flor Mauque/paxali/

General Lagos y Sipita /panqara/

redondo Mauque /muru $\chi \mathrm{u} /$

General Lagos y Sipita /muruq'u/ 
barba Mauque /c"unk"a/

General Lagos y Sipita /sunk"a/

En otros ítemes al menos una variante de Mauque fue diferente a las otras dos localidades, como en:

$\begin{array}{ll}\text { vulva } & \text { Mauque /cinqi/ /cinki/ } \\ & \text { General Lagos y Sipita /cinqi/ } \\ \text { montaña } & \text { Mauque /xaq"i/ /aq"i/ } \\ \text { cortada a pique } & \text { General Lagos y Sipita /xaq"i/ } \\ \text { ala } & \text { Mauque /c"iqa/ /c"iq"a/ } \\ & \text { General Lagos y Sipita /c"iq"a/ }\end{array}$

Algunos ítemes fueron ligeramente diferentes en las tres localidades, pero General Lagos y Sipita se asemejaron más entre sí, de modo que Mauque resultó ser la localidad divergente, como en:

$\begin{array}{ll}\text { negro } & \text { Mauque /c'ara/ } \\ & \text { General Lagos /c'iara/ } \\ & \text { Sipita /c'iyara/ } \\ \text { gusano } & \text { Mauque /luq'u/ } \\ & \text { General Lagos /laq'uta/ } \\ & \text { Sipita /laq'u/ }\end{array}$

En el ítem 'gato' una de las variantes de Mauque: /mici/ /micitu/ fue divergente con respecto a General Lagos /p"isitu/ y a Sipita /p"isi/. En 'rayo' una de las dos variantes de General Lagos se aproximó a Mauque y la otra a Sipita:
Mauque /q'i $\chi$ u/

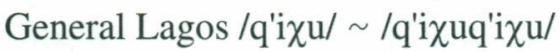
Sipita /q'i $\chi u q ' i \chi u /$

En algunos ítemes se dio la situación inversa: Mauque y General Lagos coincidieron y Sipita se apartó levemente, como en:

\begin{tabular}{|c|c|}
\hline hinchazón & $\begin{array}{l}\text { Mauque y General Lagos /p'usutata/ } \\
\text { Sipita /p'usuta/ }\end{array}$ \\
\hline insípido & $\begin{array}{l}\text { Mauque y General Lagos /c'ap"a/ } \\
\text { Sipita /c'apaqa/ /c'apa } \chi \text { a/ }\end{array}$ \\
\hline tallo de quinua & $\begin{array}{l}\text { Mauque y General Lagos /caxa/ } \\
\text { Sipita /cäka/ }\end{array}$ \\
\hline perdiz & $\begin{array}{l}\text { Mauque y General Lagos /p"isala/ } \\
\text { Sipita /p"isaqa/ }\end{array}$ \\
\hline tallo de maíz & $\begin{array}{l}\text { Mauque y General Lagos /cala/ } \\
\text { Sipita /c"ala/ }\end{array}$ \\
\hline erco & $\begin{array}{l}\text { Mauque y General Lagos /qiñca/ } \\
\text { Sipita/kiñca/ }\end{array}$ \\
\hline
\end{tabular}




\begin{tabular}{|c|c|}
\hline zorrino & $\begin{array}{l}\text { Mauque y General Lagos /añasu/ } \\
\text { Sipita /añut"aya/ }\end{array}$ \\
\hline gato & $\begin{array}{l}\text { Mauque y General Lagos /p"isitu/ } \\
\text { Sipita /p"isi/ }\end{array}$ \\
\hline perro & $\begin{array}{l}\text { Mauque y General Lagos /anuqara/ } \\
\text { Sipita /anu/ }\end{array}$ \\
\hline flamenco & $\begin{array}{l}\text { Mauque y General Lagos /parina/ } \\
\text { Sipita /pariwana/ }\end{array}$ \\
\hline roca & $\begin{array}{l}\text { Mauque y General Lagos /canq"a/ } \\
\text { Sipita /c"ank"a/ }\end{array}$ \\
\hline paquete hecho & Mauque y General Lagos /t'i $\chi$ i/ \\
\hline
\end{tabular}

El ítem 'sarna' es el único que aparece igualmente distante en las tres localidades:

$\begin{array}{ll}\text { Mauque } & \text { /q'asar } \chi \text { a/ } \\ \text { General Lagos } & \text { /q'asari/ } \\ \text { Sipita } & \text { /qaraci/ }\end{array}$

Si alguna conclusión provisoria puede sacarse de estos pocos datos es la notable unidad del léxico aymara en la dimensión espacial. Ligeras divergencias dejan eventualmente lugar para separar el altiplano iquiqueño como una subárea dentro del territorio aymara. Por su parte, Parinacota parece un área de transición o traslapo entre el aymara central y el aymara altiplánico iquiqueño. La fonología y aparentemente también la morfología, apoyan una conclusión así.

\section{Textos}

\subsection{Rasgos generales}

Los dos primeros textos que se presentan a continuación fueron producidos por un hombre, adulto joven, del poblado de Belén, en la precordillera de la Comuna de Putre, Provincia de Parinacota, I Región. Es un emigrante urbano educado, que habla un castellano casi nativo. Consideramos que es un bilingüe con ligero predominio del castellano. Su pronunciación aymara es fluida, consistente y típica, sin hispanización ostensible. Sus textos son relativamente sencillos, compuestos por oraciones cortas, coordinadas por yuxtaposición, y de estructura interna poco variada. Los componentes internos de las oraciones intransitivas tienden a aparecer en la ordenación (Sujeto) Verbo, con los componentes de Detalle, o sea, de Tiempo, Modo, Procedencia, Destino, Compañía, etc. dispuestos alrededor de los componentes focales, pero con clara tendencia a dejar el Verbo en posición final: 


$\begin{array}{llllll}\text { 1. } & \text { (Detalle) } & \text { (Sujeto) } & \begin{array}{l}\text { (Detalle) } \\ \text { aramat }\end{array} & \begin{array}{l}\text { Verbo } \\ \text { sartañani }\end{array} & \text { Detalle } \\ \text { 2. } & & \text { naya } & \text { yapuru } & \text { saran } & \\ \text { 3. } & \text { ukat } \chi & \begin{array}{l}\text { xumasti } \\ \text { xumasti }\end{array} & & \text { kut'an } \chi \text { atawa } & \text { quawranti } \\ & & & \text { maqasana } & \text { markata } \\ \text { 4. } & \text { ukat } \chi & & & & \end{array}$

Para las oraciones transitivas el canon incluye el Complemento Directo, en posición preverbal inmediata:

\begin{tabular}{|c|c|c|c|c|}
\hline 1. & $\begin{array}{l}\cdots \\
\text { ukat } \chi\end{array}$ & $\begin{array}{l}\cdots \\
\text { taypir }\end{array}$ & $\begin{array}{l}\text { C.Directo } \\
\text { inkuñ }\end{array}$ & $\begin{array}{l}\text { Verbo } \\
\text { ust'añani }\end{array}$ \\
\hline 2. & ukat $\chi$ & & pa sik' qawr & kat'uñani \\
\hline 3. & ukat $\chi$ & & ma xaca qawr & kat'uñani \\
\hline 4. & ukat $\chi$ & & taqi qawr & k'ilp"añani \\
\hline 5. & ukat $\chi$ & & ayca kank & maq'at'asiñani \\
\hline
\end{tabular}

La subordinación está representada por subordinaciones de finalidad, como:

$\begin{array}{lllll} & \ldots & \text { Sujeto } & \text { Finalidad } & \text { Verbo } \\ \text { 1. } & \text { xumasti } & \begin{array}{l}\text { uywa awatir } \\ \text { maq'a p"ayir }\end{array} & \text { saranta } \\ \text { 2. ukat } & & & \text { purinta }\end{array}$

donde la subordinada de finalidad sigue la pauta general Complemento Directo-Verbo:

$\begin{array}{ll}\text { C.Directo } & \text { Verbo Subordinado de Finalidad } \\ \text { aywa } & \text { awatir } \\ \text { maq'a } & \text { p"ayir }\end{array}$

En la morfología es notorio el sufijo $-/ \chi a /$, usualmente reducido en $-|\chi|$, que va aplicado por lo general al primer nominal de la oración, el que suele ser un nexo ilativo, /ukata/, reducido en /ukat/: /ukat(a) $\chi(a) /$ o un pronombre personal de sujeto, al que por lo general se le ha sufijado previamente un ilativo -/sti/, como en:

$$
\begin{aligned}
& \mid \text { naya } /+\mid \chi(\mathrm{a}) /=/ \text { naya } \chi \mid \\
& \mid \text { xuma } /+/ \text { sti } /+|\chi(\mathrm{a}) /=| \text { xumasti } \chi
\end{aligned}
$$

La marca de Destino o Dirección es el sufijo -/ru/, a veces reducido a -/r/, como en:

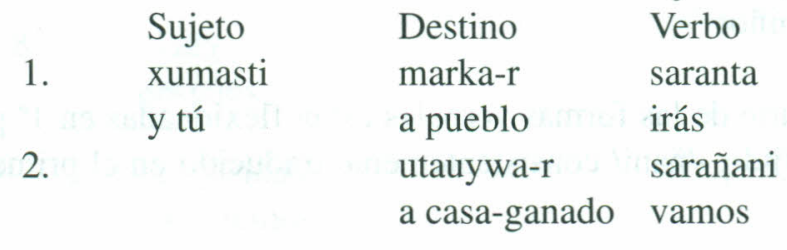


$\begin{array}{lll}\text { 3. nayax } & \text { yapu-r } & \text { saran } \\ \text { yo } & \text { a chacra } & \text { iré }\end{array}$

este sufijo indica el punto en el cual concluye un movimiento, como en:
1 .
taypi-
inkuñ
ust'añani
en la mitad alfombra
ponemos

o en la intención de una acción, como en:
2. wilañcaña
pacamama-ru
rociamos sangre
a la Pachamama
3. cimpuñani
urqu-ru
ponemos chimpos
a los machos

La compañía se marca por medio del sufijo -/nti/, como en:

$\begin{array}{lll}\text { xumasti } & \text { kut'anxatawa } & \text { qawra-nti } \\ \text { y tú } & \text { regresarás } & \text { con las llamas }\end{array}$

El material o contenido está marcado por el sufijo -/nti/, como en:

$\begin{array}{lll}\text { inkuñ } & \text { ust'añani } & \text { kukan-nti } \\ \text { alfombra } & \text { ponemos } & \text { con coca }\end{array}$

La procedencia está expresada por el sufijo -/ta/, como en:

$\begin{array}{lll}\text { xumasti } & \text { kut'an } \chi \text { atawa } & \text { marka-ta } \\ \text { y tú } & \text { regresarás } & \text { del pueblo }\end{array}$

Con el sufijo -/ta/ se marca también el momento en que empieza a originarse una acción, como en:
arama-t(a) sartañani
desde noche nos levantaremos

Aparece en los textos el sufijo -/sa/, generalmente reducido a -/s/, que sirve para marcar componentes en serie. En los dos textos aparece afijado siguiendo al pluralizador nominal -/naka/:

$$
\begin{aligned}
& \text { sarañani } \downarrow \mid \quad \text { taqpaca } \rightarrow \mid \quad \text { warmi-naka-s } \downarrow \mid \\
& \text { vamos todos juntos las mujeres } \\
& \text { caca-naka-s } \downarrow \mid \text { wa-naka-s } \downarrow|| \\
& \text { los hombres los niños }
\end{aligned}
$$

En los dos textos la mayor parte de las formas verbales están flexionadas en $1^{\mathrm{a}}$ persona plural excluyente, marcado por el sufjido -/ñani/ consistentemente traducido en el primer texto por la forma del futuro castellano: 


$\begin{array}{ll}\text { sarta-ñani } & \text { nos levantaremos } \\ \text { maq'asi-ñani } & \text { comeremos }\end{array}$

y en el segundo texto por la forma del presente castellano:

$\begin{array}{ll}\text { sarañani } & \text { vamos } \\ \text { apañani } & \text { llevamos }\end{array}$

En el primer texto hay además una forma en $1^{\mathrm{a}}$ persona singular marcada por el sufijo $/ \mathrm{y} /:$ /saran/ 'iré', y tres formas en $2^{\mathrm{a}}$ persona singular del futuro.

Los verbos de la oración subordinada de finalidad están marcados por el sufijo -/ir(i)/, como en:

$\begin{array}{ll}\text { awatir } & \text { a pastar } \\ \text { p"ayir } & \text { a cocinar } \\ \text { alir } & \text { a comprar }\end{array}$

2.2. Texto 1 (Belén, Parinacota)

1. qalt'í $\chi$ mañana

2. xumasti $\chi$ y tú

3. xumasti y tú

4. nayaxa yo

5. ukat $\chi$ después

qawranti con las llamas

6. ukat $\chi$ después

7. $\chi$ umasti y tú aramat desde noche

uywa

el ganado

markar |

al pueblo

yapur

a la chacra

xumasti

tu

$$
\text { a } \lambda \text { pacunti } \downarrow \|
$$

con las alpacas

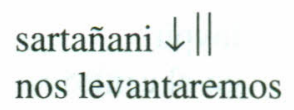

is alír

ropa

a comprar saránta $\downarrow \|$ irás

\section{$\operatorname{sara\eta } \downarrow \|$}

iré

kut'an $\chi$ atawa

regresarás

$$
\begin{array}{lll}
\text { maq'a } & \text { p"ayir } & \text { purinta } \downarrow \| \\
\text { comida } & \text { a cocinar } & \text { vendrás }
\end{array}
$$$$
\text { kut'an } \chi \text { atawa markata } \downarrow \|
$$$$
\text { regresarás del pueblo }
$$

8. ukat $\chi$

después

ma'qàsiñani $\downarrow \|$

comeremos 


\subsection{Texto 2. (Belén, Parinacota)}

1. qawra k'ilp"aña $\downarrow \|$

llamas marcaje

2. taqi xaqinakas

aramat

sartapxañani $\downarrow \|$

todas las gentes

desde oscuro

nos levantamos

3. ukat $\chi$

$\begin{array}{lll}\text { uta } & \text { uywar } & \text { sarañani } \downarrow \\ \text { a la casa } & \text { ganado } & \text { vamos }\end{array}$

taqpac $\rightarrow \mid \quad$ warminakas $\downarrow \mid$ cacanakas $\downarrow \mid$ wawanakas $\downarrow||$

todos juntos las mujeres los hombres los niños

4. wista $\quad$ apañani $\downarrow \mid$ cimpu apañani $\downarrow \|$

taleguitas llevamos "chimpos" llevamos

$\begin{array}{llll}\text { 5. ukat } \chi & \text { taypir } & \text { inkuñ } & \text { ust'añani } \downarrow \\ \text { después } & \text { en el centro } & \text { una alfombra } & \text { ponemos }\end{array}$

kukanti $\rightarrow \mid \quad$ alkulanti $\rightarrow \mid$

con coca con alcohol

winunti $\downarrow$ qupalanti $\downarrow$ insinsiunti $\downarrow \mid$ q'uwanti $\downarrow||$

con vino con copal con incienso con coba

6. ukat $\chi$ pa sik' qawr kat'uñani $\downarrow \mid$ ma $\quad$ urqu $\rightarrow \mid$ ma

después dos chicas llamas agarramos una macho una

qacu $\downarrow \|$

hembra

7. aka paypac qawranakas $\rightarrow \mid$ sik'a $\quad$ qawra $\rightarrow \mid$ cimpuñani $\downarrow \mid$ estas dos juntas llamas chicas llamas ponemos chimpus

$\begin{array}{lll}\text { taqpac } & \text { xaqi } & \text { cimpuñani } \downarrow \| \\ \text { toda junta } & \text { la gente } & \text { ponemos chimpus }\end{array}$

8. ukat $\chi$ ma xaca

después una grande

qawr kat'uñani $\downarrow \|$

llama agarramos 


$\begin{array}{lll}\text { 9. ukanti } & \begin{array}{l}\text { wilañcañ [ni] } \\ \text { rociamos } \\ \text { sangre }\end{array} & \begin{array}{l}\text { pacamamaru } \downarrow \\ \text { a la pachamama }\end{array} \\ \text { ma } \lambda \text { qu } & \begin{array}{l}\text { qu } \lambda \text { uru } \downarrow \| \\ \text { mayores }\end{array} & \text { a los cerros }\end{array}$

$\begin{array}{llll}\text { 10. ukat } \chi & \text { taqi } & \text { qawr } & \text { k'ilp"añani } \downarrow \mid \\ \text { después } & \text { todas } & \text { llamas } & \text { marcamos }\end{array}$

$\begin{array}{lllll}\text { cimpuñanis } & \text { urquru } \downarrow & \text { sarsi } \lambda u & \text { ust'añani } & \text { qacunakaru } \downarrow \| \\ \text { ponemos chimpus } & \text { a los machos } & \text { aretes } & \text { ponemos } & \text { a todas las hembras }\end{array}$

\begin{tabular}{|c|c|c|}
\hline 11. & \multicolumn{2}{|c|}{$\begin{array}{l}\text { k"irk"iñani } \downarrow \| \\
\text { cantamos con charango }\end{array}$} \\
\hline 12. & $\begin{array}{l}\text { wayñ } \\
\text { huainos }\end{array}$ & $\begin{array}{l}\text { t"uquntañani } \downarrow \| \\
\text { bailamos }\end{array}$ \\
\hline 13. & 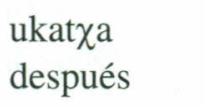 & $\begin{array}{l}\text { ayca } \\
\text { carne }\end{array}$ \\
\hline & $\begin{array}{l}\text { kank } \\
\text { asada }\end{array}$ & $\begin{array}{l}\text { maq'at'asiñan } \\
\text { comemos }\end{array}$ \\
\hline 14. & $\begin{array}{l}\text { taqipaca } \\
\text { todas juntas }\end{array}$ & $\begin{array}{l}\text { xaqinakanti } \\
\text { personas }\end{array}$ \\
\hline & $\begin{array}{l}\text { muspa } \\
\text { mucho }\end{array}$ & $\begin{array}{l}\text { t"uquñani } \downarrow \| \\
\text { bailamos }\end{array}$ \\
\hline
\end{tabular}

\subsection{Rasgos generales (Texto 3)}

El tercer texto fue producido por un hombre adulto, de Chujkkuta, en la Comuna de General Lagos, Provincia de Parinacota. Su patrón de residencia incluye desplazamiento habitual sistemático entre Chujlluta y Arica. Es un bilingüe con marcado predominio del aymara. Habla castellano fluidamente, pero con frecuentes desviaciones, motivadas tanto en interferencia del aymara como en un aprendizaje deficiente del español.

Es notorio en el texto el uso del sufijo -/mpi/ en vez del sufijo -/nti/ de los textos de Belén, como en:

$$
\begin{array}{ll}
\text { alkula-mpi } & \text { con alcohol } \\
\text { insinsiu-mpi } & \text { con incienso }
\end{array}
$$


Aparece el sufijo -/ta/ marcando al complemento de verbos como/rutaña/ 'rogar' y /mayt'aña/ 'implorar':

$$
\begin{aligned}
& \begin{array}{l}
\text { yusata } \\
\text { a Dios }
\end{array} \\
& \text { rogamonani } \\
& \text { wirxina uraqi-ta mayt'ani } \\
& \text { a la virgen de la tierra imploran }
\end{aligned}
$$

Aparece la forma -/ni/ sufijada a /taqi/ 'todos', formando /taqi-ni/ 'todos, toda la gente'.

En las formas verbales destaca el sufijo -/sina/ que aparece en el verbo de la oración subordinada adverbial con el significado de 'acción concluida previa a la acción principal', como en:
ukt'ut'asina
akult'asirkiñani
una vez termindado eso
masticamos coca

Las formas verbales de este texto están en su mayor parte en $1^{a}$ persona plural exclu-

\begin{tabular}{|c|c|c|}
\hline caca $\chi$ & yusata & rutani \\
\hline los hombres & a Dios & ruegan \\
\hline $\begin{array}{l}\text { warmi } \chi \\
\text { las mujeres }\end{array}$ & $\begin{array}{l}\text { wirxina } \\
\text { a la virgen }\end{array}$ & $\begin{array}{l}\text { uraqita } \\
\text { de la tierra }\end{array}$ \\
\hline
\end{tabular}
yente, marcada por -/ñani/, consistentemente traducidas por una forma del presente indicativo del castellano. Hay dos formas verbales en $3^{\text {a }}$ persona plural, marcada por $-/ \mathrm{ni} /$ traducidas por presente castellano:

\begin{tabular}{|c|c|c|c|}
\hline 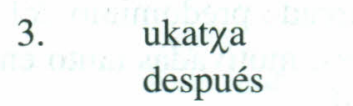 & $\begin{array}{l}\text { uywa } \\
\text { del ganado }\end{array}$ & $\begin{array}{l}\text { koralaru } \\
\text { al corral }\end{array}$ & $n i \downarrow \|$ \\
\hline $\begin{array}{l}\text { taqpaca } \\
\text { todas juntas }\end{array}$ & $\begin{array}{l}\text { warminakas } \rightarrow 1 \\
\text { las mujeres }\end{array}$ & $\begin{array}{l}\text { cacanakas } \rightarrow 1 \\
\text { los hombres }\end{array}$ & $\begin{array}{l}\text { wawanakas } \rightarrow \\
\text { los niños }\end{array}$ \\
\hline $\begin{array}{l}\text { wista } \lambda \mathrm{a} \\
\text { las taleguitas }\end{array}$ & $\begin{array}{l}\text { apañani } \downarrow \mid \\
\text { llevamos }\end{array}$ & $\begin{array}{l}\text { cimpu } \\
\text { los chimpus }\end{array}$ & $\begin{array}{l}\text { apañani } \downarrow \| \\
\text { llevamos }\end{array}$ \\
\hline
\end{tabular}

\subsection{Texto 3 (Chujlluta, Parinacota)}

$\begin{array}{llll}\begin{array}{l}\text { 1. } \\ \text { qawra }\end{array} & \begin{array}{l}\text { k'ilp"aña } \downarrow \| \\ \text { marcaje }\end{array} \\ \begin{array}{l}\text { taqpaca } \\ \text { todas juntas }\end{array} & \begin{array}{l}\text { xaqinakas } \\ \text { las personas }\end{array} & \begin{array}{l}\text { alwat } \\ \text { al alba }\end{array} \\ & \\ & \text { sartañani } \downarrow \| \\ & \\ & \text { nos levantamos }\end{array}$



5
misastasiñani $\downarrow \|$
disponemos como mesa [de ofrenda]

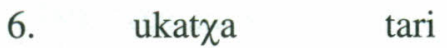
después una alfombra
misastasiñaniwa $\downarrow \|$
disponemos como mesa [de ofrenda]

\begin{tabular}{|c|c|c|}
\hline 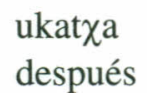 & $\begin{array}{l}\text { koral } \\
\text { del corral }\end{array}$ & $\begin{array}{l}\text { cika } \\
\text { la mitad }\end{array}$ \\
\hline
\end{tabular}

7. ukaru $\quad$ kuka

después la coca

$\begin{array}{llll}\text { misastiñani } \downarrow \mid & \text { pa } & \text { wutiya } & \text { alkulampi } \downarrow \| \\ \text { colocamos en la mesa [y] } & \text { dos } & \text { botellas } & \text { con alcohol }\end{array}$

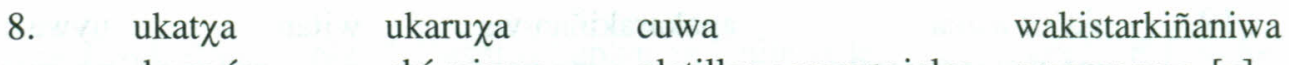

después ahímismo platillos ceremoniales preparamos [y]

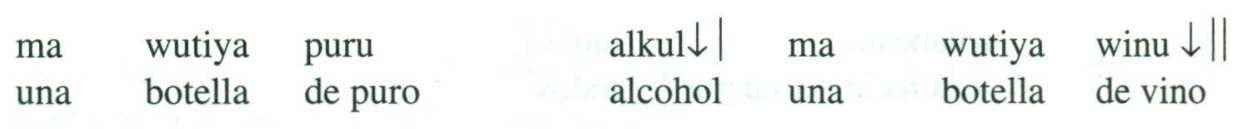

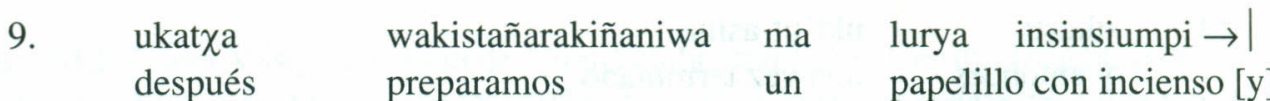

ma qupalampi $\downarrow \|$

uno con copal

\begin{tabular}{|c|c|c|c|}
\hline $\begin{array}{l}\text { ukat } \chi \mathrm{a} \\
\text { después }\end{array}$ & $\begin{array}{l}\text { yusata } \\
\text { a Dios }\end{array}$ & $\begin{array}{l}\text { rugutañani } \downarrow \| \\
\text { rogamos }\end{array}$ & \\
\hline $\begin{array}{l}\text { ukatxa } \\
\text { después }\end{array}$ & $\begin{array}{l}\text { caca } \\
\text { los hombres }\end{array}$ & $\begin{array}{l}\text { yusata } \\
\text { a Dios }\end{array}$ & ii $\downarrow \|$ \\
\hline $\begin{array}{l}\text { ukasti } \\
\text { y entonces }\end{array}$ & $\begin{array}{l}\text { warmi } \chi \\
\text { mujeres }\end{array}$ & $\begin{array}{l}\text { wirxinauraqita } \\
\text { a la virgen de la tierra }\end{array}$ & $\begin{array}{l}\text { mayt'ani } \downarrow \| \\
\text { imploran }\end{array}$ \\
\hline $\begin{array}{l}\text { ukasti } \\
\text { y entonces } \\
\text { wirxinaru } \rightarrow \mid \\
\text { a la virgen }\end{array}$ & $\begin{array}{l}\text { misapasaraya } \\
\text { hacemos que } \\
\text { ma } \lambda \text { kunakaru } \\
\text { a los mayores }\end{array}$ & $\begin{array}{ll}\text { ñani } & \text { q'uwampi } \rightarrow \mid \\
\text { aritual } & \text { con coba }[y] \\
\text { cerros] } & \end{array}$ & $\begin{array}{l}\text { su } \lambda \text { umpi } \rightarrow \mid \\
\text { con fetos (de llama) }\end{array}$ \\
\hline
\end{tabular}



$\begin{array}{lll}\text { 14. ukasti } & \text { ukt'ut'asina } & \text { taqini } \\ \text { y entonces } & \text { una vez terminado } & \text { todos }\end{array}$

akult'asirkiñani $\downarrow \|$

nos masticamos coca

15. ukasti parawintasu $\chi$ arkiñani $\downarrow \|$

y entonces nos damos parabienes $\begin{array}{llll}\text { 16. ukasti } & \begin{array}{l}\text { kalt'arkiñani } \\ \text { y entonces }\end{array} & \text { uywa } & \text { k'ilp"ampi } \downarrow \| \\ \text { empezamos } & \text { al ganado } & \text { con el marcaje }\end{array}$

17. ukasti sarsi $\lambda$ tarkiñaniwa $\downarrow \|$

y entonces aretes colocamos

18. ukasti cimp tarkiñaniwa $\downarrow \|$

y entonces chimpus colocamos

19. ukt'ut'asina

apakarakiñaniwa wilan uywa

una vez terminado vamos a separar para sangrar un animal

$\begin{array}{ll}\text { wilancaña } & \text { taqi } \downarrow \| \\ \text { para rociar la sangre } & \text { todos }\end{array}$

20. ukasti ukt'ut'asina

y entonces una vez terminado

t"uqunt"arkiñaniwa $\downarrow \mid$ taqinis caku q'ipt'asita $\downarrow$ ||

empezamos a bailar todos las maneas cargando la espalda

$\begin{array}{llll}\text { 21. ukasti } & \text { utaru } & \text { sarxañani } & \text { taqini } \downarrow \| \\ \text { y entonces } & \text { a casa } & \text { vamos } & \text { todos }\end{array}$

22. ukasti taqini

y entonces todos

kanka maq’asiñani $\downarrow \|$

asado nos comemos

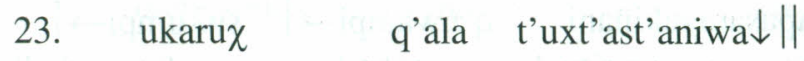

y ahí mismo todo ha terminado 


\section{Bibiografía}

Briggs, Lucy Therina. 1976. Dialectal Variation in the Aymara Language of Bolivia and Perú. Tesis de grado doctoral. Universidad de Florida. Ann Arbor. University Microfilms Internacional. Cit. en Harmelink 1985.

1980. "Algunos rastos dialectales del aymara de Bolivia y Perú". NNL 3:7-8. Cit. en Hardman et al.1988.

Clair-Vasiliadis, Christos. 1976. "Esquisse phohologique de l'aymara paré au Chili". La linguistique. 12.2:143-152.

Cotari, Daniel; Jaime Mejía y Víctor Carrasco. 1978. Diccionario aymara-castellano; castellano-aymara. Cochabamba, Bolivia. Instituto de Idiomas Padres de Mayknoll.

Dannemann, Manuel y Alba Valencia. 1989. Grupos aborígenes chilenos. Su situación actual $y$ distribución territorial. Santiago. Universidad de Santiago de Chile. Instituto de Investigaciones del Patrimonio Territorial de Chile. Col. Terra Nostra $N^{\circ} 5$.

Gunderman Kröll, Hans. 1994. “¿Cuántos hablan en Chile la lengua aymara?”. R.L.A. Revista de Lingüística Teórica y Aplicada. 32:125-139.

Hardman, M.J. 1983. Jaqaru: Compendio de estructura fonológica y morfológica. Lima. Instituto de Estudios Peruanos. Cit. en Harmenlink 1985.

Hardman, M.J, Juana Vásquez y Juan de Dios Yapita, con Lucy Therina Briggs, Nora Clearman England y Laura Martin /1974/. 1988. Aymara. Compendio de estructura fonológica y gramatical. La Paz, Boliva. Instituto de Lengua y Cultura Aymara y The Aymara Foundation Inc., Gainesville, Florida.

Harmelink, Bryan L. 1985. Investigaciones lingüísticas en el altiplano chileno. Un estudio entre la comunidad aymara chilena. Arica. Instituto Linguístico de Verano y Universidad de Tarapacá.

Herrero, R.P Joaquín; Daniel Cotari y Jaime Mejía. 1978. Lecciones de Aymara, Niveles I y II. $2^{a}$ ed. Cochabamba, Bolivia. Instituto de Idiomas Padres de Maryknoll.

Ross, Ellen H. 1963. Rudimentos de gramática aymara. La Paz. Canadian Baptist Mission.

Salas, Adalberto y Alba Valencia. 1988. "Fonología del aymara altiplánico chileno". Revista de Filología y Lingüística de la Universidad de Costa Rica. 16 (2): 119-122. 
